ODILSON MARCOS SILVESTRE

\title{
Efeito do metoprolol na reversão da disfunção cardíaca em cirróticos não alcoólicos. Estudo randomizado
}

Tese apresentada à Faculdade de Medicina da Universidade de São Paulo para obtenção do título de Doutor em Ciências

Programa de Cardiologia

Orientador: Prof. Dr. Fernando Bacal

Coorientador: Prof. Dr. Alberto Queiroz Farias 
Dados Internacionais de Catalogação na Publicação (CIP)

Preparada pela Biblioteca da

Faculdade de Medicina da Universidade de São Paulo

(Creprodução autorizada pelo autor

\section{Silvestre, Odilson Marcos}

Efeito do metoprolol na reversão da disfunção cardiaca $\mathrm{em}$ cirróticos não alcoólicos. Estudo randomizado / Odilson Marcos Silvestre. -- São Paulo, 2014.

Tese(doutorado)--Faculdade de Medicina da Universidade de São Paulo. Programa de Cardiologia.

Orientador: Fernando Bacal.

Coorientador: Alberto Queiroz Farias.

Descritores: 1.Cardiomiopatias 2.Remodelação miocárdica ventricular 3.Cirrose 4.Antagonistas adrenérgicos beta 5 .Metoprolol 6 . Hipertensão portal 7.Ensaio clínico controlado aleatório

USP/FM/DBD-337/14 
Aos meus pais, Teresinha Silvestre e José Paulo Silvestre que me alfabetizaram em casa e nunca hesitaram em deixar sempre claro o quão modificador é estudar.

Aos professores, todos eles, desde o Miguel da escola rural até o Peter, da Harvard University, que no vocacionado uso do espontâneo e do proposital, enalteceram o maravilhamento do percurso entre a pergunta e a resposta.

Aos meus: Solange, Sirlei, Carlos e Isadora, que fazem coisas parecidas de formas diferentes. 
Ao meu orientador, Prof. Dr. Fernando Bacal, e meu coorientador, Prof. Dr. Alberto Queiroz Farias, por correrem o risco de investir numa linha de pesquisa nova e incerta; e por me terem deixado conviver, entender e absorver deles virtudes distintas e peculiares que os fazem destacados.

À enfermeira Danusa Ramos, que se dedicou a essa tese como se fosse a sua.

Às enfermeiras de pesquisa Patrícia Momoyo e Juliana Medeiros e à bióloga Elisângela Belleti.

Aos Profs. Flair José Carrilho e Luiz Augusto Carneiro D'Albuquerque por ajudarem a viabilizar esse projeto.

Aos Profs. Célia Strunz, Américo Friedmann e José Andrade.

Às profissionais de enfermagem Selma e Rosane.

Aos médicos assistentes da Gastroenterologia e Transplante do Fígado, por terem cedido espaço e por ajudarem nos cuidados aos pacientes.

Aos médicos residentes da Gastroenterologia e do Transplante do Fígado.

Aos funcionários do Departamento de Gastroenterologia (em especial, Cláudia Arruda, Silvana, Dorotéia, Fátima e Renato Madrid), aos funcionários da enfermagem e do administrativo do Ambulatório de Transplante do Fígado e das enfermarias da Gastroenterologia e do Transplante do Fígado.

Aos colegas/amigos de estrada (na Cardiologia) Sandrigo Mangini e Fabiana Marcondes Braga - já doutores; Eduardo Lima, Luis Seguro, Jefferson Vieira, Miguel Morita, Paulo Cury Rezende, Bruno Biselli, Eduardo Adam, Caio Fernandes, Thiago Midlej, Lucas Tachotti, Bárbara Alves e Philippe Vieira - ainda na estrada.

Aos colegas/amigos de pós-graduação (na Gastroenterologia): Rafael Ximenes, Flavia Folchini, Estevão Mendes, Evandro Souza, Mary Ellen Dias e Ricardo Miyake.

Aos amigos: Ricardo Vieira, Guilherme Felga, Andreia Evangelista, Leopoldo Scheifer, Fabiano Scheifer, Jonathas Stifft, Pedro Barros e Thiago Mazer. 
Aos funcionários do Laboratório de Análises Clínicas do InCor, em especial à Adriana Nogueira, Marli e Alessandra.

Aos farmacêuticos: Márcia Marin e Cleuber Chaves.

Aos funcionários do Setor de Eletrocardiograma do HC, em especial Marlene Silveira.

Aos médicos e funcionários do Ecocardiograma do INRAD, em especial Meive Furtado e Ana Clara Rodrigues.

Ao estatístico Márcio Diniz, que com poucas palavras e muitos números deixou sua marca no trabalho.

Aos membros participantes da minha banca de qualificação, Prof. Dr. Edimar Bocchi, Prof. Dr. Félix Ramires e Prof. Dr. Marcelo Vieira pelas sugestões que contribuíram para a finalização desta tese.

À Comissão de Pós-graduação e a Neusa Dini, Juliana Lattari Sobrinho e Tatiane pela atenção e orientação.

À Fundação do Amparo à pesquisa do Estado de São Paulo (FAPESP), pela concessão do auxílio à pesquisa e apoio financeiro para a realização desse projeto.

Aos pacientes que contribuíram com essa pequena manifestação da ciência. 
"Saber não é o bastante; devemos aplicar.

Desejar não é o bastante; devemos fazer."

- Goethe 


\section{Normalização adotada}

Esta tese está de acordo com as seguintes normas, em vigor no momento desta publicação:

Referências: adaptado de International Committee of Medical Journals Editors (Vancouver). Universidade de São Paulo. Faculdade de Medicina. Divisão de Biblioteca e Documentação. Guia de apresentação de dissertações, teses e monografias. Elaborado por Anneliese Carneiro da Cunha, Maria Julia de A. L. Freddi, Maria F. Crestana, Marinalva de Souza Aragão, Suely Campos Cardoso, Valéria Vilhena. 3a ed. São Paulo: Divisão de Biblioteca e Documentação; 2011. Abreviaturas dos títulos dos periódicos de acordo com List of Journals Indexed in Index Medicus. 


\section{SUMÁRIO}

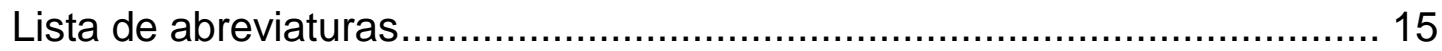

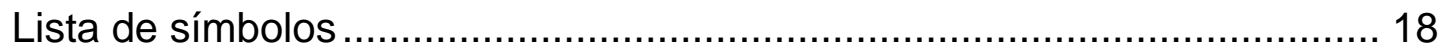

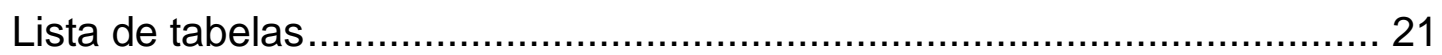

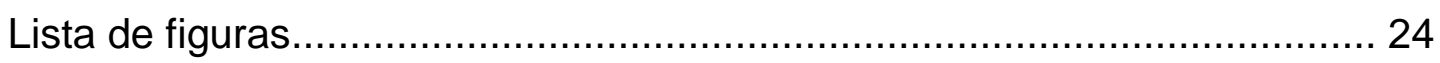

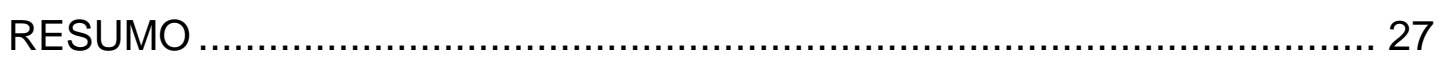

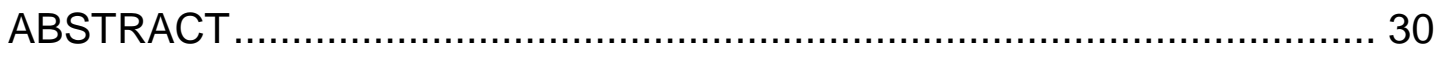

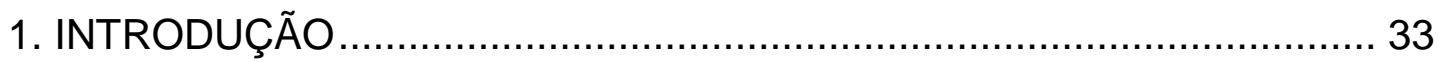

1.1. Cirrose e suas alterações hemodinâmicas ......................................... 33

1.2. Remodelamento cardíaco ........................................................... 36

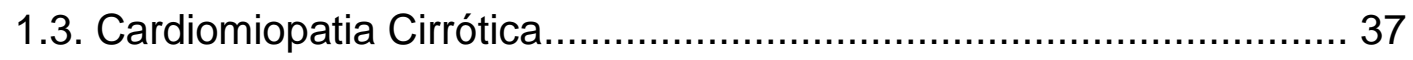

1.4. Betabloqueadores e o remodelamento reverso .............................. 40

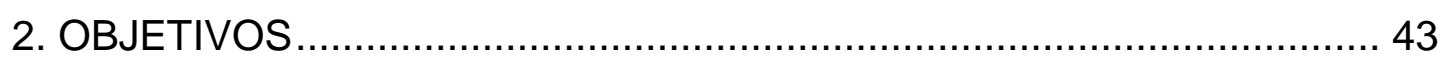

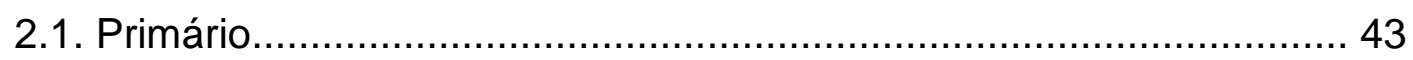

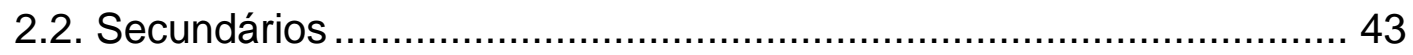

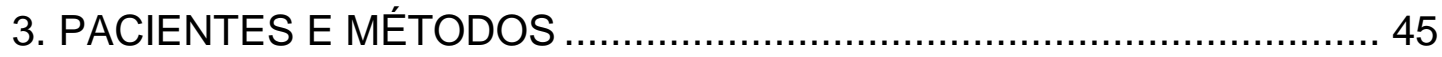

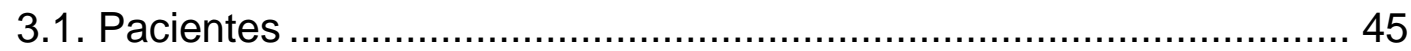

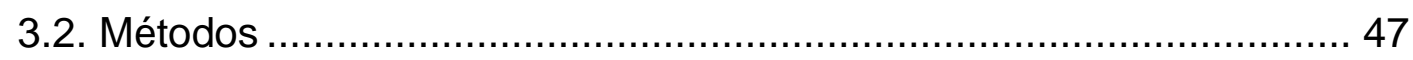

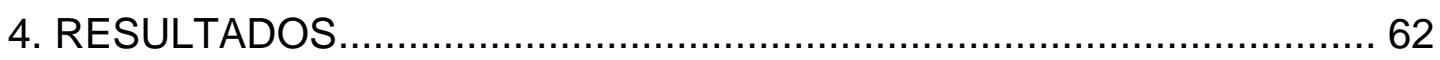

4.1. Comparação metoprolol versus placebo nos pacientes com resposta

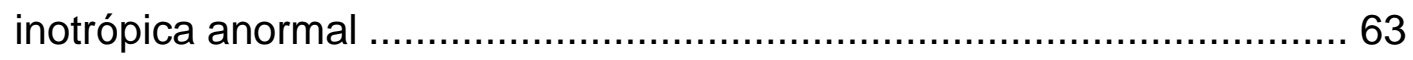

4.2. Comparação dos pacientes com resposta inotrópica anormal versus

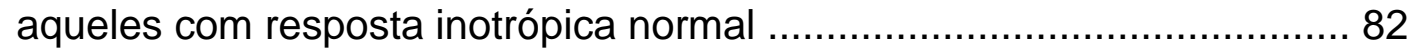

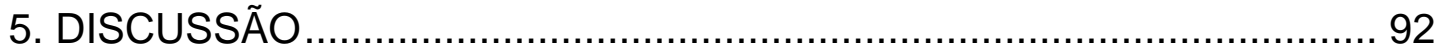

5.1. Efeito do succinato de metoprolol na disfunção cardíaca relacionada à cirrose 92

5.2. Comparação entre os pacientes com resposta inotrópica anormal e resposta inotrópica normal............................................................... 101

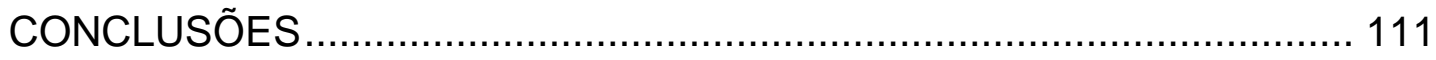

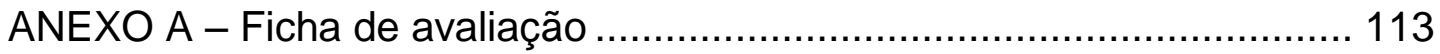

ANEXO B - Termo de Consentimento Livre e Esclarecido ....................... 123 
ANEXO C - Randomização.

126

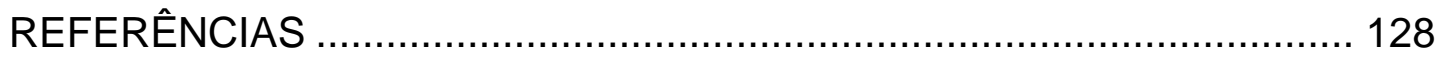


Lista de abreviaturas 


\section{Lista de abreviaturas}

$\begin{array}{ll}\text { AE } & \text { átrio esquerdo } \\ \text { BNP } & \text { peptídeo natriurético tipo B } \\ \text { ECA } & \text { enzima conversora da angiotensina } \\ \text { ECG } & \text { eletrocardiograma } \\ \text { FC } & \text { frequência cardíaca } \\ \text { FE } & \text { fração de ejeção } \\ \text { GMPc } & \text { monofosfato cíclico de guanosina } \\ \text { HAS } & \text { hipertensão arterial sistêmica } \\ \text { IC } & \text { insuficiência cardíaca } \\ \text { IC } & \text { intervalo de confiança } \\ \text { IMC } & \text { índice de massa corporal } \\ \text { Intervalo QT } & \text { intervalo entre o início da onda Q e o final da onda T } \\ \text { MELD } & \text { modelo para doença hepática avançada (model for end- } \\ \text { stage liver disease) } \\ \text { NA }\end{array}$




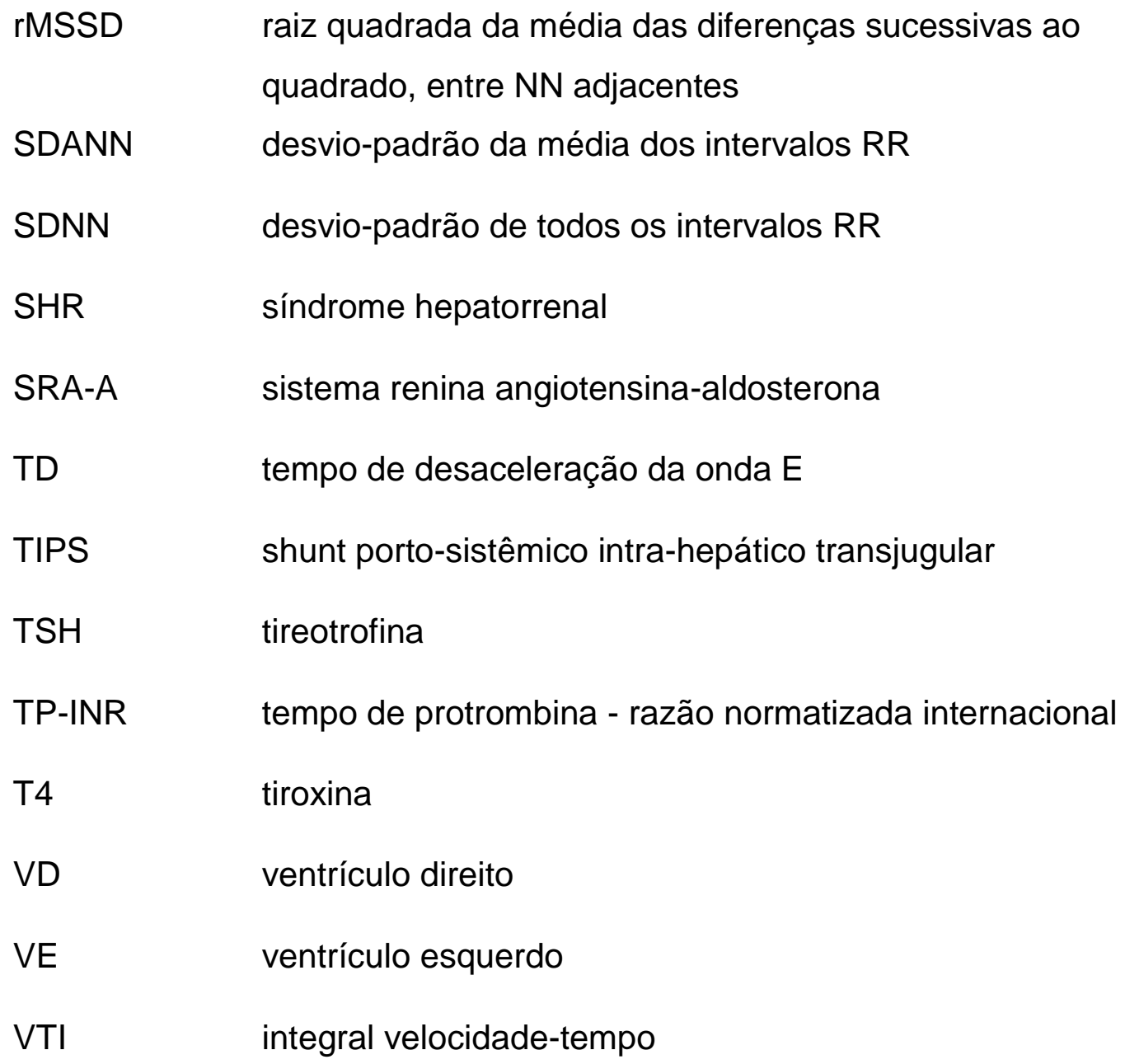




\section{Lista de símbolos}

\begin{tabular}{|c|c|}
\hline$a^{\prime}$ & velocidade diastólica tardia \\
\hline$A$ & onda diastólica tardia \\
\hline $\mathrm{b} / \mathrm{min}$ & batimento por minuto \\
\hline $\mathrm{cm}$ & centímetro \\
\hline $\mathrm{cm} / \mathrm{s}$ & centímetro por segundo \\
\hline$E$ & onda diastólica precoce \\
\hline erro $\beta$ & erro beta \\
\hline$E / A$ & relação entre as ondas $E$ e $A$ \\
\hline E/e' & relação entre as ondas E e e' \\
\hline$e^{\prime}$ & velocidade diastólica precoce \\
\hline$g$ & grama \\
\hline $\mathrm{g} / \mathrm{Kg}$ & grama por quilograma \\
\hline $\mathrm{mcg} / \mathrm{kg} / \mathrm{min}$ & micrograma por quilo por minuto \\
\hline $\mathrm{mg}$ & miligrama \\
\hline $\mathrm{mg} / \mathrm{dia}$ & miligrama por dia \\
\hline $\mathrm{mg} / \mathrm{dL}$ & miligrama por decilitro \\
\hline $\mathrm{ml}$ & mililitro \\
\hline $\mathrm{ml} / \mathrm{mm}^{3}$ & mililitro por milímetro ao cubo \\
\hline $\mathrm{ml} / \mathrm{m}^{2}$ & mililitro por metro quadrado \\
\hline $\mathrm{mm}$ & milímetro \\
\hline $\mathrm{mmHg}$ & milímetros de mercúrio \\
\hline
\end{tabular}




\begin{tabular}{ll}
$\mathrm{mmol} / \mathrm{L}$ & milimol por litro \\
$\mathrm{ms}$ & milisegundo \\
$\mathrm{ms}^{2}$ & milisegundo ao quadrado \\
$\mathrm{n}$ & tamanho da amostra \\
$\mathrm{ng} / \mathrm{mL} / \mathrm{h}$ & nanograma por mililitro por hora \\
$\mathrm{p}$ & valor-p \\
$\mathrm{S}^{\prime}$ & onda que representa o movimento sistólico \\
$/ \mathrm{mm}$ & por milímetro ao cubo \\
+ & mais \\
\pm & mais ou menos \\
$<$ & menor \\
$\leq$ & menor ou igual \\
\hline & maior \\
\hline & maior ou igual \\
\hline &
\end{tabular}




\section{Lista de tabelas}

Tabela 1. Comparação entre os grupos metoprolol e placebo em relação às características gerais $-\mathrm{n}=78$ pacientes.

Tabela 2. Comparação entre os grupos metoprolol e placebo em relação aos parâmetros ecocardiográficos - $\mathrm{n}=78$ pacientes 65

Tabela 3. Comparação entre os grupos metoprolol e placebo em relação aos parâmetros eletrocardiográficos - $\mathrm{n}=78$ pacientes 66

Tabela 4. Comparação entre os grupos metoprolol e placebo em relação aos parâmetros laboratoriais $-\mathrm{n}=78$ pacientes. 68

Tabela 5. Comparação entre os grupos metoprolol e placebo na normalização da VTI - desfecho primário. 72 Tabela 6. Efeito do succinato de metoprolol na reversão da disfunção cardíaca: avaliação dos parâmetros ecocardiográficos $-n=78$ pacientes ... 73 Tabela 7. Efeito do tratamento nos níveis de BNP, noradrenalina, troponina e atividade da renina plasmática $-\mathrm{n}=78$ pacientes 74

Tabela 8. Efeito do succinato de metoprolol nos parâmetros eletrocardiográficos $-\mathrm{n}=78$ pacientes

Tabela 9. Desfechos clínicos do grupo metoprolol em relação ao grupo placebo $-\mathrm{n}=78$ pacientes

Tabela 10. Comparação entre os grupos metoprolol e placebo em relação aos efeitos adversos do tratamento - desfecho de segurança $(n=78$ pacientes)

Tabela 11. Características gerais dos pacientes com resposta inotrópica normal e anormal - $\mathrm{n}=125$ pacientes

Tabela 12. Características ecocardiográficas dos pacientes - $n=125$ pacientes

Tabela 13. Comparação entre os grupos resposta inotrópica anormal e normal quanto aos parâmetros laboratoriais ( $\mathrm{n}=125$ pacientes) 86

Tabela 14. Características eletrofisiológicas dos pacientes $-\mathrm{n}=125$ pacientes 
Tabela 15. comparação entre os grupos resposta inotrópica anormal e resposta normal em relação aos desfechos clínicos - $n=125$ pacientes ..... 88 


\section{Lista de figuras}

Figura 1.Fisiopatologia da circulação hiperdinâmica na cirrose. 34

Figura 2. Resposta inotrópica anormal na cirrose, em modelos animais (A) (Zenghua) e em humanos (B) 38

Figura 3. Fluxograma do estudo 62

Figura 4. Comparação da frequência cardíaca entre os grupos metoprolol e placebo no início e após 6 meses $-\mathrm{n}=78$ pacientes 69

Figura 5. Efeito do tratamento na pressão arterial sistólica. Comparação entre os grupos metoprolol e placebo $-\mathrm{n}=78$ pacientes

Figura 6. Efeito do tratamento na pressão arterial diastólica. Comparação entre os grupos metoprolol e placebo ( $\mathrm{n}=78$ pacientes)

Figura 7. Percentual de normalização da resposta inotrópica conforme o grupo após o tratamento $-\mathrm{n}=78$ pacientes. 72

Figura 8. Comparação ente os grupos metoprolol e placebo quanto aos níveis de BNP no início e após 6 meses $-\mathrm{n}=78$ pacientes 75

Figura 9. Comparação ente os grupos metoprolol e placebo quanto aos níveis de noradrenalina no início e após 6 meses $-\mathrm{n}=78$ pacientes 76

Figura 10. Comparação ente os grupos metoprolol e placebo quanto Intervalo QT no início e após 6 meses - $\mathrm{n}=78$ pacientes 77

Figura 11. Evolução da cirrose, avaliada pelo escore MELD, conforme o grupo de tratamento $-\mathrm{n}=78$ pacientes 78

Figura 12. Evolução da cirrose, dividida em classes pelo Child-Pugh, conforme o grupo de tratamento $-\mathrm{n}=66$ pacientes 79

Figura 13. Curva de sobrevida livre de eventos. Comparação entre os grupos metoprolol e placebo $(n=78)$

Figura 14. Curva de sobrevida livre de eventos comparando os grupos resposta inotrópica anormal e normal (desfechos combinados: ascite, encefalopatia, síndrome hepatorrenal, infecções, hemorragia varicosa, internações e morte) 
Figura 15. Curva de sobrevida livre de eventos comparando os grupos com os "parâmetros combinados" (alteração de sístole, diástole e QT prolongado) para os desfechos combinados (ascite, encefalopatia, síndrome hepatorrenal, infecções, hemorragia varicosa, internações e morte)............ 90 


\section{RESUMO}

Silvestre OM. Efeito do metoprolol na reversão da disfunção cardíaca em cirróticos não alcoólicos. Estudo randomizado. [tese]. São Paulo: Faculdade de Medicina, Universidade de São Paulo; 2014.

Introdução: A disfunção cardíaca relacionada à cirrose acomete pacientes com insuficiência hepática avançada e pode estar associada a complicações como a síndrome hepatorrenal. Diferente do que ocorre na insuficiência cardíaca, em que o tratamento farmacológico com betabloqueadores é reconhecidamente eficaz em reverter o remodelamento cardíaco e aumentar a sobrevida, ainda não foi testada nenhuma modalidade terapêutica que possa bloquear o efeito remodelador e a progressão da disfunção cardíaca nos pacientes com cirrose. Formulamos a hipótese que 0 uso de betabloqueador poderia ter efeito benéfico sobre as alterações cardíacas morfológicas e funcionais observadas em pacientes com cirrose.

Objetivos: O objetivo primário foi avaliar a eficácia do metoprolol na reversão da disfunção cardíaca em pacientes com cirrose não alcoólica. Os objetivos secundários compreenderam: reversão das alterações ecocardiográficas, biomarcadores da ativação neuro-humoral, eletrofisiológicas, eventos clínicos e efeitos adversos. Avaliou-se também o impacto da resposta inotrópica anormal no prognóstico da cirrose.

Material e métodos: Conduzimos um estudo prospectivo, randomizado, duplo-cego, placebo-controlado, fase II, com análise "por intenção de tratar". Os critérios de inclusão foram cirrose de etiologia não alcoólica, escore MELD entre 10 e 20 pontos e idade entre 18 e 60 anos. Os critérios de exclusão foram doença cardiovascular prévia, doenças sistêmicas com acometimento cardíaco e contraindicação ao uso de betabloqueadores. No momento da inclusão e após 180 dias de tratamento, realizamos avaliação clínica, dosagem de biomarcadores (noradrenalina, troponina, peptídeo natriurético tipo $\mathrm{B}$ e atividade da renina plasmática), mensuração indireta da atividade simpática (ECG dinâmico de 24 horas) e ecocardiograma sob estresse com dobutamina. A disfunção cardíaca foi caracterizada pela resposta inotrópica anormal ao eco-estresse (incremento do débito cardíaco $\leq 30 \%$ após o estresse em relação ao basal, medido pela integral velocidadetempo na via de saída do ventrículo esquerdo). O desfecho primário foi definido como o aumento $\geq 30 \%$ da resposta inotrópica ao estresse. Os eventos clínicos avaliados como desfecho foram: ascite, síndrome hepatorrenal, encefalopatia, infecções, hemorragia digestiva varicosa, internações e mortalidade. Considerando a possibilidade de erro alfa de 0,05 , erro beta de 0,2 e diferença de proporções na melhora da VTI ( $\geq$ de $30 \%$ ) entre os grupos, o tamanho amostral foi estimado em 72 pacientes. $O$ protocolo foi aprovado pela Comissão de ética institucional e registrado na base de dados internacional ClinicalTrials.gov (NCT01676285, acrônimo "Cardiac Remodeling in cirrhosis - CARE cirrhosis"). 
Resultados: No período de junho de 2011 a dezembro de 2013, 478 pacientes com cirrose foram prospectivamente avaliados e 190 preencheram os critérios de elegibilidade, sendo incluídos 125 pacientes. Desses, 78 (62\%) apresentaram resposta inotrópica anormal ao estresse farmacológico. Os demais $47(38 \%)$ pacientes com resposta inotrópica normal foram seguidos sem intervenção farmacológica. Os pacientes com resposta anormal foram randomizados para receber tratamento (succinato de metoprolol, $\mathrm{n}=41$ ou placebo, $\mathrm{n}=37)$. Três $(7,3 \%)$ dos pacientes no grupo metoprolol e $9(24,3 \%)$ no grupo placebo apresentaram normalização da resposta inotrópica ao estresse, diferença não estatisticamente significante $(p=0,057)$. Não houve diferença entre os grupos metoprolol e placebo em relação à reversão das alterações ecocardiográficas, laboratoriais e eletrofisiológicas. Não houve diferença quanto aos desfechos clínicos isolados ou combinados na comparação entre metoprolol e placebo: síndrome hepatorrenal $n=1(2,4 \%)$ versus $n=0, p=0,99$; ascite $n=4(12 \%)$ versus $n=2(5,4 \%), p=0,27$; infecções bacterianas $n=2(4,8 \%)$ versus $n=2$ $(5,4 \%), p=0,94$; encefalopatia hepática $n=5(12,1 \%)$ versus $n=6(16.2 \%)$, $p=0,59$, hemorragia varicosa $n=0$ em ambos os grupos; internações $n=6$ $(14,6 \%)$ versus $n=8(21,6 \%), p=0,45$; morte $n=5(12,1 \%)$ versus $n=2(5,4 \%)$, $\mathrm{p}=0,94$; respectivamente. Não houve diferença entre metoprolol e placebo em relação ao surgimento de efeitos adversos $n=4(9,7 \%)$ versus $n=6$ $(16,2 \%)$, respectivamente, $p=0,5$. Os pacientes no grupo com resposta inotrópica anormal apresentaram maiores taxas de desfechos combinados (26 $(33,3 \%)$ versus $8(17,0 \%), p=0,03)$ em relação àqueles com resposta inotrópica normal.

Conclusão: embora seguro, o metoprolol não foi eficaz na reversão da disfunção cardíaca em pacientes com cirrose não alcoólica. Não houve benefício na terapia com metoprolol em relação aos desfechos ecocardiográficos, laboratoriais, eletrofisiológicos e clínicos, incluindo mortalidade. Os pacientes com resposta inotrópica normal tiveram melhor evolução em relação àqueles com resposta inotrópica anormal.

Descritores: Cardiomiopatias; Remodelação miocárdica ventricular; Cirrose; Hipertensão portal; Metoprolol; Antagonistas adrenérgicos beta; Ensaio clínico controlado aleatório. 


\begin{abstract}
Silvestre OM. Effect of metoprolol on cardiac dysfunction in patients with non alcoholic cirrhosis: a randomized trial. [thesis]. São Paulo. "Faculdade de Medicina, Universidade de São Paulo"; 2014.

Background: Cardiac dysfunction is found in patients with end-stage liver disease and is implicated in complications such as hepatorenal syndrome. Unlike heart failure, in which beta-blockers are admittedly effective in reversing cardiac remodeling and improving survival, the effect of beta-blockade on the cardiac dysfunction of patients with cirrhotic cardiomyopathy is unknown. We hypothesized that beta-blockers could have a beneficial effect on the morphological and the functional cardiac changes seen in patients with cirrhosis.
\end{abstract}

Aim: To assess the efficacy of metoprolol in the reversal of the cardiac dysfunction in patients with non-alcoholic cirrhosis.

Methods: We conducted a prospective, randomized, double-blind, placebocontrolled, with an "intention to treat" analysis, phase II study. Inclusion criteria were cirrhosis of non-alcoholic etiology, MELD score between 10 and 20 points and age between 18 and 60 years old. Exclusion criteria were previous cardiovascular disease, systemic diseases with cardiac involvement and contraindications to beta-blockers. Clinical assessment, measurements of biomarkers (norepinephrine, troponin, B-type natriuretic peptide and plasma renin activity), 24-hours Holter and stress echocardiography with dobutamine were performed at inclusion and after 180 days of treatment. Cardiac dysfunction was defined by an abnormal inotropic response to stress echo (an increasing in cardiac output $\leq 30 \%$ during peak stress in relation to baseline values, as measured by the left ventricular outflow tract velocity-time integral). Primary end-point was an increase of $30 \%$ in the inotropic response. The frequency of ascites, hepatorenal syndrome, encephalopathy, bacterial infections, variceal bleeding, hospitalization and mortality were also assessed. Considering an alpha error of 0.05 , a beta error of 0.2 , a difference between proportions of improvement of VTI between the groups of $20 \%$, and an anticipated dropout rate of $10 \%$, the sample size was estimated in 72 patients. The protocol was approved by the institutional ethics board and registered in the database ClinicalTrials.gov (NCT01676285 acronym "Cardiac Remodeling in cirrhosis - cirrhosis CARE").

Results: From June 2011 to December 2013, 478 patients with cirrhosis were prospectively evaluated. 190 were eligible to participate in the study. From these, 125 met the inclusion criteria and 78 had abnormal inotropic response to pharmacological stress. These 78 patients, who comprise the present series, were randomly assigned to receive treatment (metoprolol succinate, $n=41$ or placebo, $n=37)$. The remaining $47(38 \%)$ patients with normal inotropic response were followed without pharmacological intervention. Three (7.3\%) patients in the metoprolol group and $9(24.3 \%)$ in 
the placebo group achieved normalization of the inotropic response to stress $(p=0.057)$. There was no difference between metoprolol or placebo with respect to the reversal of the echocardiographic, electrophysiological and laboratory changes. There was no difference in clinical outcomes between the groups: hepatorenal syndrome $n=1 \quad(2.4 \%)$ versus $n=0, p=0.99$; ascites $n=4(12 \%)$ versus $n=2(5.4 \%), p=0.27$; bacterial infections $n=2$ $(4.8 \%)$ versus $n=2(5.4 \%), p=0.94$; hepatic encephalopathy $n=5(12.1 \%)$ versus $n=6(16.2 \%), p=0.59)$, variceal bleeding $n=0$ in both groups; admissions $n=6(14.6 \%)$ versus $n=8(21.6 \%), p=0.45$; death $n=5(12.1 \%)$ versus $\mathrm{n}=2(5.4 \%), \mathrm{p}=0.94 ;$ for metoprolol and placebo, respectively. Adverse effects were similar in both groups: metoprolol $n=4$ $(9.7 \%)$ versus placebo $n=6(16.2 \%), p=0.5$. Patients in the group with abnormal inotropic response showed higher rates of combined outcomes (26 $(33.3 \%)$ versus $8(17.0 \%), p=0.03)$ compared to those with normal inotropic response.

Conclusion: Although safe, metoprolol was not effective in reversing the cardiac dysfunction in patients with nonalcoholic cirrhosis. There was neither improvement in echocardiographic, laboratory, and electrophysiological parameters nor in clinical outcomes, including mortality. Abnormal inotropic response was associated with a higher incidence of clinical events.

Key words: Cardiomyopathies; Cardiac remodeling; Cirrhosis; Portal hypertension; Metoprolol; Adrenergic beta-antagonists; Randomized controlled trial. 


\section{INTRODUÇÃO}

\subsection{Cirrose e suas alterações hemodinâmicas}

A cirrose constitui afecção caracterizada por fibrose do parênquima do fígado, com formação de nódulos de regeneração. Representa as consequências de uma resposta cicatrizante a uma lesão hepática de causas variadas. A alteração da arquitetura lobular hepática - pela colagenização sinusoidal e formação de nódulos regenerativos - é o passo inicial para o desenvolvimento da hipertensão portal. As consequências da insuficiência hepática e da hipertensão portal ocorrem em múltiplos órgãos e sistemas do organismo, principalmente nos sistemas cardiocirculatório, renal, de coagulação, pulmonar, neurológico e metabólico. ${ }^{1}$

Tomadas em conjunto, as modificações circulatórias na doença hepática avançada correspondem ao termo "circulação hiperdinâmica", cujas características são o elevado débito cardíaco e a reduzida resistência vascular periférica. A hipertensão portal é o mecanismo inicial para o seu desenvolvimento. ${ }^{2}$ Com a piora da insuficiência hepática e a progressão da hipertensão portal, há aumento da tensão de cisalhamento (shear stress) nos vasos esplâncnicos e, por conseguinte, forte estímulo para a liberação de óxido nítrico com consequente vasodilação e queda da resistência vascular sistêmica. ${ }^{3}$ Concomitantemente, os estímulos angiogênicos levam à formação de comunicações arteriovenosas tanto intra-hepáticas como periféricas no intuito de desviar o fluxo da barreira hepática em direção à circulação portossistêmica, colaborando para a queda da resistência vascular sistêmica e da pressão arterial sistêmica.

A vasodilatação da circulação esplâncnica pelo efeito de inúmeros mediadores, principalmente do óxido nítrico, leva à desproporção continente e conteúdo, gerando um estado de hipovolemia central relativa. ${ }^{4}$ Consequentemente, há ativação simpática por meio das catecolaminas, ${ }^{5}$ com elevação da frequência cardíaca e da capacidade contrátil do miocárdio que, quando somados à resistência vascular periférica reduzida, determinam 
aumento do débito cardíaco.(figura 1) Essas alterações fisiopatológicas são clinicamente percebidas pela frequência cardíaca de repouso elevada e pela pressão arterial média reduzida. ${ }^{6}$ As modificações circulatórias têm correlação com a gravidade da doença e são mais ostensivas nos estádios mais avançados da doença hepática. ${ }^{2}$

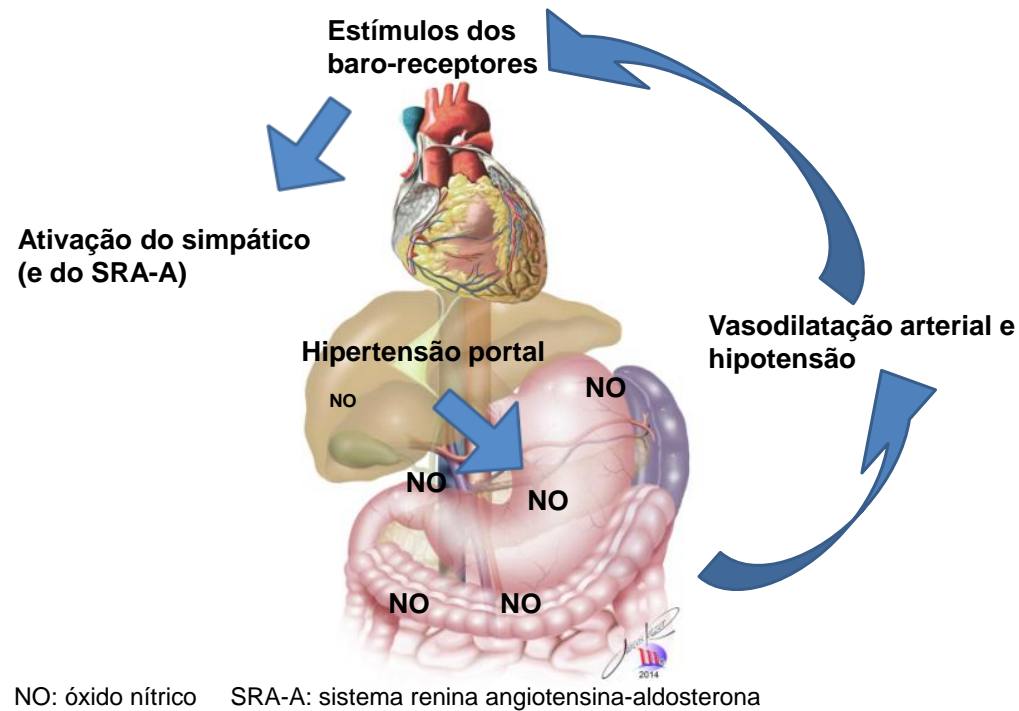

Figura 1.Fisiopatologia da circulação hiperdinâmica na cirrose. A hipertensão portal leva à liberação de óxido nítrico na circulação esplâncnica com vasodilatação e consequente hipotensão arterial sistêmica. O estímulo dos barorreceptores arteriais provoca a ativação de sistemas neurohumorais, em especial, sistema nervoso simpático e eixo reninaangiotensina-aldosterona.

Concomitante aos efeitos da ativação do sistema nervoso simpático e da circulação hiperdinâmica, o coração dos pacientes cirróticos é exposto à ativação do sistema renina-angiotensina-aldosterona, ${ }^{7 ;} 8$ especialmente nos casos de doença avançada, ficando sob as interferências circulatórias e também efeitos diretos da angiotensina II e da aldosterona no miocárdio. Além disso, a hipertensão portal leva à produção esplâncnica dos endocanabinóides e do monóxido de carbono, substâncias que também têm efeitos tóxicos diretos sobre o miocárdio dos cirróticos, contribuindo para o surgimento das alterações cardíacas na cirrose. ${ }^{9}$ 
Sob essas influências circulatórias e neuro-humorais deletérias, surgem modificações histopatológicas no miocárdio. Assim, anormalidades nas características biofísicas da membrana plasmática com consequente perda da fluidez normal de membrana, transdução defeituosa do sinal betaadrenérgico, redução da densidade de receptores beta-adrenérgicos na membrana plasmática e 0 aumento da atividade de sistemas cardiodepressores mediados pelo monofosfato cíclico de guanosina (GMPc). Esses últimos incluem as endotoxinas, óxido nítrico, endotelinas e citocinas, cujos níveis plasmáticos estão aumentados nos pacientes cirróticos com hipertensão portal. ${ }^{10 ; 11}$

É mister ressaltar que o aumento do estímulo beta-adrenérgico é um mecanismo de compensação que, no entanto, se mostra deletério em longo prazo. ${ }^{5} \mathrm{Na}$ insuficiência cardíaca, o aumento do tônus simpático está associado à intolerância ao exercício, anormalidades hemodinâmicas e aumento da mortalidade. ${ }^{12}$ Porém, na cirrose, os consequências negativas da hiperatividade simpática ainda não foram estudadas. Sabe-se que o excesso de catecolaminas aumenta a frequência cardíaca e causa vasoconstricção coronariana, além de aumentar a pré e a pós-carga. A hiperestimulação simpática pode potencializar a hiperatividade do sistema renina-angiotensina-aldosterona, que habitualmente tem atividade exacerbada na cirrose, levando à retenção de sal e água e agindo de forma sinérgica no remodelamento cardíaco. ${ }^{13} \mathrm{O}$ hiperaldosteronismo desempenha um papel central na fisiopatologia da disfunção cardíaca, exercendo seus efeitos na produção de fibrose miocárdica, remodelamento, função endotelial, concentração de eletrólitos, particularmente nos níveis de potássio e na resposta barorreceptora. ${ }^{8}$

O coração fica exposto a tais fatores ao longo da história natural da cirrose. Em consequência, apresenta modificações morfológicas e funcionais, em especial aumento das cavidades esquerdas e elevação da pressão da artéria pulmonar. Esses efeitos que culminam em um remodelamento cardíaco específico dos pacientes com cirrose são mais 
evidentes no estádio final da insuficiência hepática, e são reunidos sob o termo cardiomiopatia cirrótica. ${ }^{14}$

\subsection{Remodelamento cardíaco}

O remodelamento cardíaco é um fator determinante na evolução clínica das miocardiopatias. É definido como uma alteração na estrutura (dimensão, massa, forma) e na função cardíaca em resposta às sobrecargas hemodinâmicas (volume e/ou pressão) e agressão ao coração, associadas com ativação neurohormonal. ${ }^{13} \mathrm{O}$ processo de remodelamento caracterizase por hipertrofia dos miócitos, perda de células devido à apoptose, necrose e proliferação de fibroblastos. Entre os mecanismos envolvidos nessas alterações tem-se o aumento na produção e liberação local de angiotensina II, norepinefrina e endotelina, com aumento do estímulo de fibrogênese, hipertrofia do miócito e redução da bioatividade do óxido nítrico, levando ao aumento das células e do interstício. ${ }^{15}$

Por isso, a reversão ou a redução do processo de remodelamento cardíaco passou a ser um objetivo no tratamento das cardiomiopatias qualquer que seja a sua etiologia.

O remodelamento patológico (mal adaptativo) pode ocorrer nas sobrecargas de volume e/ou pressão ou após lesão do miocárdio (por exemplo, infarto do miocárdio, miocardites ou cardiomiopatias dilatadas). O resultado final é uma piora no desempenho cardíaco e aumento da ativação neurohormonal. ${ }^{13}$

Analisados conjuntamente, os mecanismos fisiopatológicos envolvidos na cardiomiopatia cirrótica seriam, de um modo geral, semelhantes ao remodelamento observado na insuficiência cardíaca, em que ocorrem mudanças na forma e volume ventricular, incluindo perda de tecido e de função, em resposta a diversos estímulos. Embora, a rigor, o conceito de remodelamento tenha sido proposto para descrever as alterações que se seguem ao infarto do miocárdio, ${ }^{16}$ o termo vem sendo estendido às cardiomiopatias não isquêmicas, sugerindo a existência de mecanismos comuns para a disfunção cardíaca. ${ }^{17}$ Entretanto, ainda não há 
certeza se, na cirrose, ocorre o mesmo tipo de comprometimento celular cardíaco.

O resultado do remodelamento contínuo e mal adaptativo inclui disfunção diastólica e sistólica, que podem ser progressivas, com surgimento de insuficiência cardíaca descompensada nas situações de sobrecarga (infecções, transplante hepático ou colocação de stents portosistêmicos (TIPS - Transjugular Intrahepatic Portosystemic Shunt)) ou participação no desenvolvimento de complicações da cirrose (síndrome hepatorrenal).

\subsection{Cardiomiopatia Cirrótica}

Inicialmente, as descrições das disfunções cardíacas nos cirróticos incluíram predominantemente pacientes com cirrose alcoólica, portanto expostos a um fator agressor bem estudado, o álcool. Dessa forma, os primeiros estudos em cirróticos exploravam as alterações possivelmente relacionadas à cardiomiopatia alcoólica, entidade distinta da cardiomiopatia cirrótica. ${ }^{18 ;} 19$ Mas, em 1986, demonstrou-se através de experimentos em modelos animais que a disfunção cardíaca ocorria da mesma forma na cirrose cuja etiologia não era alcoólica. ${ }^{20}$ Estudos subsequentes, em humanos, comprovaram que a perda da resposta contrátil cardíaca estava associada à cirrose per se, ao invés de ser uma alteração consequente aos efeitos do álcool no coração. Em 1989, foi introduzido o termo cardiomiopatia cirrótica para denominar a disfunção cardíaca relacionada à cirrose não alcoólica. $^{21}$

Em que pese não haver ainda consenso, atualmente, a cardiomiopatia cirrótica é definida pela maior parte dos autores como uma disfunção cardíaca crônica em pacientes com cirrose, caracterizada por resposta contrátil inadequada do miocárdio ao estresse e/ou alteração na função diastólica com anormalidades eletrofisiológicas, na ausência de doença cardíaca conhecida. ${ }^{22}$ As principais alterações da cardiomiopatia cirrótica podem ser listadas em cinco categorias: disfunção sistólica, disfunção diastólica, alterações eletrofisiológicas, alterações histológicas e estruturais, além de alterações bioquímicas. 
No repouso, os cirróticos têm o débito cardíaco aumentado em relação aos pacientes hígidos; isso ocorre pela elevação da frequência cardíaca, além do aumento do volume sistólico ejetado, já que a pós-carga está reduzida. ${ }^{23}$ A disfunção sistólica vista nesses pacientes é caracterizada por resposta inadequada do débito cardíaco quando o paciente é submetido a um estresse físico ou farmacológico. ${ }^{10}$ (figura 2)
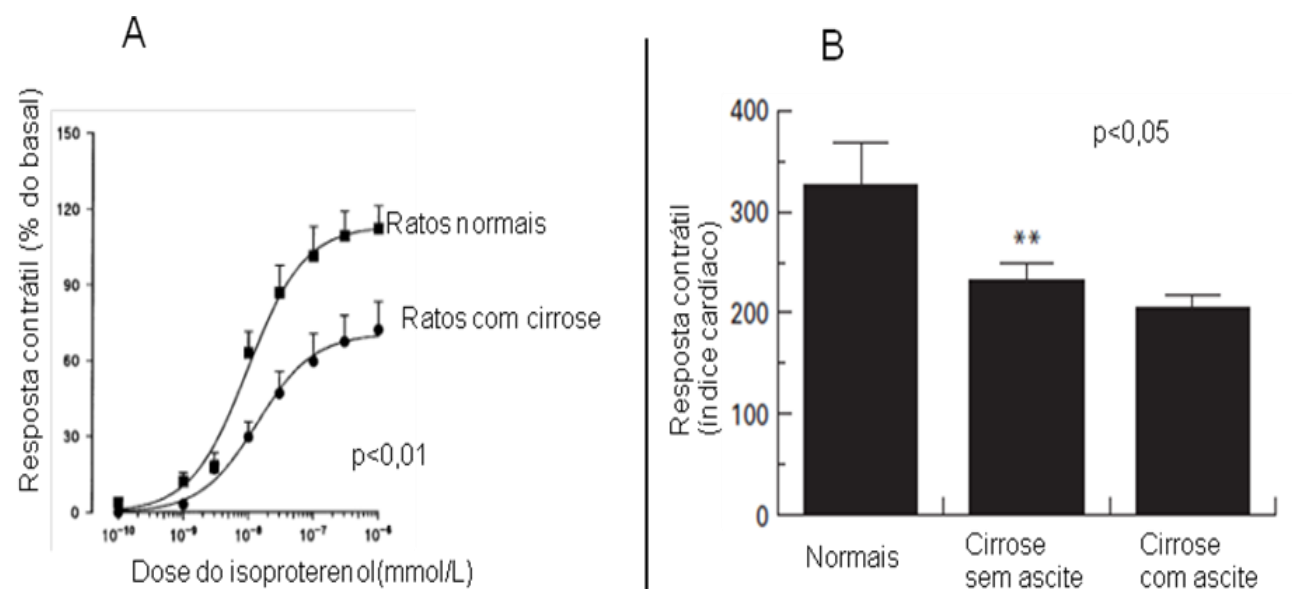

Figura 2. Resposta inotrópica anormal na cirrose, em modelos animais $(A)^{24}$ e em humanos $(B) .{ }^{25}$ Nota-se que, nos modelos animais, a resposta contrátil ao estímulo com isoproterenol é percentualmente menor nos ratos com cirrose. Nos humanos, a resposta contrátil é menor nos cirróticos em relação aos saudáveis, sendo ainda menor entre aqueles com ascite.

Outro achado proeminente da cardiomiopatia cirrótica é a disfunção diastólica. Embora os marcadores ecocardiográficos sejam heterogêneos nos estudos, vê-se que há alta prevalência de alteração do relaxamento cardíaco entre os pacientes com cirrose. ${ }^{26}$ Recentemente, demonstrou-se associação com pior prognóstico. ${ }^{27}$ Porém, devido à heterogeneidade na definição da diástole, há dificuldade na demonstração do efeito prognóstico da alteração do relaxamento na história natural da cirrose.

As alterações eletrofisiológicas são descritas e prevalentes nessa população. O prolongamento do intervalo QT e a incompetência cronotrópica são as alterações mais frequentes. Sabe-se que o prolongamento do intervalo QT ocorre em 30\% a 60\% dos pacientes cirróticos e tem correlação com a gravidade da doença hepática; e que há reversão dessa alteração 
após a realização do transplante hepático. ${ }^{28} \mathrm{O}$ uso de beta-bloqueador nessa situação parece reduzir o intervalo QT. ${ }^{29}$

Os biomarcadores de doença cardiovascular, em especial o peptídeo natriurético tipo $B(B N P)$, têm-se mostrado úteis na avaliação dos cirróticos. A sua aplicação no diagnóstico diferencial da ascite permite a distinção entre as causas cardiológica, hepática e peritoneal. Os níveis séricos do BNP são mais elevados na cirrose do que em controles com ascite de causa peritoneal, mas, por outro lado, seus níveis são menores do que na insuficiência cardíaca. ${ }^{30} \mathrm{~A}$ alteração do BNP sérico na cirrose, guardando correlação com a gravidade da doença, ${ }^{31}$ denota as repercussões do hiperfluxo na dinâmica cardíaca, com aumento do estresse sobre as paredes do coração. A troponina, um dos principais marcadores cardiovasculares de síndrome coronariana aguda, também denuncia lesões miocárdicas em doenças crônicas; está alterada em $32 \%$ dos cirróticos, sendo provavelmente um marcador de miocardiopatia pelo álcool. ${ }^{32}$

Assim como em outras cardiomiopatias incipientes, há dificuldade na definição precisa da anormalidade pela ausência de marcadores acurados e heterogeneidade de critérios definidores e classificatórios. Na cardiomiopatia cirrótica, os estudos mostram formas diferentes de definir a doença, de forma que se torna difícil atrelá-la às complicações clínicas da cirrose e complicações no peri-operatório do transplante ou da colocação do TIPS.

Acredita-se que a cardiomiopatia cirrótica não seja clinicamente manifesta devido à marcante vasodilatação periférica típica da cirrose, que leva ao "autotratamento" do quadro cardíaco e, portanto, mascara a plena expressão clínica da síndrome. ${ }^{11}$ Além disso, as manifestações da doença hepática, com astenia, adinamia e mesmo a caquexia, levam o cirrótico a graus variados de imobilidade. Além da possibilidade de ocultar sintomas cardiológicos, certas queixas cardiológicas podem ser atribuídas às alterações da cirrose, como nos casos de dispneia, que é atribuída à ascite. Logo, a disfunção cardíaca se manifestaria somente nas situações patológicas, fisiológicas ou iatrogênicas que impõem ao miocárdio uma maior sobrecarga (infecções, atividade física, drogas vasopressoras, 
sobrecarga volêmica, shunts porto-cavais, inserção de TIPS, transplante hepático).

A disfunção miocárdica na cirrose pode ter participação na patogênese da síndrome hepatorrenal. Ruiz-del-Arbol et $a^{\beta 3}$ estudou a relação entre síndrome hepatorrenal (SHR) e função cardíaca em 23 pacientes com cirrose e peritonite bacteriana espontânea. Nos pacientes que desenvolveram SHR, notou-se débito cardíaco e pressão arterial média diminuídos, antes e depois da infecção. Esses achados foram reproduzidos em um estudo subsequente com casuística maior, conduzido pelo mesmo grupo de autores, com delineamento semelhante, sugerindo que a queda do débito cardíaco com redução da pressão de perfusão renal possa precipitar o desenvolvimento da SHR. ${ }^{34} \mathrm{Um}$ estudo recente mostrou que a disfunção cardíaca - medida pelo índice cardíaco por meio de cintilografia - esteve relacionada à piora da função renal e à mortalidade, ou seja, pacientes com índice cardíaco reduzido têm menor sobrevida. ${ }^{35 ; 36}$

A implantação do TIPS e o transplante hepático são procedimentos para o tratamento da cirrose e suas complicações que apresentam elevada incidência de eventos cardiovasculares. Logo após a colocação do TIPS, há aumento importante e rápido da pré-carga, com desenvolvimento de insuficiência cardíaca em $12 \%$ dos pacientes. ${ }^{37} \mathrm{~A}$ descompensação cardíaca é, em alguns centros, descrita como terceira causa mais comum de óbito no período pós-operatório imediato do transplante hepático. Todavia, as consequências clínicas, em longo prazo, e o espectro clínico dessa disfunção nos cirróticos ainda não estão suficientemente esclarecidos. Além disso, não há testes de boa acurácia para estimar a probabilidade de complicação cardiológica no contexto do transplante hepático. ${ }^{10}$

\subsection{Betabloqueadores e o remodelamento reverso}

Os betabloqueadores são os principais modificadores da história natural da insuficiência cardíaca. $O$ uso de betabloqueadores para a reversão do remodelamento mostrou-se eficaz em melhorar as alterações morfológicas (geometria e massa), a função do ventrículo esquerdo, o 
performance status e a sobrevida em longo prazo nos pacientes com insuficiência cardíaca (IC). ${ }^{38} \mathrm{O}$ efeito benéfico estende-se aos pacientes assintomáticos, conforme demonstrado em um estudo controlado que avaliou a eficácia do succinato de metoprolol, onde o grupo intervenção teve aumento significante da fração de ejeção em relação ao grupo controle que recebeu placebo. ${ }^{39}$

Os betabloqueadores testados e comprovados como benéficos, em termos de sobrevida, na insuficiência cardíaca são o metoprolol, o carvedilol, o bisoprolol e o nebivolol. Todas essas drogas têm efeito antiremodelamento miocárdico já descrito. Estudos com carvedilol em cirróticos, desenhados para reduzir hipertensão portal, mostraram notória incidência de hipotensão sintomática, constituindo-se no principal motivo de intolerância ao uso da droga nesses pacientes. ${ }^{40} \mathrm{O}$ metoprolol também já foi usado em cirróticos com o objetivo de redução da hipertensão portal. ${ }^{41}$ Nesse estudo, não houve relato de intolerância ao medicamento. Portanto, essa droga parece ser a mais adequada em termos de segurança para ser testada nos cirróticos com intuito de reverter o remodelamento na miocardiopatia cirrótica.

O metoprolol é um antagonista dos receptores beta-adrenérgicos, com seletividade para os receptores beta-1. É desprovido de atividade simpaticomimética intrínseca e atividade estabilizadora da membrana. A redução da mortalidade em $34 \%$ nos casos de IC ocorre pela redução da progressão da doença e diminuição da incidência de morte súbita. ${ }^{42}$ Os estudos em IC com disfunção sistólica mostram que tais drogas promovem uma melhora da fração de ejeção (FE) e essa ação anti-remodelamento, o que explica a diminuição das mortes por progressão da doença nessa população. ${ }^{43}$

As propriedades da droga são bem conhecidas no remodelamento cardíaco de cardiomiopatias onde há disfunção sistólica por diferentes causas. No entanto, a sua ação no remodelamento cardíaco e nos desfechos clínicos em cirróticos ainda não foi estudada. 


\section{OBJETIVOS}

\subsection{Primário}

No presente estudo, nosso objetivo principal foi avaliar a eficácia do succinato de metoprolol na reversão da resposta inotrópica inadequada ao estresse em pacientes com cirrose de etiologia não alcoólica.

\subsection{Secundários}

2.2.1 Tivemos como objetivos secundários, em relação à terapia com metoprolol, avaliar:

- A reversão das alterações ecocardiográficas (morfologia da câmaras e função diastólica);

- A reversão das alterações laboratoriais (BNP, troponina, atividade da renina plasmática e noradrenalina);

- A reversão das alterações eletrofisiológicas (Holter de 24h);

- O efeito na gravidade da cirrose e nos seus eventos clínicos (ascite, síndrome hepatorrenal, encefalopatia, infecções, hemorragia digestiva varicosa, internação e mortalidade);

- Efeitos adversos.

2.2.2. Em relação à resposta inotrópica relacionada ao estresse do paciente com cirrose, tivemos como objetivo avaliar o impacto dessa disfunção na evolução clínica. 


\section{PACIENTES E MÉTODOS}

\subsection{Pacientes}

\section{Recrutamento e inclusões}

Critérios de inclusão:
a) Idade entre 18 e 60 anos;
b) Diagnóstico de cirrose de etiologia não alcoólica;
c) Escore MELD entre 10 e 20;
d) Concordância em participar do estudo.

\section{Critérios de exclusão:}

a) Contraindicação ao uso de drogas beta-bloqueadoras;

b) Insuficiência cardíaca com disfunção sistólica;

c) Hipotireoidismo descompensado;

d) Doenças que causam estado de alto débito cardíaco, exceto cirrose;

e) Insuficiência renal com creatinina $>2,5 \mathrm{mg} / \mathrm{dL}$;

f) Carcinoma hepatocelular avançado segundo critérios de Milão ${ }^{44}$ ou outra malignidade avançada;

g) História de uso de álcool acima de $60 \mathrm{~g} /$ dia para homem e $40 \mathrm{~g}$ para mulher;

h) Doenças que podem causar cardiopatias (doenças infiltrativas ou de depósito).

Critérios diagnósticos de cirrose, síndrome hepatorrenal e da resposta inotrópica anormal (disfunção cardíaca do cirrótico) 


\section{Cirrose}

O diagnóstico da cirrose foi estabelecido pela combinação dos critérios clínicos, radiológicos ou endoscópicos ou alternativamente pelo achado histológico de cirrose. Tais critérios foram:

- Clínicos: presença de sinais periféricos de doença hepática ao exame físico: aranhas vasculares, ginecomastia, eritema palmar, circulação colateral, esplenomegalia, icterícia e ascite;

- Radiológicos: ultrassonografia, tomografia computadorizada ou ressonância magnética com sinais de doença hepática crônica;

- Endoscópicos: presença de varizes esofágicas ou gástricas e/ou gastropatia hipertensiva.

\section{Resposta inotrópica anormal (disfunção cardíaca do cirrótico)}

A resposta da integral velocidade-tempo (VTI) ao estresse, avaliada pelo ecocardiograma sob estresse com dobutamina e medida na via de saída do ventrículo esquerdo (VE), foi caracterizada como anormal quando o incremento da VTI foi menor que $30 \%$ em relação à medida no repouso, conforme descrito na literatura. ${ }^{45 ; 46 ; 47}$

\section{Síndrome hepatorrenal}

A síndrome hepatorrenal foi diagnosticada conforme os critérios diagnósticos revisados de 2007 do Clube Internacional de Ascite: ${ }^{48}$

- Cirrose com ascite;

- Creatinina sérica >1,5 mg/dl;

- Ausência de melhora da função renal (diminuição da creatinina para $<1,5$ $\mathrm{mg} / \mathrm{dl}$ ) após dois dias sem diuréticos e expansão de volume com albumina na dose de $1 \mathrm{~g} / \mathrm{kg}$ de peso/dia;

- Ausência de choque;

- Ausência de tratamento recente ou atual com drogas nefrotóxicas;

-Ausência de doença parenquimatosa renal indicada por proteinúria>500mg/dia, microhematúria (>50 hemácias/campo) e/ou ultrassonografia renal com anormalidades. 


\subsection{Métodos}

\section{Desenho do estudo}

Trata-se de estudo prospectivo, randomizado, duplo-cego, controlado com placebo, por intenção de tratar, fase de evolução II, unicêntrico, de superioridade (droga versus placebo).

\section{Procedimentos do estudo}

a) Convite para o paciente participar do estudo, exposição do protocolo, assinatura do termo de consentimento;

b) Entrevista do paciente para obtenção de dados demográficos (sexo e idade), anamnese e exame físico;

c) Consulta aos dados de prontuário. Foram avaliados todos os exames destinados à definição etiológica da cirrose, estratificação da gravidade e deteç̧ão de complicações da doença, além da identificação de comorbidades. A sua solicitação (ou realização) ocorreu de forma independente da inclusão ou não do paciente no protocolo. Foram avaliados sistematicamente os resultados dos exames listados a seguir:

- Parâmetros laboratoriais no sangue: creatinina, uréia, sódio, potássio, albumina, hemograma, glicose, tempo de protrombina (TP-INR), bilirrubinas, tireotrofina (TSH), tiroxina (T4) livre, sorologia para vírus hepatotrópicos, autoanticorpos hepáticos, marcadores de hepatopatias metabólicas, marcadores tumorais;

- Endoscopia digestiva alta e/ou colonoscopia;

- Radiografia de tórax;

- Biópsias hepáticas, quando disponíveis.

d) Exames específicos do presente estudo:

- Eletrocardiograma de repouso;

- Holter 24h;

- Ecodopplercardiograma sob estresse com dobutamina; 
- Coleta de amostra de sangue (10 ml) no momento da inclusão e seis meses após para dosagem de BNP, troponina, catecolaminas e atividade da renina plasmática.

\section{Momento de realização das avaliações e exames específicos do protocolo}

A consulta médica com coleta dos dados de história e exame físico foi realizada no momento da inclusão, quinzenalmente durante o seguimento ou conforme a necessidade, até completar seis meses, quando foi feita a avaliação de encerramento. As dosagens de BNP, catecolaminas, troponina, atividade plasmática de renina, a realização do ecocardiograma em repouso e com estresse farmacológico, do ECG em repouso e do ECG dinâmico por 24 horas deu-se no momento da inclusão (antes da randomização) e após 6 meses.

\section{Protocolos e técnicas dos exames e procedimentos}

\section{Eletrocardiograma de repouso e dinâmico 24 horas pelo sistema Holter}

O eletrocardiograma de repouso foi realizado conforme procedimento habitual, com 12 derivações. A monitorização eletrocardiográfica ambulatorial por 24 horas foi realizada com o gravador portátil de Holter Digital 300-9T da marca DMS, Califórnia, EUA. Três derivações eletrocardiográficas foram usadas para análise, conforme padrão internacionalmente aceito. Foram obtidos os parâmetros que avaliaram a frequência cardíaca média, a ocorrência de arritmias e o intervalo QT (posteriormente corrigido pela fórmula de Fridericia). ${ }^{29} \mathrm{~A}$ variabilidade da frequência cardíaca foi analisada a partir da sequência dos intervalos $R-R$, obtida tanto nos domínios de tempo quanto de frequência, conforme recomendação da diretriz da Sociedade Europeia de Cardiologia. ${ }^{49}$ Os índices de avaliação da variação da freqüência cardíaca obtidos foram: desvio-padrão de todos os intervalos RR (SDNN), desvio-padrão da média dos intervalos RR (SDANN), raiz quadrada da média das diferenças 
sucessivas ao quadrado, entre NN adjacentes (rMSSD), percentagem das diferenças sucessivas entre os intervalos $N N>50 \mathrm{~ms}$ (pNN50), além da análise espectral (por 24 horas). Esses parâmetros são interpretados como segue:

- SDNN: como marcador prognóstico, considera-se como alto risco quando $\leq$ $50 \mathrm{~ms}$, médio risco entre 51 e $100 \mathrm{~ms}$ e baixo risco para os valores $>100 \mathrm{~ms}$.

- SDANN: como marcador prognóstico, considera-se alto risco quando $\leq 50$ ms, médio risco entre 51 e $100 \mathrm{~ms}$ e baixo risco quando acima de $100 \mathrm{~ms}$.

- rMSSD: são considerados valores normais entre 15 e 39 ms. Esse índice é utilizado especialmente para avaliação da variação autonômica em 24 horas, sendo influenciado pelo sistema vagal. Valores abaixo de $15 \mathrm{~ms}$ são considerados de alto risco (predomínio simpático) e acima de 39 ms baixo risco (predomínio vagal).

- pNN50: valores superiores a $5 \%$ definem atividade predominantemente vagal e inferiores a $5 \%$, predomínio de atividade simpática.

- Análise espectral: analisada na faixa de baixa frequência, sendo considerados normais os valores entre 754 e 1586 ms²$^{2}$.

\section{Ecodopplercardiograma em repouso}

Realizou-se ecodopplercardiograma transtorácico bidimensional com mapeamento colorido e utilização de imagem harmônica usando o aparelho Artida Toshiba (Tokyo, Japão), equipado com transdutor multi-frequência 2,5-3,5 MHz. Todo o exame foi armazenado em formato DICOM para posterior análise. Foram adquiridas imagens dos planos paraesternal eixo curto e longo, apical quatro e duas câmaras, além do subcostal. A partir do plano paraesternal foram obtidas as seguintes medidas: diâmetro da aorta e do átrio esquerdo, diâmetros diastólico e sistólico do ventrículo esquerdo (VE), espessura diastólica do septo interventricular e da parede posterior do VE para cálculo da massa ${ }^{50}$ e índice de massa do VE e o percentual de encurtamento sistólico do diâmetro do VE (Delta D\%). A partir dos planos apicais quatro e duas câmaras foram obtidos os volumes sistólico e diastólico do ventrículo esquerdo para cálculo da FE, além das medidas do 
volume máximo do átrio esquerdo (no final da diástole ventricular, imediatamente antes da abertura da valva mitral), ambas pelo método Simpson. A medida do ventrículo direito foi obtida a partir do plano apical quatro câmaras, paralelamente ao anel valvar tricúspide.

Para a análise da função diastólica, o fluxo mitral foi avaliado utilizando-se a amostra de volume do Doppler de 2-3 mm posicionada na borda das cúspides da valva mitral, paralelamente e o mais próxima possível do centro do fluxo, de forma perpendicular ao plano do anel. Foram medidas as velocidades máximas das ondas diastólica precoce $(E)$ e tardia $(A)$ e 0 tempo de desaceleração da onda $E$ (TD). Foram analisados os traçados de Doppler tecidual obtidos a partir do corte apical quatro câmaras com 0 volume de amostragem do Doppler de 3-5 mm posicionado nas regiões do anel mitral medial (base do septo ventricular) e anel mitral lateral, sendo então medidos os picos negativos das velocidades diastólicas, que correspondem ao pico de velocidade diastólica precoce (e') e diastólica tardia (a'), além do pico positivo (s'), que representa o movimento sistólico. A relação E/e' foi calculada considerando-se a média entre as velocidades de e' septal e e' lateral. Foi obtida a onda s' do Doppler tecidual a partir do anel tricuspídeo para estimativa da função sistólica do ventrículo direito.

Todo o exame ecocardiográfico foi sincronizado com o traçado eletrocardiográfico. As medidas de Doppler foram obtidas no final da expiração e representadas pela média de três batimentos.

A identificação e classificação de disfunção diastólica foi realizada a partir dos critérios da Sociedade Americana de Ecocardiografia. ${ }^{51}$ Foi considerada disfunção diastólica discreta (alteração do relaxamento ventricular) a presença de e' septal $<8 \mathrm{~cm} / \mathrm{s}$, e' lateral $<10 \mathrm{~cm} / \mathrm{s}$, relação $E / A<0,8$ e relação $E / e^{\prime} \leq 8$, e TD $>200$ ms. A disfunção diastólica moderada (padrão pseudonormal) foi caracterizada por e' septal $<8 \mathrm{~cm} / \mathrm{s}$, e' lateral < $10 \mathrm{~cm} / \mathrm{s}$, relação E/A entre 0,8 e 1,5 com diminuição em $50 \%$ ou mais após manobra de Valsalva, relação E/e' entre 9 e 12, TD entre 160 e 200 ms, e volume atrial esquerdo $\geq 34 \mathrm{ml} / \mathrm{m}^{2}$. A disfunção diastólica importante (padrão 
restritivo) foi caracterizada por e' septal $<8 \mathrm{~cm} / \mathrm{s}$, e' lateral $<10 \mathrm{~cm} / \mathrm{s}$, relação $E / A \geq 2$, relação $E / e^{\prime} \geq 13$, TD $<160 \mathrm{~ms}$, e volume atrial esquerdo $\geq$ $34 \mathrm{ml} / \mathrm{m}^{2}$.

As medidas de variabilidade inter e intraobservador foram calculadas como a diferença entre 2 observações divididas pela média das observações e expressa em percentagem.

\section{Ecodopplercardiograma com estresse farmacológico e obtenção da variação da integral velocidade-tempo}

Foi realizado ecocardiograma sob estresse farmacológico com dobutamina em doses progressivas, sob infusão controlada, iniciada com 5 $\mathrm{mcg} / \mathrm{kg} / \mathrm{min}$ e, a partir de então, com aumento da dose em $10 \mathrm{mcg} / \mathrm{Kg} / \mathrm{min}$ em intervalos de três minutos até atingir a frequência cardíaca submáxima ou a dose máxima de $40 \mathrm{mcg} / \mathrm{kg} / \mathrm{min}$. A atropina foi utilizada para incremento da frequência cardíaca em protocolo precoce, a partir de $20 \mathrm{mcg} / \mathrm{Kg} / \mathrm{min}$ de dobutamina, em infusões de 0,5 mg a cada minuto, até a dose máxima de 2 mg nos casos em que a FC submáxima não foi atingida apenas com a dobutamina. Foram realizados eletrocardiograma de 12 derivações e monitorização da pressão arterial ao final de cada estádio e na fase de recuperação após término do teste. A obtenção do valor da integral velocidade-tempo (VTI) foi feita com o Doppler pulsado na via de saída do ventrículo esquerdo e o Doppler contínuo no interior da aorta, 2 a $3 \mathrm{~cm}$ após a válvula, em repouso, durante a administração de $10 \mathrm{mcg} / \mathrm{kg} / \mathrm{min}$ de dobutamina e no pico do estresse. As medidas foram realizadas em três diferentes ciclos cardíacos contínuos, considerando-se a média de três medidas, tanto no repouso quanto durante o pico do estresse. Fez-se a vigilância das alterações da contratilidade miocárdica, queixas e sintomas, e alterações eletrocardiográficas se presentes.

\section{Dosagens do peptídeo natriurético tipo $B$}

A dosagem do nível de BNP no sangue foi realizada com a utilização do kit de BNP ADVIA Centaur, manufaturado pelo laboratório Siemens (San 
Diego, Califórnia, EUA). O teste consiste em um imunoensaio tipo sanduíche de duas etapas que utiliza tecnologia quimioluminescente direta e quantidades constantes de dois anticorpos monoclonais. As amostras foram dosadas em duplicata, segundo as recomendações do fabricante do kit e analisadas em até duas horas após a sua coleta.

\section{Dosagem da noradrenalina}

As catecolaminas foram extraídas do plasma com óxido de alumínio (alumina) e em seguida separadas por fase reversa e quantificadas por cromatografia líquidade alta pressão com detector eletroquímico. A $1 \mathrm{~mL}$ de plasma acrescentaram-se $10 \mathrm{mg}$ de alumina, $300 \mu \mathrm{l}$ de tampão Tris-EDTA, 2 $\mathrm{M}, \mathrm{pH} 8,7$ e $50 \mu \mathrm{l}$ de padrão interno (solução de $10 \mathrm{ng} / \mathrm{ml}$ de DHBA em ácido acético $0,1 \mathrm{~N}$ ), seguido de agitação por inversão durante 5 minutos. Após homogeneização, o sobrenadante foi desprezado e a alumina lavada com $\mathrm{H}_{2} \mathrm{O}$ ultra pura e submetida à agitação por inversão durante 1 minuto. $\mathrm{O}$ processo de lavagem foi repetido por mais uma vez e as catecolaminas foram eluídas da resina em solução de ácido acético 0,1N, EDTA a 5\% e dissulfito de sódio a 10\%. Este material foi centrifugado por 1 minuto e o sobrenadante filtrado através de filtro Millipore $0,45 \mu$. Uma parte deste filtrado $(25 \mu \mathrm{l}$ a $50 \mu \mathrm{l})$ foi injetada em um sistema de cromatografia de alta pressão com detector eletroquímico (HPLC).

\section{Dosagens da troponina}

Para a dosagem da troponina foi usado o Kit IMMULITE/IMMULITE 1000 fabricado pela Siemens (Erlangen, Alemanha), que consiste em um ensaio imunoenzimático de fase sólida por quimioluminescência. A fase sólida (esfera) está revestida com um anticorpo monoclonal murino antitroponina I. A fase líquida consiste em fosfatase alcalina (obtida de intestino de bezerro) conjugada com um anticorpo policlonal anti-troponina I, obtido de cabras. A amostra do paciente e o reagente são incubados com a esfera durante oito minutos. Durante esse período, a troponina I da amostra forma um sanduíche com o anticorpo monoclonal anti-troponina I da esfera e o 
anticorpo policlonal de cabra anti-troponina I do reagente. Na amostra do, a enzima conjugada foi removida por lavagem e centrifugação. Finalmente, o substrato quimioluminescente foi adicionado à unidade de teste que contém a esfera gerando um sinal proporcional à quantidade de enzima ligada.

\section{Atividade da renina plasmática}

Foi usado o kit de radioimunoensaio GammaCoat (Stillwater, Minnesota, E.U.A.), que mede a atividade da renina plasmática, a partir da angiotensina I gerada. A determinação da atividade da renina plasmática envolve uma incubação inicial de plasma para gerar a angiotensina I, seguida por uma quantificação da angiotensina I através do radioimunoensaio. Os resultados são apresentados em nanograma de angiotensina I liberados por $\mathrm{mL}$ por hora $(\mathrm{ng} / \mathrm{mL} / \mathrm{h})$.

\section{Sequência de randomização}

$O$ processo de randomização central foi feito com uma sequência numérica gerada por computador na Farmácia Central do HCFMUSP, colocados em envelopes opacos lacrados. Os pacientes foram randomizados para receber succinato de metoprolol ou placebo, na proporção de 1:1. A lista de randomização permaneceu na Farmácia Central do HCFMUSP.

\section{Alocação}

Seguindo as diretrizes do CONSORT ${ }^{52}$ todos os pacientes que, ao ecocardiograma sob estresse com dobutamina não aumentaram a integral velocidade-tempo (VTI) acima de $30 \%$ em relação ao valor obtido no repouso foram randomizados para receber succinato de metoprolol (grupo metoprolol) ou placebo (grupo placebo), durante 6 meses. A alocação dos grupos randomizados foi feita por sorteio realizado na farmácia de cada envelope lacrado contendo o número do paciente. As caixas contendo as cápsulas (succinato de metoprolol ou placebo) eram marcadas com o número randomizado e foram destinadas de forma sequencial para cada 
paciente, conforme determinado na referida farmácia. Dessa forma, os pesquisadores envolvidos no atendimento dos pacientes e coleta dos dados não participaram dos processos de randomização e alocação e não tinham conhecimento se o paciente fora sorteado para receber a droga ativa ou o placebo.

O grupo constituído por pacientes com boa resposta contrátil (variação positiva da VTI ao estresse > 30\%) foi apenas acompanhado por 6 meses (grupo sem intervenção) e não recebeu metoprolol nem placebo.

\section{Cegamento de participantes e de pesquisadores}

Houve cegamento dos pacientes e pesquisadores que tinham contato com os pacientes e que fizeram as coletas das variáveis-desfechos. Isso foi garantido pela identificação codificada dos frascos com as cápsulas, assim como das respectivas caixas apenas com o número da randomização $A$ farmácia teve o cuidado de realizar o mascaramento visual da medicação ativa e do placebo. O placebo foi composto por cápsulas preenchidas com amido. Os comprimidos de succinato de metoprolol foram postos dentro de cápsulas com a mesma conformação do placebo. Além dos comprimidos da droga de intervenção, havia a necessidade de adicionar amido para garantir o "mascaramento auditivo". Os medicamentos foram armazenados no Serviço de Farmácia do HCFMUSP, segundo as normas habituais, e entregues ao pesquisador para cada novo paciente incluído.

\section{Esquema posológico}

O succinato de metoprolol foi administrado por via oral, iniciado na dosagem de 1 comprimido de $25 \mathrm{mg}$, uma vez ao dia. O aumento da dose foi realizado em intervalos de duas semanas até atingir a frequência cardíaca de 60 bpm, surgimento de efeitos colaterais ou até atingir a dose máxima de 8 comprimidos (equivalente a $200 \mathrm{mg}$ de metoprolol) ao dia. Uma vez atingida a dose adequada, o tratamento foi mantido por 6 meses. Os pacientes foram avaliados clinicamente a cada quinze dias, sendo sempre inquiridos sobre efeitos colaterais, aferição da pressão arterial e frequência 
cardíaca. O grupo controle seguiu o mesmo esquema posológico do grupo metoprolol em relação ao número de comprimidos e intervalos de ajuste de doses.

\section{Verificação da adesão ao tratamento}

Foi realizada pela contagem dos comprimidos restantes no frasco anteriormente entregue ao paciente, assim como através de perguntas sobre a medicação a cada consulta.

\section{Tratamentos concomitantes permitidos e proibidos}

Todos os tratamentos necessários, do ponto de vista assistencial, foram permitidos, segundo o julgamento do médico responsável pelo paciente. As únicas medicações não permitidas foram outros betabloqueadores, por representar a classe de drogas em estudo. No grupo que tinha resposta normal da VTI no ecocardiograma sob estresse, não houve intervenção (grupo sem intervenção), logo, permitiu-se o uso do propranolol, conforme indicação do médico assistente. A profilaxia do sangramento por varizes esofágicas foi feita com tratamento endoscópico (ligadura elástica), conforme as recomendações do Consenso de Baveno V. ${ }^{53}$

\section{Critérios de retirada do estudo}

Foram considerados como critérios para retirada dos pacientes do estudo o surgimento de efeitos adversos proibitivos à continuidade da terapêutica com succinato de metoprolol, em particular: bradicardia sinusal ( $F C<50$ bpm), bloqueio átrio-ventricular avançado, surgimento de sintomas de insuficiência cardíaca descompensada, hipotensão importante (PA< $90 / 60 \mathrm{mmHg}$ ) ou a manifestação do paciente de sair do estudo.

\section{Tratamento dos pacientes não incluídos e dos excluídos do estudo}

Os pacientes avaliados que não preencheram os critérios de inclusão foram registrados, indicando a causa pela qual não puderam 
participar do ensaio, conforme as recomendações CONSORT. ${ }^{54}$ Igualmente, foram registradas todas as exclusões (figura 3). Esses pacientes foram mantidos em acompanhamento na instituição e receberam tratamento adequado à sua situação clínica, do mesmo modo que os demais pacientes matriculados na Divisão de Gastroenterologia e Hepatologia e Divisão de Transplante de Fígado e Órgãos do Aparelho Digestivo.

\section{Desfechos avaliados}

\section{Primário}

Aumento de pelo menos $30 \%$ da VTI medida no estresse em relação ao basal.

\section{Secundários}

- Clínicos e evolutivos:

- Síndrome hepatorrenal- Infecções bacterianas

- Ascite

- Encefalopatia hepática

- Hemorragia digestiva varicosa

- Internações hospitalares

- Morte

- Eletrocardiográficos:

- Redução do intervalo QT (<440 ms)

- Aumento dos índices de SDNN, SDANN, rMSSD, pNN50 e análise espectral

- Laboratoriais:

- Redução dos níveis de BNP

- Redução dos níveis de troponina

- Redução dos níveis de noradrenalina 
- Redução da atividade da renina plasmática

- Relacionados à terapia

- Efeitos adversos da medicação

- Ocorrência de sangramento relacionado à hipertensão portal

\section{Avaliação da resposta ao tratamento}

$\mathrm{Na}$ avaliação do desfecho primário, foi considerada resposta ao tratamento a "normalização da resposta inotrópica", conforme avaliada pelo ecocardiograma sob estresse com dobutamina. A resposta inotrópica adequada (normal) caracterizou-se pelo incremento da integral velocidadetempo (função sistólica) maior que 30\% ao estresse com dobutamina, em relação à VTI de repouso. Além disso, melhora estatisticamente significante dos parâmetros laboratoriais, ecocardiográficos, eletrofisiológicos e redução dos eventos clínicos (ascite, encefalopatia, infecções, internações, síndrome hepatorrenal e morte) com o tratamento, assim como a reversão das alterações eletrofisiológicas, a saber, o prolongamento do intervalo QT e variabilidade da frequência cardíaca.

\section{Análise estatística}

\section{Cálculo do tamanho da amostra}

O parâmetro utilizado para o cálculo da amostra foi o desfecho primário "normalização da resposta da VTI". Como não há estudos prévios publicados com metoprolol nessa população, inferimos que o efeito do medicamento no remodelamento cardíaco seria semelhante àquele obtido em pacientes com IC. Baseados nos resultados de remodelamento miocárdico com uso de metoprolol na insuficiência cardíaca, a diferença de remodelamento entre os grupos que se buscou foi de $20 \%$. Considerando um erro $\beta$ de 0,20 - poder do estudo $80 \%$-, erro alfa de 0,05 , foi estimado um tamanho amostral de 32 pacientes por grupo. Considerando uma porcentagem de perdas (drop outs) de 10\%, estimamos a necessidade de, 
no mínimo, 36 pacientes por grupo para receber medicamento. O grupo seguimento "sem intervenção" farmacológica foi composto por pacientes que responderam adequadamente ao estresse com dobutamina, sem necessidade de tratamento. Por isso, não houve necessidade de cálculo da amostra para esse grupo.

\section{Análise interina dos resultados}

Um comitê independente de monitoramento de segurança realizou uma análise interina, utilizando o método sequencial de O'Brien e Fleming, ${ }^{55}$ após 39 pacientes completarem o seguimento. Neste momento, a análise não revelou diferenças entre os grupos de tratamento (nível de significância $<0,005$ não foi alcançado), levando à decisão de continuar o estudo.

\section{Análise subsequente dos resultados}

A análise dos resultados foi feita por pesquisador cegado e foi confirmada por um comitê de dois revisores, que também foi encarregado de avaliar se o tratamento aplicado correspondeu ao designado, e se a ordem de randomização estava correta. Para a avaliação da normalidade na distribuição das variáveis, usou-se o teste de Anderson-Darling. Para a comparação das variáveis nos dois grupos com distribuição normal (teste $t$ Student) e naquelas com distribuição não-normal Mann-Whitney; para variáveis qualitativas usou-se o teste exato de Fisher e o teste de McNemar para verificar associação. Também foi utilizada uma análise de sobrevida (regressão de riscos proporcionais de Cox) para avaliar o efeito das diferentes variáveis sobre a sobrevida livre de desfechos. Gráficos com as curvas de probabilidade de Kaplan Meier foram construídos. Para a análise de sobrevida, considerou-se o seguimento por 6 meses ou ocorrência de morte (ou ocorrência de eventos nos casos de análise de sobrevida livre de eventos) e censurados por transplante ou perda de seguimento. Todos esses cálculos foram realizados com o pacote estatístico 3.0.2 R ( $R$ Core Team, R Foundation for Statistical Computing Viena, Áustria). $\mathrm{P}<0,044$ foi 
considerado estatisticamente significante ( $p$-valor corrigido para a análise interina).

\section{Custos}

O estudo foi financiado parcialmente pela FAPESP (processo número 2010/12223-6) e complementado com recursos próprios do Departamento de Gastroenterologia da FMUSP.

\section{Aspectos éticos e regulatórios}

O estudo foi conduzido segundo os princípios éticos estabelecidos pela Declaração de Helsinque. O protocolo do estudo e o Termo de Consentimento Livre e Esclarecido (TCLE) foram submetidos e aprovados pela Comissão de Ética para Análise de Projetos de Pesquisa (CAPPesq) do Hospital das Clínicas da Faculdade de Medicina da Universidade de São Paulo (HCFMUSP), em sessão de 11/05/2011, sob o número 0010/11. Todos os pacientes receberam informações claras, em linguagem acessível, acerca dos objetivos do estudo, procedimentos necessários, riscos e benefícios esperados, e assinaram o termo de consentimento pós-informado previamente à inclusão. O estudo foi registrado na base internacional de dados ClinicalTrials.gov com o título "Metoprolol Succinate in Cardiac Remodeling Related to Cirrhosis", identificador NCT01676285 e acrônimo "CARE Cirrhosis".

Nesse estudo, não houve qualquer vinculação com os fabricantes do medicamento ou dos equipamentos utilizados. O succinato de metoprolol e o placebo foram adquiridos com verba do projeto de pesquisa, não havendo nenhuma forma de auxílio ou vinculação com a indústria farmacêutica. Desta forma, não há qualquer relacionamento que possa ser considerado conflito de interesses.

\section{Local do estudo}

O estudo foi realizado no Instituto Central, Divisão de Gastroenterologia e Hepatologia e Divisão de Transplante de Fígado e 
Órgãos do Aparelho Digestivo (inclusão, tratamento clínico e endoscópico quando necessário e seguimento dos pacientes, assim como a coleta de exames laboratoriais, ECG de repouso e dinâmico), Instituto de Radiologia (ecocardiograma sob estresse) e no Instituto do Coração do HCFMUSP (exames laboratoriais específicos do estudo). 


\section{RESULTADOS}

Entre maio de 2011 e setembro de 2013, foram avaliados para inclusão no estudo 478 pacientes em acompanhamento nos Ambulatórios de Hepatologia e de Transplante do Fígado do Hospital das Clínicas da FMUSP. Desses, 190 preencheram os critérios de inclusão e 65 foram excluídos, sendo os motivos: transplante no período da avaliação $(n=18)$; óbito no período da avaliação $(n=13)$; insuficiência renal crônica $(n=13)$; cardiopatias primárias (Insuficiência cardíaca $n=6$; doença arterial coronariana $n=3$; estenose aórtica grave $n=1)$; pneumopatia grave $(n=5)$; bradicardia $(n=2)$; história de intolerância aos betabloqueadores $(n=2)$; carcinoma hepatocelular avançado $(n=2)$. No total, foram incluídos 125 pacientes, tendo ocorrido oito $(6,4 \%)$ perdas de seguimento, as quais também foram analisadas, uma vez que utilizamos análise por intenção de tratar (figura 3).

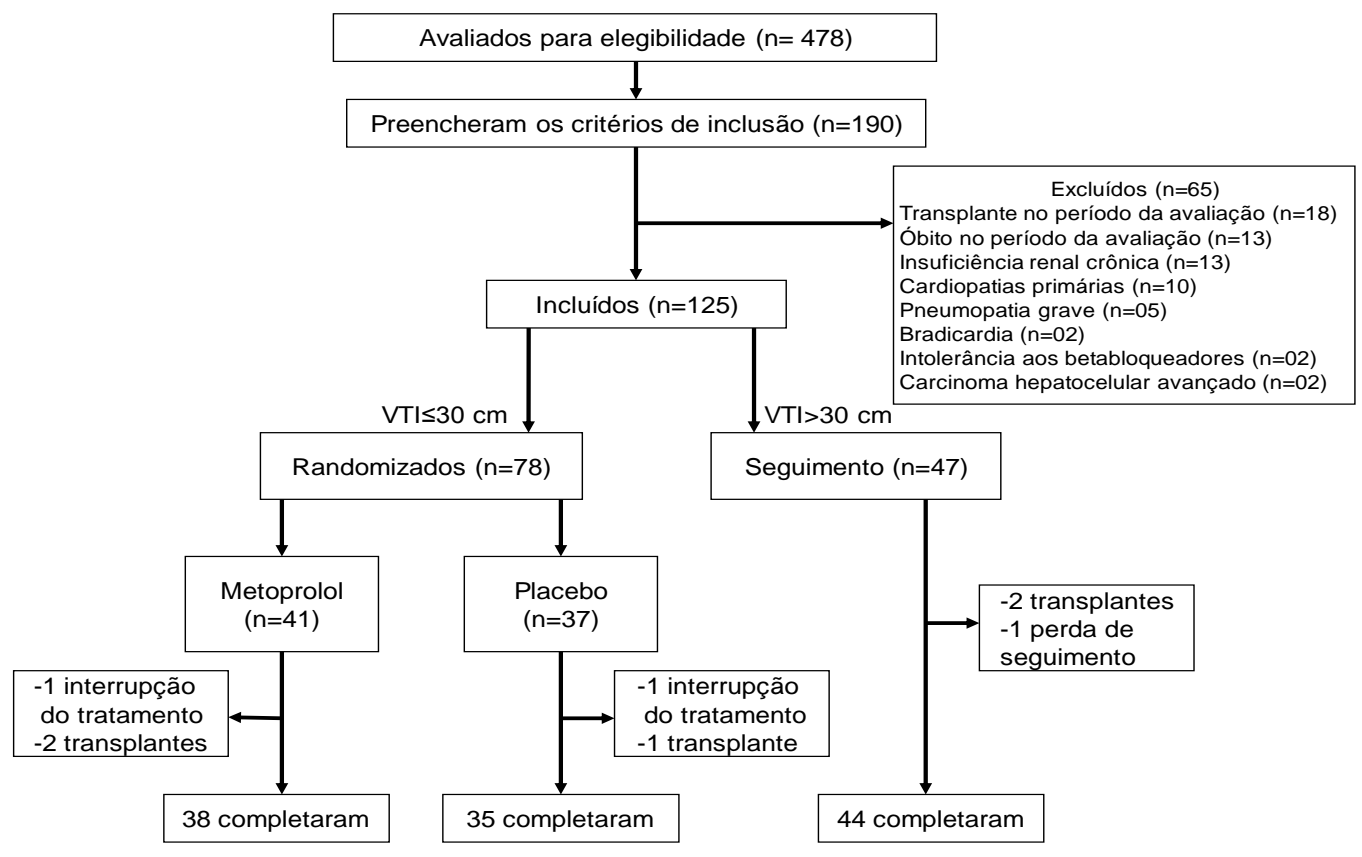

Figura 3. Fluxograma do estudo

Setenta e oito (62\%) dentre os 125 pacientes incluídos tiveram resposta inotrópica anormal ao estresse com dobutamina e foram 
randomizados para receber metoprolol ou placebo. Os demais 47 pacientes (38\%) apresentaram boa resposta inotrópica ao estresse e foram seguidos sem intervenção farmacológica (grupo resposta inotrópica normal) e reavaliados no final do período. Todos os pacientes completaram um período de seguimento de 6 meses.

Os resultados estão apresentados em dois tópicos: 1) comparação metoprolol versus placebo nos pacientes com resposta inotrópica anormal; 2) comparação dos pacientes com resposta inotrópica anormal versus aqueles com resposta inotrópica normal.

\subsection{Comparação metoprolol versus placebo nos pacientes com resposta inotrópica anormal}

\section{Características basais}

O grupo com resposta inotrópica anormal foi submetido à randomização para o tratamento com metoprolol ou placebo. $\mathrm{Na}$ comparação, ambos mostraram características clínicas e demográficas semelhantes, conforme exposto na Tabela 1.

Tabela 1. Comparação entre os grupos metoprolol e placebo em relação às características gerais $-\mathrm{n}=78$ pacientes

\begin{tabular}{lccc}
\hline Parâmetros & $\begin{array}{c}\text { Metoprolol } \\
\mathbf{n = 4 1}\end{array}$ & $\begin{array}{c}\text { Placebo } \\
\mathbf{n = 3 7}\end{array}$ & $\mathbf{p}$ \\
\hline $\begin{array}{l}\text { Idade em anos - mediana } \\
\text { (intervalo interquartil) }\end{array}$ & $49(43-57)$ & $52(47-57)$ & 0,64 \\
Gênero feminino n (\%) & $23(56,1)$ & $23(62,1)$ & 0,64 \\
Cor branca n (\%) & $19(48,7)$ & $13(35,1)$ & 0,29 \\
IMC (Kg/m²) & $26,2(23,5-28,0)$ & $24,5(23,7-26,6)$ & 0,36 \\
Frequência cardíaca (b/min) & $72(60-76)$ & $72(68-80)$ & 0,07 \\
Pressão arterial - mmHg & & & \\
$\quad$ Pressão arterial sistólica & $120(110-126)$ & $120(100-130)$ & 0,89 \\
$\quad$ Pressão arterial diastólica & $70(68-80)$ & $80(70-80)$ & 0,35 \\
$\begin{array}{l}\text { Classe Funcional (NYHA) } \\
\text { n(\%) }\end{array}$ & & &
\end{tabular}




\begin{tabular}{|c|c|c|c|}
\hline | e || & $24(61,5)$ & $22(59,4)$ & 1 \\
\hline III e IV & $15(38,4)$ & $15(40,5)$ & 1 \\
\hline \multicolumn{4}{|l|}{ Etiologia da cirrose $n(\%)$} \\
\hline Hepatite C & $21(51,2)$ & $22(59,4)$ & 0,5 \\
\hline Outras causas & $20(48,8)$ & $15(40,6)$ & 0,5 \\
\hline \multicolumn{4}{|l|}{ Classe Child-Pugh n(\%) } \\
\hline$A / B$ & $32(80)$ & $34(92,9)$ & 0,19 \\
\hline C & $8(20)$ & $3(8,1)$ & 0,19 \\
\hline Escore MELD & $12(10-16)$ & $13(11-16)$ & 0,42 \\
\hline $\begin{array}{l}\text { Tempo de doença - cirrose - } \\
\text { em anos }\end{array}$ & $7(3-10)$ & $5(2-10)$ & 0,41 \\
\hline \multicolumn{4}{|l|}{ Comorbidades n(\%) } \\
\hline Diabetes mellitus & $9(22,5)$ & $7(18,9)$ & 0,78 \\
\hline HAS & $8(20)$ & $6(16)$ & 0,77 \\
\hline Dislipidemia & $1(2,5)$ & $1(2,7)$ & 1 \\
\hline História de tabagismo & $16(40)$ & $11(29,7)$ & 0,47 \\
\hline Sedentarismo & $29(78,3)$ & $22(64,7)$ & 0,29 \\
\hline \multicolumn{4}{|l|}{ Medicamentos $\mathrm{n}(\%)$} \\
\hline Uso prévio de propranolol & $20(48,7)$ & $21(50,7)$ & 0,64 \\
\hline Espironolactona & $13(31,7)$ & $15(40,5)$ & 0,48 \\
\hline Furosemida & $11(26,8)$ & $13(35,1)$ & 0,62 \\
\hline Inibidores da ECA & $5(12,1)$ & $1(2,7)$ & 0,20 \\
\hline
\end{tabular}

As variáveis contínuas estão expressas em medianas e intervalos interquartis. NA: não se aplica

MELD: model for end-stage liver disease; HAS: hipertensão arterial sistêmica; IMC: índice de massa corpórea; NYHA: New York Heart Association; ECA: enzima conversora da angiotensina

\section{Resposta hemodinâmica ao estudo com ecocardiograma sob estresse}

Vinte e nove (37.2\%) pacientes não atingiram a frequência cardíaca submáxima, 15 (36,5\%) no grupo metoprolol e 14 (37,8\%) no placebo, $p=1$. Não houve diferença entre os grupos na dose máxima de dobutamina injetada (40 [30-40] vs 30 [30-40] $\mathrm{mcg} / \mathrm{kg} / \mathrm{min}, \mathrm{p}=0,43)$, na frequência cardíaca atingida (144 [138-151] vs 145 [123-155] bpm, $p=0,88)$, na pressão arterial sistólica no pico de estresse (130 [124-146] vs 135 [116- 
149] $\mathrm{mmHg}, \mathrm{p}=0,62)$, assim como no pico da VTI (25,1 [22-30] vs 24,4 $[21,6-26] \mathrm{cm}, p=0,059)$ nos grupos placebo e metoprolol, respectivamente.

Não houve diferença na variação da freqüência cardíaca e da pressão arterial sistólica nos grupos metoprolol e de placebo (variação da frequência cardíaca: 71 ( 60-79) versus 75 (53-84) bpm, $p=0,57$ e pressão arterial sistólica: 8 (0-23) versus $9(-6-20) \mathrm{mmHg}, \mathrm{p}=0,73)$, respectivamente. A variação da VTI foi zero $(-0.1-0.19) \mathrm{cm}$ no grupo metoprolol e -0,04 (-0.17$0.05) \mathrm{cm}$ no grupo placebo, $p=0,04$.

\section{Características ecocardiográficas do grupo randomizado para tratamento}

Na comparação entre os grupos metoprolol e placebo em relação aos parâmetros ecocardiográficos, nota-se que a disfunção diastólica foi mais prevalente no grupo randomizado para receber placebo $(27 \%)$, enquanto o grupo randomizado para metoprolol teve $4,8 \% \quad(p=0,01)$. Os demais parâmetros foram semelhantes em ambos os grupos (tabela 2).

Tabela 2. Comparação entre os grupos metoprolol e placebo em relação aos parâmetros ecocardiográficos $-\mathrm{n}=78$ pacientes

\begin{tabular}{|c|c|c|c|}
\hline Parâmetros & Metoprolol & Placebo & $\mathbf{p}$ \\
\hline Volume do $\mathrm{AE}\left(\mathrm{ml} / \mathrm{mm}^{3}\right)$ & $\begin{array}{c}26 \\
(24-31)\end{array}$ & $\begin{array}{c}28 \\
(25,5-34,5)\end{array}$ & 0,17 \\
\hline Diâmetro diastólico do VE -mm & $\begin{array}{c}47 \\
(45-52)\end{array}$ & $\begin{array}{c}48 \\
(44-51)\end{array}$ & 0,73 \\
\hline Diâmetro sistólico do VE - mm & $\begin{array}{c}29 \\
(27-34)\end{array}$ & $\begin{array}{c}30 \\
(28-33)\end{array}$ & 0,72 \\
\hline Volume diastólico do VE -ml & $\begin{array}{c}79,5 \\
(64,5-98,2)\end{array}$ & $\begin{array}{c}84 \\
(66,5-104)\end{array}$ & 0,53 \\
\hline Volume sistólico do VE - ml & $\begin{array}{c}26 \\
(20-39,7)\end{array}$ & $\begin{array}{c}27,5 \\
(21,2-36,7)\end{array}$ & 0,58 \\
\hline Espessura da parede VE - mm & $\begin{array}{c}9 \\
(8-9)\end{array}$ & $\begin{array}{c}8 \\
(8-9)\end{array}$ & 0,69 \\
\hline Septo interventricular - $\mathrm{mm}$ & $\begin{array}{c}9 \\
(8-10)\end{array}$ & $\begin{array}{c}9 \\
(8-10)\end{array}$ & 0,76 \\
\hline Índice de massa do VE - $\mathrm{g} / \mathrm{m}^{2}$ & $\begin{array}{c}83 \\
(74,2-92,7)\end{array}$ & $\begin{array}{c}85,5 \\
(72-96,2)\end{array}$ & 0,96 \\
\hline
\end{tabular}




\begin{tabular}{lccc} 
Fração de ejeção do VE -\% & 66,5 & 65 & 0,19 \\
Diâmetro do VD - mm & $(62,7-71)$ & $(60-70)$ & \\
& 37 & 37 & 0,94 \\
Onda S do VD - cm/s & $(32-40)$ & $(32,7-40)$ & 0,34 \\
Disfunção diastólica n(\%) & 15 & 15 & \\
VTI basal- cm & $2 / 41(4,8)$ & $10 / 37(27)$ & 0,01 \\
VTI no estresse - cm & 25 & 26 & \\
PSAP - mmHg & $(23-27,8)$ & $(23-29,6)$ & 0,66 \\
\hline
\end{tabular}

Resultados apresentados em mediana e intervalo interquartil.

$\mathrm{AE}$ : átrio esquerdo; VE: ventrículo esquerdo; VD: ventrículo direito; VTI: integral velocidadetempo;

PSAP: pressão sistólica da artéria pulmonar.

\section{Características eletrocardiográficas do grupo randomizado para} tratamento

O intervalo QT estava aumentado nessa população, indicando alteração da repolarização. O intervalo QT, em ambos os grupos, apresentou mediana de valores muito próximos do limite superior da normalidade $(440 \mathrm{~ms})$. Na aferição dos parâmetros SDNN 24h e índice SDANN, observou-se que o grupo metoprolol apresentou valores mais elevados em relação ao grupo placebo, indicando aumento da atividade simpática medida indiretamente pelos marcadores da variabilidade da frequência cardíaca (tabela 3).

Tabela 3. Comparação entre os grupos metoprolol e placebo em relação aos parâmetros eletrocardiográficos $-\mathrm{n}=78$ pacientes

\begin{tabular}{lccc}
\hline Parâmetro & Metoprolol & Placebo & $\mathbf{p}$ \\
\hline Intervalo $\mathrm{QT}^{\star}-\mathrm{ms}$ & 445 & 434 & 0,14 \\
& $(432-458)$ & $(425-455)$ & \\
SDNN 24h $-\mathrm{ms}$ & 96 & 82 & 0,02
\end{tabular}


Índice SDANN - ms

Índice SDNN - ms

rMSSD - ms

pNN50 - \%

Análise espectral $24 \mathrm{~h}-\mathrm{ms}^{2}$
89

(66-98)

40

(32-49)

24

(16-33)

5

$(1-10)$

1525,1

(1018-2115)
71

(58-83)

0,01

39

(33-45)

0,67

29

(22-39)

0,23

8

0,19

1375,4

$(1036,9-1613,5)$

*Intervalo QT corrigido pela fórmula de Fridericia ${ }^{29}$

Resultados apresentados em mediana e intervalo interquartil.

SDNN: desvio-padrão de todos os intervalos RR

SDANN: desvio-padrão da média dos intervalos RR

RMSSD:raiz quadrada da média das diferenças sucessivas ao quadrado, entre NN adjacentes

pNN50: percentagem das diferenças sucessivas entre os intervalos NN>50 ms.

\section{Exames laboratoriais do grupo randomizado para tratamento}

O BNP mostrou-se em níveis normais, em se comparando com populações com insuficiência cardíaca onde o BNP é considerado alterado em níveis acima de $100 \mathrm{pg} / \mathrm{dL} .{ }^{56}$ Apesar do grupo placebo ter apresentado, na comparação das medianas, níveis pouco mais elevados de BNP, não houve diferença entre os dois grupos em relação ao número de pacientes com valores de BNP acima de $100 \mathrm{pg} / \mathrm{dL}$ (6 pacientes no grupo metoprolol e 10 pacientes no grupo placebo), $p=0,26$. A noradrenalina, a atividade da renina plasmática e os demais exames laboratoriais foram semelhantes entre os grupos. (tabela 4) 
Tabela 4. Comparação entre os grupos metoprolol e placebo em relação aos parâmetros laboratoriais $-\mathrm{n}=78$ pacientes

\begin{tabular}{|c|c|c|c|}
\hline Parâmetros & Metoprolol & Placebo & p \\
\hline $\mathrm{BNP}(\mathrm{pg} / \mathrm{mL})$ & $\begin{array}{c}42 \\
(26-59)\end{array}$ & $\begin{array}{c}62 \\
(49-101)\end{array}$ & 0,008 \\
\hline Noradrenalina (pg/mL) & $\begin{array}{c}383,5 \\
(233,5-494,5)\end{array}$ & $\begin{array}{c}360,5 \\
(245-494,5)\end{array}$ & 0,054 \\
\hline $\begin{array}{l}\text { Atividade da renina plasmática } \\
(\mathrm{ng} / \mathrm{mL} / \mathrm{h})\end{array}$ & $\begin{array}{c}0,85 \\
(0,38-4,07)\end{array}$ & $\begin{array}{c}1,3 \\
(0,4-5)\end{array}$ & 0,06 \\
\hline Troponina I (ng/mL) & $\begin{array}{c}0,01 \\
(0,01-0,01)\end{array}$ & $\begin{array}{c}0,01 \\
(0,01-0,01)\end{array}$ & 0,15 \\
\hline Hemoglobina $(\mathrm{mg} / \mathrm{mL})$ & $\begin{array}{c}12,9 \\
(11,7-14,3)\end{array}$ & $\begin{array}{c}12,6 \\
(11,5-13,3)\end{array}$ & 0,31 \\
\hline Plaquetas $\left(/ \mathrm{mm}^{3}\right)$ & $\begin{array}{c}64.000 \\
(46.000-89.000)\end{array}$ & $\begin{array}{c}70.000 \\
(47.000-99.000)\end{array}$ & 0,95 \\
\hline Creatinina $(\mathrm{mg} / \mathrm{mL})$ & $\begin{array}{c}0,66 \\
(0,54-0,71)\end{array}$ & $\begin{array}{c}0,7 \\
(0,61-0,83)\end{array}$ & 0,07 \\
\hline Sódio sérico (mg/mL) & $\begin{array}{c}141 \\
(139-142)\end{array}$ & $\begin{array}{c}141 \\
(138-142)\end{array}$ & 0,95 \\
\hline Bilirrubina total $(\mathrm{mg} / \mathrm{mL})$ & $\begin{array}{c}1,7 \\
(1,3-4,0)\end{array}$ & $\begin{array}{c}2,0 \\
(1,5-2,8)\end{array}$ & 0,69 \\
\hline TP-INR & $\begin{array}{c}1,5 \\
(1,2-1,5)\end{array}$ & $\begin{array}{c}1,4 \\
(1,2-1,6)\end{array}$ & 0,52 \\
\hline
\end{tabular}

Resultados apresentados em mediana e intervalo interquartil.

BNP:peptídeo natriurético tipo B; TP-INR: tempo de protrombina - razão normatizada internacional

\section{Dose do metoprolol, efeitos na frequência cardíaca e na pressão arterial e adesão ao tratamento}

Todos os pacientes foram tratados por um período de 180 dias. A dose do metoprolol (média e desvio-padrão) foi $121 \pm 60 \mathrm{mg}$ ao dia. A adesão foi verificada em cada consulta mediante contagem de comprimidos e entrevista dirigida. A adesão ao tratamento foi de $97.4 \%$.

Os pacientes do grupo droga ativa apresentaram previsivelmente significativa redução da FC (basal 72 (64-76) bpm, e após 6 meses, 64(6072) bpm, $p=0,01$. A frequência cardíaca basal no grupo placebo foi $72(68$ - 
80)bpm e, após 6 meses, de 76(72-80)bpm , diferença sem significância estatística $(p=0,1)$. Ao se comparar os dois grupos após 6 meses de tratamento, conforme esperado, houve diferença estatisticamente significante na frequência cardíaca entre aqueles pacientes que receberam metoprolol e aqueles que receberam placebo, indicando a ação da droga ativa $(p=0,004)$. (figura 4$)$

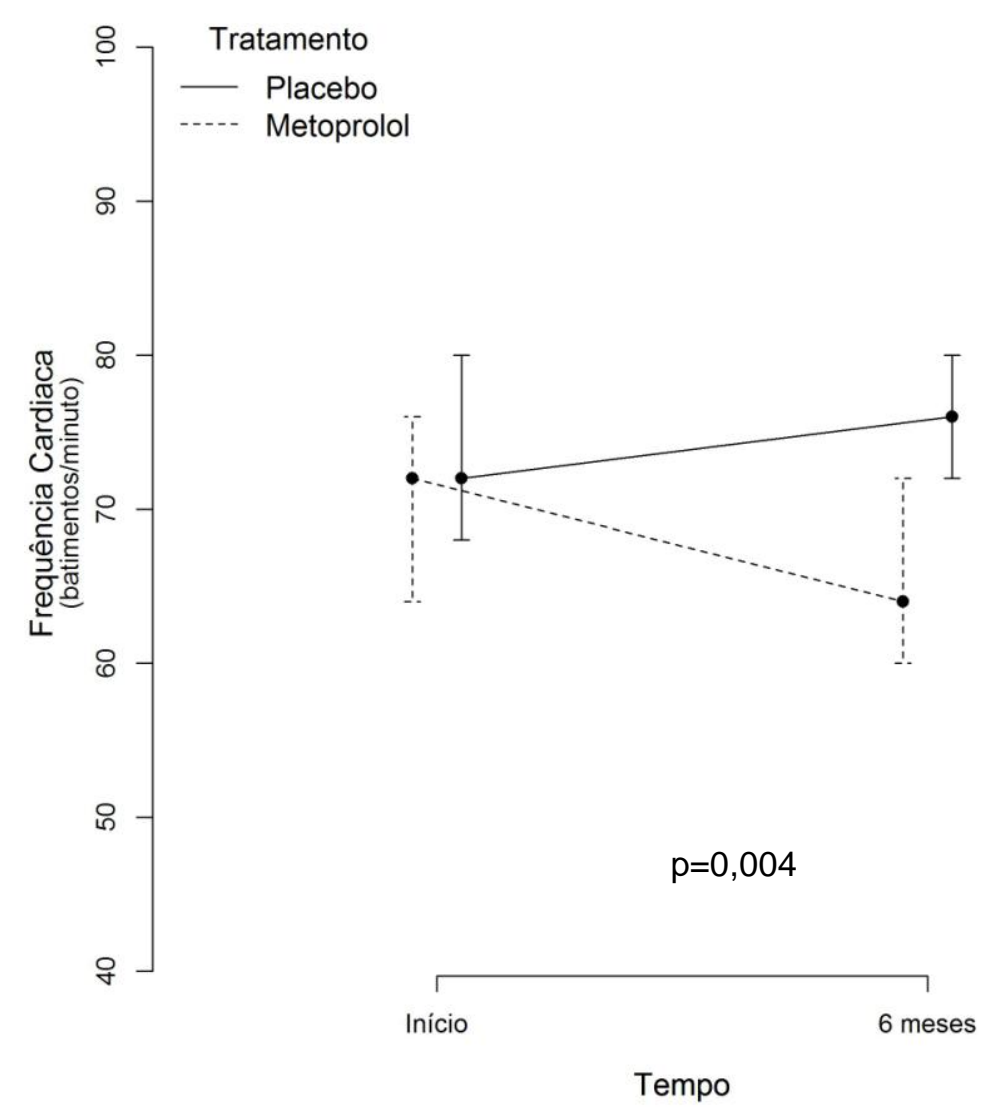

Figura 4. Comparação da frequência cardíaca entre os grupos metoprolol e placebo no início e após 6 meses $-n=78$ pacientes

Ao longo do tempo, não houve modificação da pressão arterial sistólica nos grupos. Entre os pacientes que receberam metoprolol, a pressão arterial sistólica inicial foi $120(110-126) \mathrm{mmHg}$ e a final 120 (110130) $\mathrm{mmHg}, p=0,10$. Naqueles do grupo placebo, a pressão arterial sistólica inicial foi 120 (100-130)mmHg e a final 120 (110-140), $p=0,84$. Não houve diferença entre os grupos ( $p=0,2)$ (figura 5 ). 


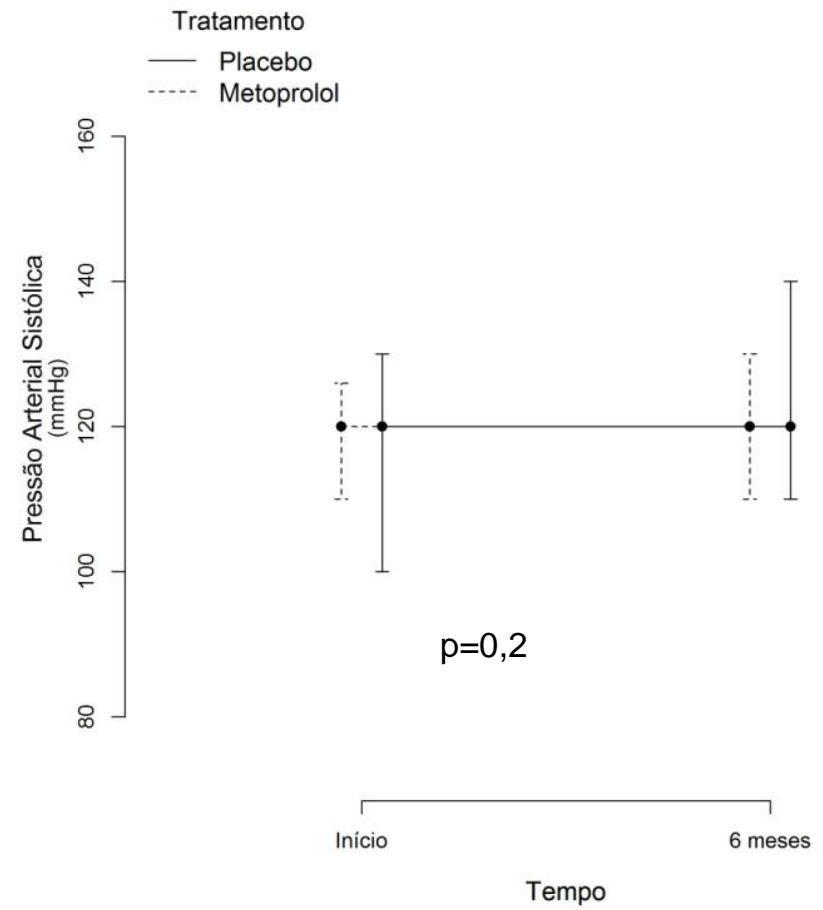

Figura 5. Efeito do tratamento na pressão arterial sistólica. Comparação entre os grupos metoprolol e placebo - $\mathrm{n}=78$ pacientes

Após 180 dias, não houve modificação estatisticamente significante da pressão arterial diastólica (figura 6). No grupo metoprolol, a pressão arterial diastólica inicial foi $70(68-80) \mathrm{mmHg}$ e após 6 meses 70 (7080) $\mathrm{mmHg}, p=0,72$. No grupo placebo a pressão arterial diastólica no início foi $80(70-80) \mathrm{mmHg}$ e a final $70(70-80) \mathrm{mmHg}, p=0,77$. Não houve diferença entre os dois grupos $(p=0,51)$. 


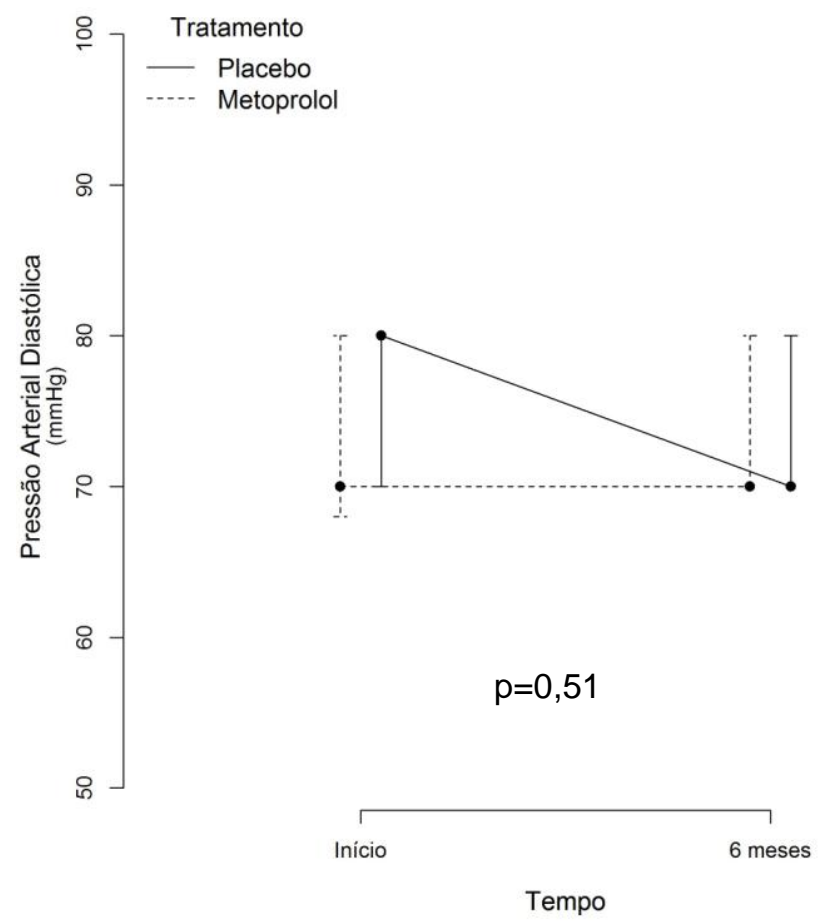

Figura 6. Efeito do tratamento na pressão arterial diastólica. Comparação entre os grupos metoprolol e placebo ( $n=78$ pacientes)

\section{Efeito do succinato de metoprolol na resposta inotrópica- desfecho} primário do estudo

O aumento da $\mathrm{VTI}>30 \%$ com estresse em relação ao basal constitui o desfecho primário do estudo. Na avaliação inicial, por definição, todos os pacientes com resposta inotrópica anormal apresentaram variação repousoestresse da VTI $30 \%$. O grupo metoprolol teve o delta VTI inicial (mediana) de $0 \%(-10 \%$ a $19 \%)$, e final de $5 \%(-10 \%$ a $13 \%), p=0,25$. Três $(9 \%)$ pacientes normalizaram a resposta da VTI. Entre o grupo placebo, o delta VTI inicial foi $-4 \%(-17 \%$ a $5 \%)$ e final $11 \%(2 \%$ a $33 \%)$, $p<0,001$, de forma que $9(24,3 \%)$ dos pacientes normalizaram a resposta da VTI. Ao se comparar o grupo metoprolol com o grupo placebo ao final do tratamento, nota-se que não houve diferença entre eles $(p=0,057)$ (tabela 5 e figura 7 ). Quando são feitas as comparações entre as medianas das diferenças de 
delta VTI antes e depois do tratamento, nota-se que o grupo metoprolol (4\%[-9\%-23\%]) foi pior que o grupo placebo (19\%[8\%-40\%]), $\mathrm{p}=0,001$.

Tabela 5. Comparação entre os grupos metoprolol e placebo na normalização da VTI - desfecho primário

\begin{tabular}{lccc}
\hline Desfecho & $\begin{array}{c}\text { Metoprolol } \\
\mathbf{n = 4 1}\end{array}$ & $\begin{array}{c}\text { Placebo } \\
\mathbf{n = 3 7}\end{array}$ & $\mathbf{p}$ \\
\hline Normalização da VTI - n(\%) & $3(7,3)$ & $9(24,3)$ & 0,057 \\
\hline
\end{tabular}

VTI: integral velocidade-tempo

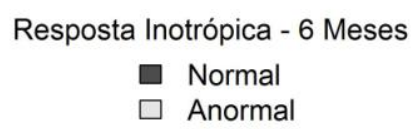

$\mathrm{p}=0,05$

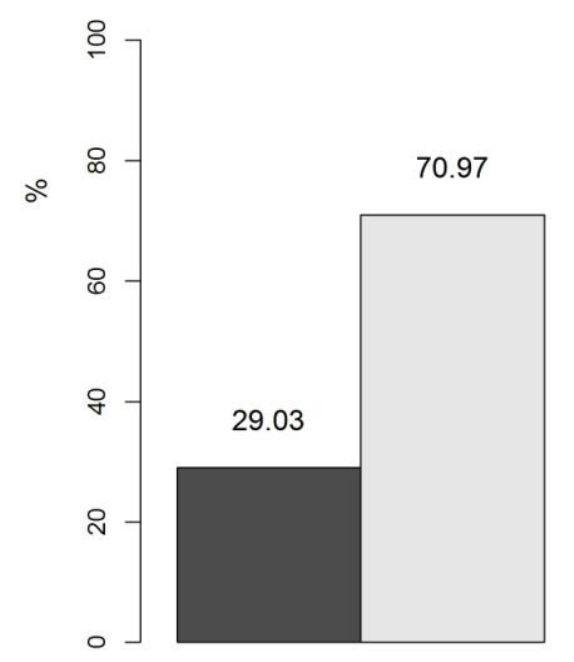

Placebo

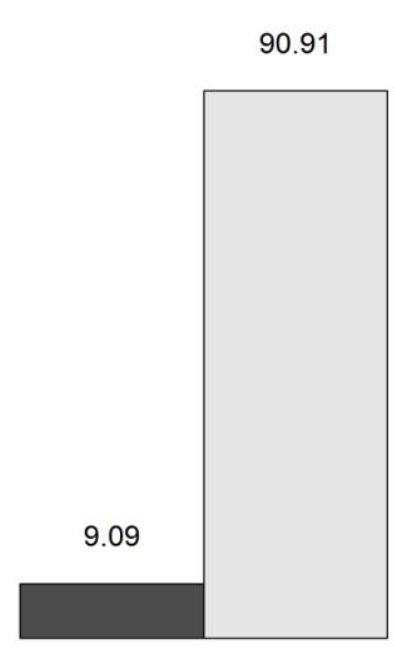

Metoprolol

Tratamento

Figura 7. Percentual de normalização da resposta inotrópica conforme o grupo após o tratamento $-\mathrm{n}=78$ pacientes

\section{Efeito do tratamento nos parâmetros ecocardiográficos}

$\mathrm{Na}$ comparação entre os grupos placebo e metoprolol, em relação às modificações nos parâmetros ecocardiográficos em 6 meses de seguimento, 
foi encontrada diferença apenas no diâmetro sistólico do ventrículo esquerdo, que mostrou valores maiores no grupo metoprolol. Os demais parâmetros foram semelhantes nos dois grupos. (tabela 6)

Tabela 6. Efeito do succinato de metoprolol na reversão da disfunção cardíaca: avaliação dos parâmetros ecocardiográficos $-\mathrm{n}=78$ pacientes

\begin{tabular}{|c|c|c|c|c|c|}
\hline \multirow{2}{*}{ Parâmetros } & \multicolumn{2}{|c|}{ Metoprolol } & \multicolumn{2}{|c|}{ Placebo } & \multirow{2}{*}{ p } \\
\hline & Início & 6 meses & Início & 6 meses & \\
\hline Volume do $\mathrm{AE}\left(\mathrm{ml} / \mathrm{mm}^{3}\right)$ & $\begin{array}{c}26 \\
(24-31)\end{array}$ & $\begin{array}{c}26,5 \\
(21-31)\end{array}$ & $\begin{array}{c}28 \\
(25,5-34,5)\end{array}$ & $\begin{array}{c}27,5 \\
(23,7-30,2)\end{array}$ & 0,39 \\
\hline $\begin{array}{l}\text { Diâmetro diastólico do } \\
\text { VE - mm }\end{array}$ & $\begin{array}{c}47 \\
(45-52)\end{array}$ & $\begin{array}{c}49 \\
(46-53)\end{array}$ & $\begin{array}{c}48 \\
(44-51)\end{array}$ & $\begin{array}{c}48 \\
(45-49)\end{array}$ & 0,48 \\
\hline $\begin{array}{l}\text { Diâmetro sistólico do } \\
\text { VE - mm }\end{array}$ & $\begin{array}{c}29 \\
(27-34)\end{array}$ & $\begin{array}{c}30 \\
(29-34)\end{array}$ & $\begin{array}{c}30 \\
(28-33)\end{array}$ & $\begin{array}{c}29 \\
(28-31)\end{array}$ & 0,02 \\
\hline $\begin{array}{l}\text { Volume diastólico do VE } \\
-\mathrm{ml}\end{array}$ & $\begin{array}{c}79,5 \\
(64,5-98,2)\end{array}$ & $\begin{array}{l}78,8 \\
(63,8- \\
108,2)\end{array}$ & $\begin{array}{c}84 \\
(66,5-104)\end{array}$ & $\begin{array}{c}80 \\
(57-91)\end{array}$ & 0,24 \\
\hline $\begin{array}{l}\text { Volume sistólico do VE } \\
-\mathrm{ml}\end{array}$ & $\begin{array}{c}26 \\
(20-39,7)\end{array}$ & $\begin{array}{c}25,5 \\
(19,5-41)\end{array}$ & $\begin{array}{c}27,5 \\
(21,2-36,7)\end{array}$ & $\begin{array}{c}27 \\
(22-33)\end{array}$ & 0,85 \\
\hline $\begin{array}{l}\text { Espessura da parede } \\
\text { VE - mm }\end{array}$ & $\begin{array}{c}9 \\
(8-9)\end{array}$ & $\begin{array}{c}9 \\
(8-9)\end{array}$ & $\begin{array}{c}8 \\
(8-9)\end{array}$ & $\begin{array}{c}8 \\
(8-9)\end{array}$ & 0,99 \\
\hline $\begin{array}{l}\text { Septo interventricular - } \\
\mathrm{mm}\end{array}$ & $\begin{array}{c}9 \\
(8-10)\end{array}$ & $\begin{array}{c}9 \\
(9-10)\end{array}$ & $\begin{array}{c}9 \\
(8-10)\end{array}$ & $\begin{array}{c}9 \\
(8-10)\end{array}$ & 0,72 \\
\hline $\begin{array}{l}\text { Índice de massa do VE } \\
\text { - } \mathrm{g} / \mathrm{m}^{2}\end{array}$ & $\begin{array}{c}83 \\
(74,2-92,7)\end{array}$ & $\begin{array}{c}85,5 \\
(77-93)\end{array}$ & $\begin{array}{c}85,5 \\
(72-96,2)\end{array}$ & $\begin{array}{c}80 \\
(68-95)\end{array}$ & 0,90 \\
\hline $\begin{array}{l}\text { Fração de ejeção do VE } \\
\text { - \% }\end{array}$ & $\begin{array}{c}66,5 \\
(62,7-71)\end{array}$ & $\begin{array}{c}67 \\
(63,7-70)\end{array}$ & $\begin{array}{c}65 \\
(60-70)\end{array}$ & $\begin{array}{c}66 \\
(62-69)\end{array}$ & 0,94 \\
\hline Diâmetro do VD - mm & $\begin{array}{c}37 \\
(32-40)\end{array}$ & $\begin{array}{c}37 \\
(33,8-40)\end{array}$ & $\begin{array}{c}37 \\
(32,7-40)\end{array}$ & $\begin{array}{c}36 \\
(34,8-39,5)\end{array}$ & 0,84 \\
\hline Onda $S$ do VD cm/s & $\begin{array}{c}15 \\
(12-17,5)\end{array}$ & $\begin{array}{c}14 \\
(11-16,5)\end{array}$ & $\begin{array}{c}15 \\
(12-15)\end{array}$ & $\begin{array}{c}15 \\
(12-16,5)\end{array}$ & 0,13 \\
\hline $\begin{array}{l}\text { Disfunção diastólica } \\
\mathrm{n}(\%)\end{array}$ & $2 / 41(4,8)$ & $5 / 32(15,6)$ & $10 / 37(27)$ & $9 / 31(29)$ & 0,67 \\
\hline VTI repouso - cm & $\begin{array}{c}25 \\
(23-27,8)\end{array}$ & $\begin{array}{c}24,8 \\
(22-27,6)\end{array}$ & $\begin{array}{c}26 \\
(23-29,6)\end{array}$ & $\begin{array}{c}25 \\
(21-27,2)\end{array}$ & 0,11 \\
\hline
\end{tabular}




\begin{tabular}{lccccc} 
VTI no estresse $-\mathrm{cm}$ & 25,1 & 26 & 24,4 & 27,5 & 0,07 \\
& $(22-30)$ & $(23-31)$ & $(21,6-26)$ & $(23,6-29)$ & 0,07 \\
PSAP - mmHg & 27 & 30 & 28 & 25,5 & \\
& $(25-29,2)$ & $(27-35)$ & $(25-31)$ & $(22,2-30)$ & 0,50 \\
\hline
\end{tabular}

Resultados apresentados em mediana e intervalo interquartil.

VE: ventrículo esquerdo; VD: ventrículo direito; VTI: integral velocidade-tempo;

PSAP:pressão sistólica da artéria pulmonar

\section{Efeito do tratamento nos níveis de BNP, noradrenalina, troponina e atividade da renina plasmática}

Após 6 meses, o grupo placebo mostrou redução dos níveis séricos de BNP (de 62 (49-101) para 39 (25-51), que se mostrou estatisticamente significante ao se comparar com o grupo metoprolol (de 42 (26-59) para 42 (20-51), $\mathrm{p}=0,02$ (figura 8). Não houve diferença entre os grupos em relação aos demais parâmetros laboratoriais avaliados (tabela 7), embora os níveis séricos de noradrenalina tenham mostrado uma tendência maior de redução no grupo metoprolol (figura 9).

Tabela 7. Efeito do tratamento nos níveis de BNP, noradrenalina, troponina e atividade da renina plasmática $-\mathrm{n}=78$ pacientes

\begin{tabular}{|c|c|c|c|c|c|}
\hline \multirow{2}{*}{ Parâmetros } & \multicolumn{2}{|c|}{ Metoprolol } & \multicolumn{2}{|c|}{ Placebo } & \multirow{2}{*}{$\mathbf{p}$} \\
\hline & Início & 6 meses & Início & 6 meses & \\
\hline$B N P(p g / m L)$ & $\begin{array}{c}42 \\
(26-59)\end{array}$ & $\begin{array}{c}42 \\
(20-51)\end{array}$ & $\begin{array}{c}62 \\
(49-101)\end{array}$ & $\begin{array}{c}39 \\
(25-51)\end{array}$ & 0,02 \\
\hline Noradrenalina $(\mathrm{pg} / \mathrm{mL})$ & $\begin{array}{c}383,5 \\
(233,5-494,5)\end{array}$ & $\begin{array}{c}262 \\
(207,5-448,5)\end{array}$ & $\begin{array}{c}360,5 \\
(245-494,5)\end{array}$ & $\begin{array}{c}350 \\
(245-632)\end{array}$ & 0,054 \\
\hline $\begin{array}{l}\text { Atividade da renina } \\
\text { plasmática }(\mathrm{ng} / \mathrm{mL} / \mathrm{h})\end{array}$ & $\begin{array}{c}0,85 \\
(0,38-4,07)\end{array}$ & $\begin{array}{c}1,05 \\
(0,4-3,88)\end{array}$ & $\begin{array}{c}1,3 \\
(0,4-5)\end{array}$ & $\begin{array}{c}1,9 \\
(1-5,1)\end{array}$ & 0,06 \\
\hline Troponina I(ng/mL) & $\begin{array}{c}0,01 \\
(0,01-0,01)\end{array}$ & $\begin{array}{c}0,01 \\
(0,01-0,01)\end{array}$ & $\begin{array}{c}0,01 \\
(0,01-0,01)\end{array}$ & $\begin{array}{c}0,01 \\
(0,01-0,01)\end{array}$ & 0,15 \\
\hline
\end{tabular}

Resultados apresentados em mediana e intervalo interquartil.

BNP:peptídeo natriurético tipo $B$. 


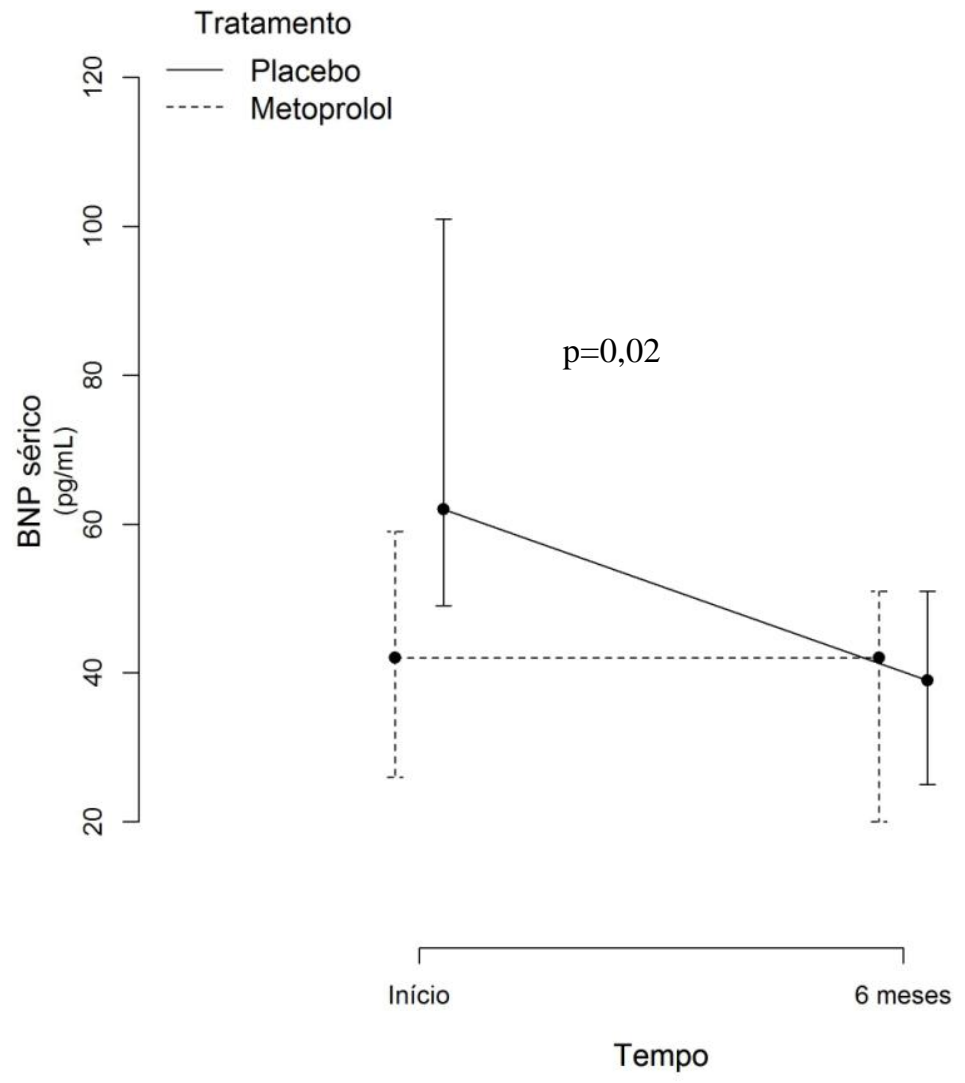

Nota: BNP: peptídeo natriurético tipo B sérico (unidade: $\mathrm{pg} / \mathrm{mL}$ )

Figura 8. Comparação ente os grupos metoprolol e placebo quanto aos níveis de BNP no início e após 6 meses $-\mathrm{n}=78$ pacientes 


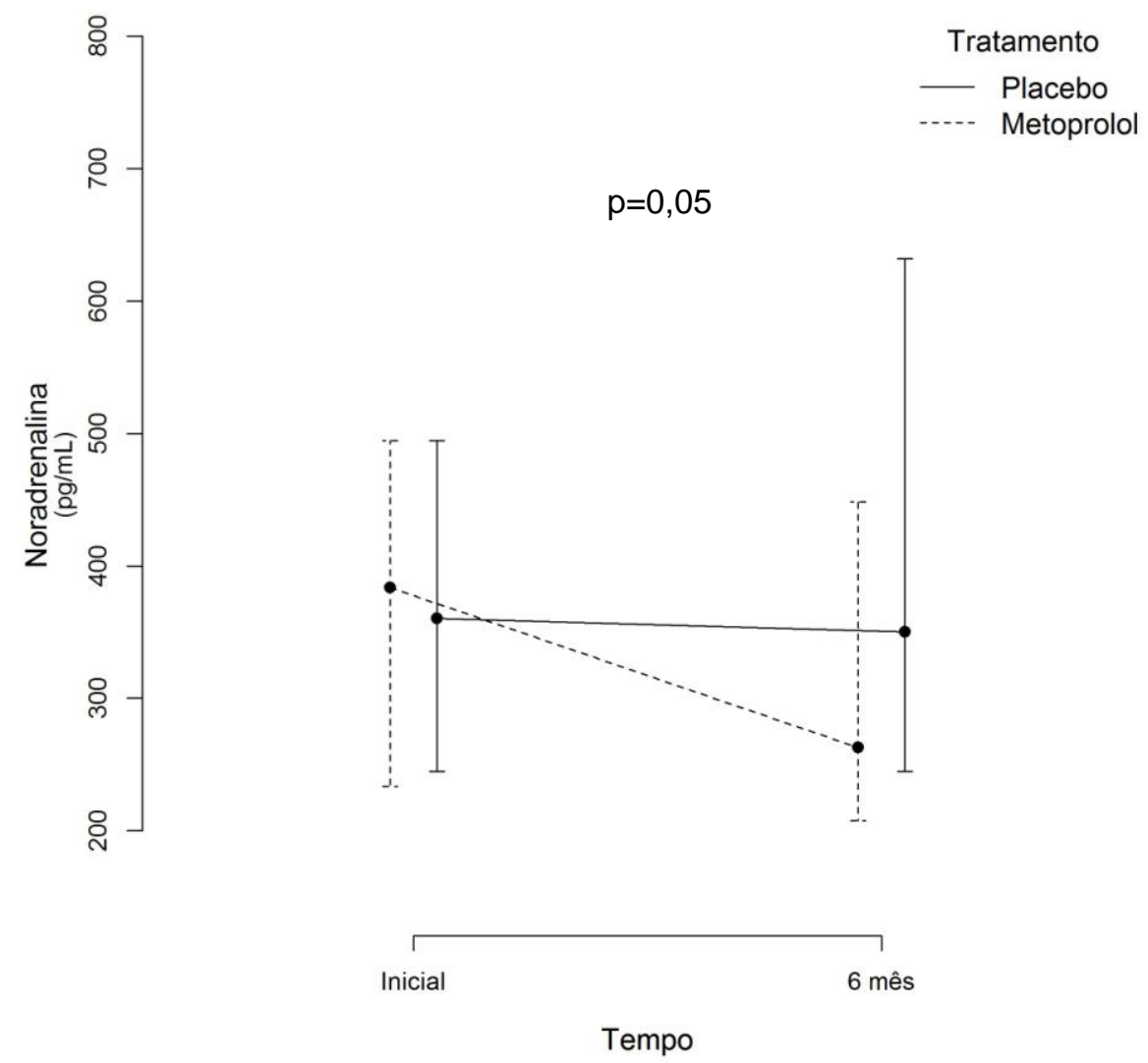

Figura 9. Comparação ente os grupos metoprolol e placebo quanto aos níveis de noradrenalina no início e após 6 meses $-\mathrm{n}=78$ pacientes

\section{Efeito do tratamento nos parâmetros eletrofisiológicos}

Após o tratamento, não houve diferença entre os grupos quanto aos parâmetros eletrocardiográficos (intervalo QT (figura 10), SDNN, índice SDANN, índice SDNN, rMSSD, pNN50 e análise espectral em 24 horas) (tabela 8). 


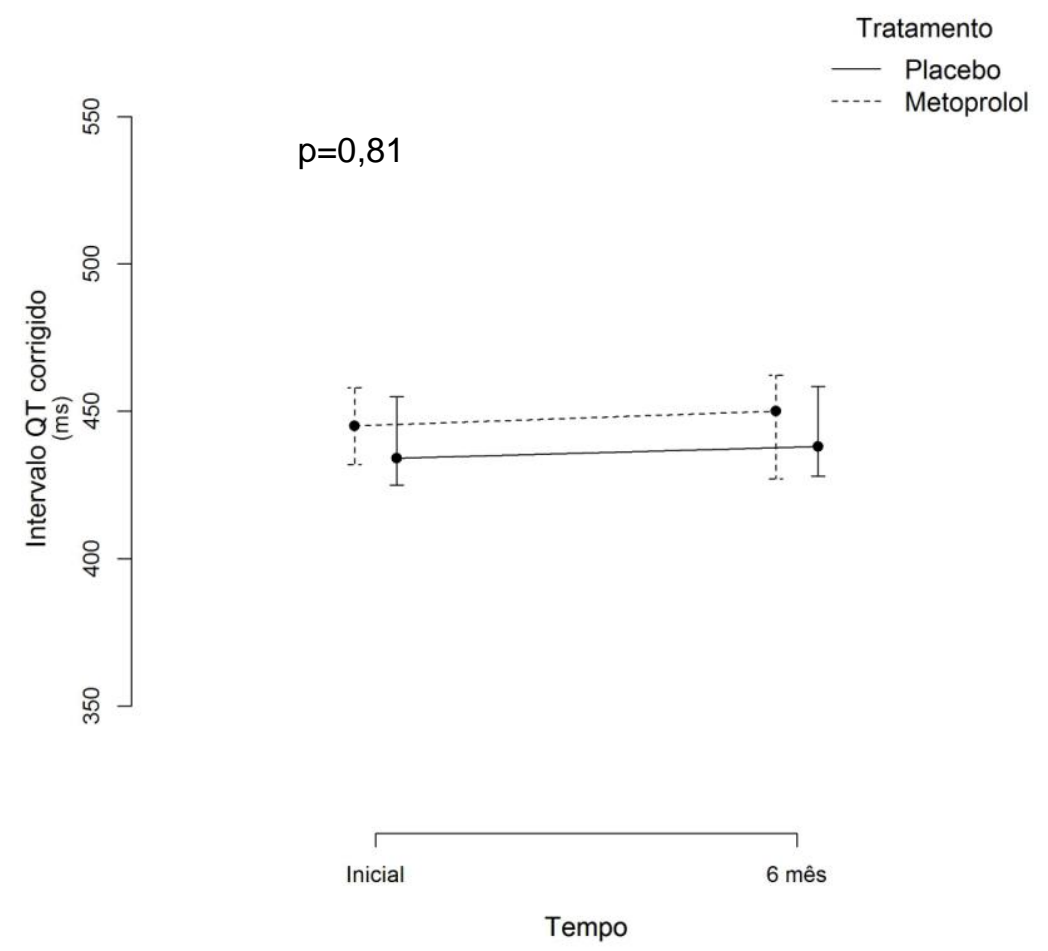

Figura 10. Comparação ente os grupos metoprolol e placebo quanto Intervalo QT no início e após 6 meses $-\mathrm{n}=78$ pacientes

Tabela 8. Efeito do succinato de metoprolol nos parâmetros eletrocardiográficos $-\mathrm{n}=78$ pacientes

\begin{tabular}{|c|c|c|c|c|c|}
\hline \multirow{2}{*}{ Parâmetros } & \multicolumn{2}{|c|}{ Metoprolol } & \multicolumn{2}{|c|}{ Placebo } & \multirow[b]{2}{*}{$\mathbf{p}$} \\
\hline & Início & 6 meses & Início & 6 meses & \\
\hline $\begin{array}{l}\text { Intervalo } \mathrm{QT}^{*} \\
\text { - ms }\end{array}$ & $\begin{array}{c}445 \\
(432-458)\end{array}$ & $\begin{array}{c}450 \\
(427-462,2)\end{array}$ & $\begin{array}{c}434 \\
(425-455)\end{array}$ & $\begin{array}{c}438 \\
(428-458,5)\end{array}$ & 0,81 \\
\hline $\begin{array}{l}\text { SDNN 24h - } \\
\text { ms }\end{array}$ & $\begin{array}{c}96 \\
(79-111)\end{array}$ & $\begin{array}{c}88 \\
(79-109)\end{array}$ & $\begin{array}{c}82 \\
(71-97)\end{array}$ & $\begin{array}{c}80 \\
(66,5-104)\end{array}$ & 0,42 \\
\hline SDANN - ms & $\begin{array}{c}89 \\
(66-98)\end{array}$ & $\begin{array}{c}80 \\
(67-97)\end{array}$ & $\begin{array}{c}71 \\
(58-83)\end{array}$ & $\begin{array}{c}69 \\
(54,5-90,5)\end{array}$ & 0,67 \\
\hline rMSSD - ms & $\begin{array}{c}24 \\
(16-33)\end{array}$ & $\begin{array}{c}19 \\
(14-27)\end{array}$ & $\begin{array}{c}29 \\
(22-39)\end{array}$ & $\begin{array}{c}19 \\
(16-26,5)\end{array}$ & 0,46 \\
\hline pNN50 - \% & $\begin{array}{c}5 \\
(1-10)\end{array}$ & $\begin{array}{c}2 \\
(0-6)\end{array}$ & $\begin{array}{c}8 \\
(3-15)\end{array}$ & $\begin{array}{c}2 \\
(1-5,5)\end{array}$ & 0,24 \\
\hline $\begin{array}{l}\text { Análise } \\
\text { espectral 24h } \\
-\mathrm{ms}^{2}\end{array}$ & $\begin{array}{c}1525,1 \\
(1018-2115)\end{array}$ & $\begin{array}{c}1334,4 \\
(940,5-2072,4)\end{array}$ & $\begin{array}{c}1375,4 \\
(1036,9-1613,5)\end{array}$ & $\begin{array}{c}1234,7 \\
(830,2-1630,4)\end{array}$ & 0,37 \\
\hline
\end{tabular}


*Intervalo QT corrigido pela fórmula de Fridericia ${ }^{29}$

Resultados apresentados em mediana e intervalo interquartil.

SDNN: desvio-padrão de todos os intervalos $R R$

SDANN: desvio-padrão da média dos intervalos RR

RMSSD:raiz quadrada da média das diferenças sucessivas ao quadrado, entre NN adjacentes

pNN50: percentagem das diferenças sucessivas entre os intervalos NN>50 ms.

\section{Efeitos do succinato de metoprolol na gravidade da cirrose e nos desfechos clínicos}

Não houve diferença estatisticamente significante entre os grupos ao se avaliar a evolução da gravidade da cirrose, na comparação pelo escore de MELD. Ao se observar a comparação entre o antes e o depois de cada grupo, nota-se que houve redução do escore MELD tanto no grupo metoprolol (antes: 12(10-16), depois 9(6-13), $p<0,001)$, quanto no grupo placebo (antes: 13(11-16), depois: 9)7-12), $p=0,001$ ). (figura 11)

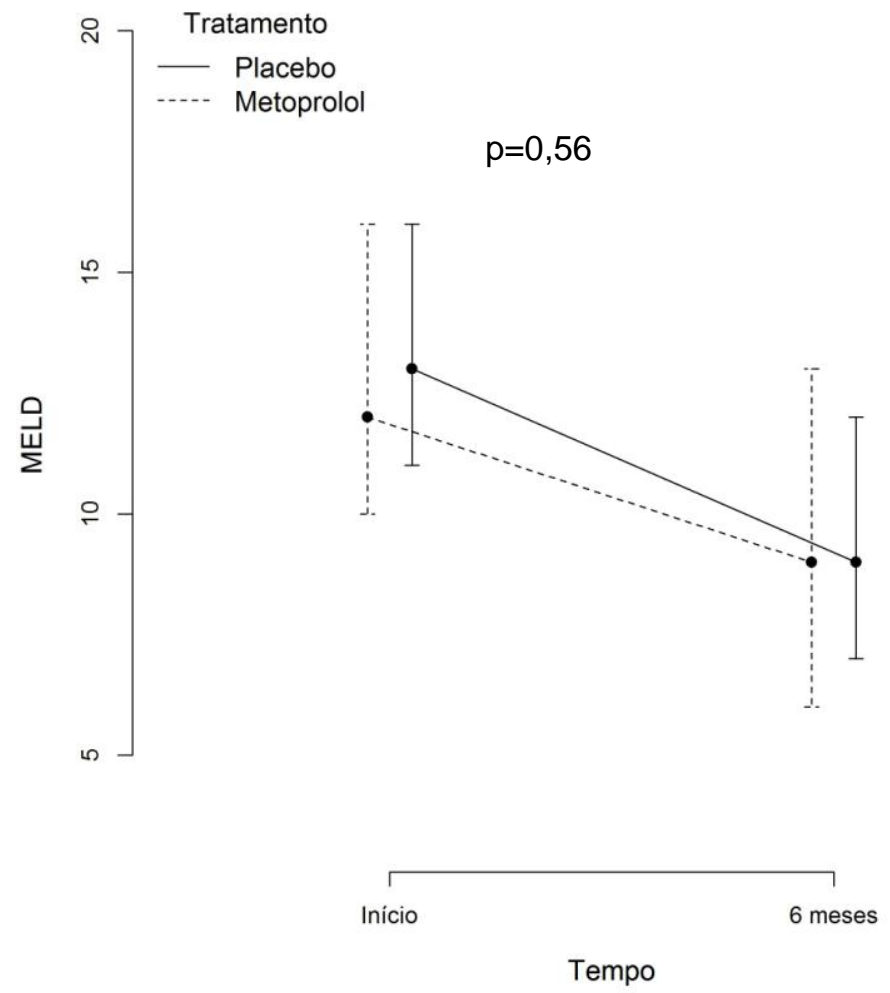

MELD: model for end-stage liver disease

Figura 11. Evolução da cirrose, avaliada pelo escore MELD, conforme o grupo de tratamento $-\mathrm{n}=78$ pacientes 
Para as comparações pela classificação de Child-Pugh, há dados de 66 pacientes. Observou-se que no grupo metoprolol, 22 (66,7\%) pacientes de 33 analisados mantiveram o Child-Pugh estável, 7 (21,2\%) melhoraram e $4(12,1 \%)$ pioraram após seis meses de tratamento. Já no grupo placebo, percebe-se que 25 (75,7\%) dos 33 pacientes analisados mantiveram o ChildPugh na mesma classe, 2 (6\%) melhoraram e $6(18,2 \%)$ pioraram após 6 meses de tratamento. Na comparação entre metoprolol e placebo, vê-se que não houve diferença $(p=0,21)$ (figura 12)

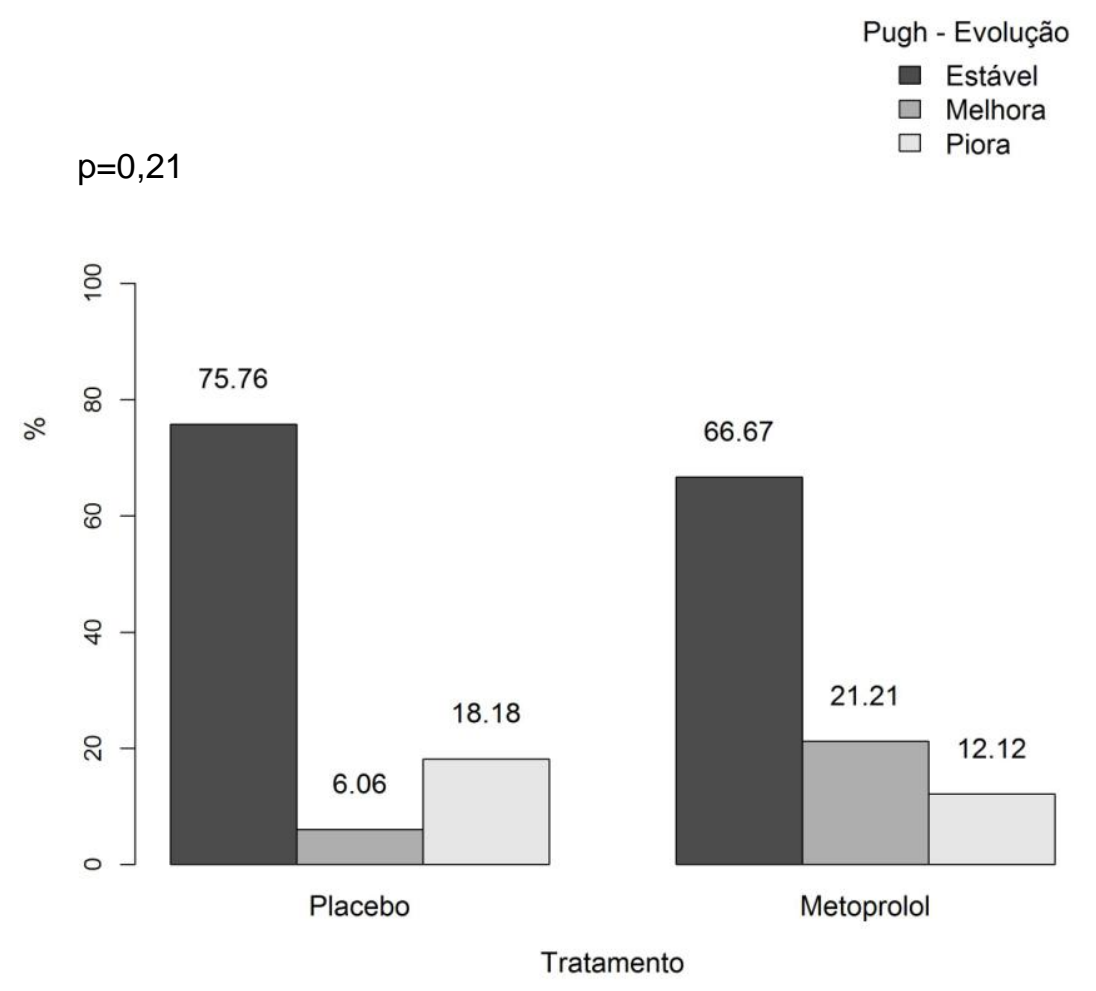

Figura 12. Evolução da cirrose, dividida em classes pelo Child-Pugh, conforme o grupo de tratamento $-\mathrm{n}=66$ pacientes

A análise dos desfechos clínicos mostrou que não houve diferença entre os grupos metoprolol e placebo em termos de desfechos clínicos, tanto quando são analisados isoladamente ou na forma de desfechos combinados (tabela 9). Na figura 10 vê-se a curva de sobrevida livre de eventos ao longo dos 180 dias. 
Tabela 9. Desfechos clínicos do grupo metoprolol em relação ao grupo placebo $-\mathrm{n}=78$ pacientes

\begin{tabular}{lcccc}
\hline Desfecho n (\%) & $\begin{array}{c}\text { Metoprolol } \\
\mathbf{n = 4 1}\end{array}$ & $\begin{array}{c}\text { Placebo } \\
\mathbf{n = 3 7}\end{array}$ & $\begin{array}{c}\text { Razão de risco } \\
\mathbf{e ~ I C}\end{array}$ & $\mathbf{p}$ \\
\hline Ascite & $4(12)$ & $2(5,4)$ & $2,48(0,48-12,77)$ & 0,27 \\
Síndrome hepatorrenal & 1 & 0 & 0 & 0,99 \\
Crises de encefalopatia & $5(12,1)$ & $6(16,2)$ & $0,72(0,22-2,37)$ & 0.59 \\
Infecções & $2(4,8)$ & $2(5,4)$ & $0,93(0,13-6,62)$ & 0,94 \\
Hemorragia digestiva & 0 & 0 & NA & NA \\
Internações & $6(14,6)$ & $8(21,6)$ & $0,67(0,23-1,92)$ & 0,45 \\
Morte & $5(12,1)$ & $2(5,4)$ & $2,32(0,45-11,96)$ & 0,31 \\
Desfechos combinados & $14(34,1)$ & $12(32,4)$ & $1,04(0,48-2,25)$ & 0,92 \\
\hline
\end{tabular}

IC: intervalo de confiança;NA:não se aplica 


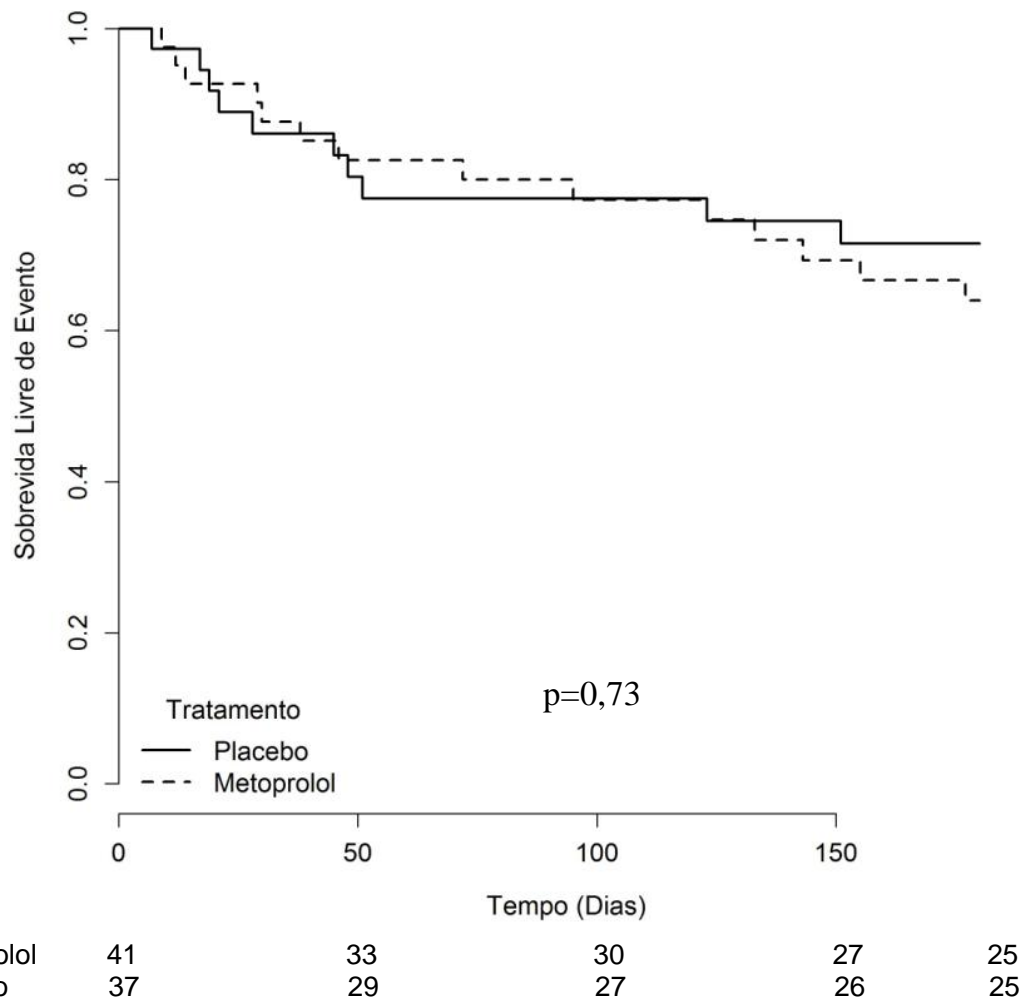

Figura 13. Curva de sobrevida livre de eventos. Comparação entre os grupos metoprolol e placebo $-\mathrm{n}=78$ pacientes

Efeitos adversos - comparação dos grupos metoprolol e placebo desfecho de segurança

Surgiram sintomas que poderiam estar relacionados ao tratamento em 10 pacientes $(12,8 \%)$. Desses, $4(9,7 \%)$ foram no grupo metoprolol e 6 $(16,2 \%)$ no grupo placebo, sem diferença estatisticamente significante entre os grupos $(p=0,5)$. A distribuição dos sintomas por grupo está representada na tabela 10. Um paciente de cada grupo abandonou o estudo ao relacionar o sintoma ao início do tratamento.

Em relação ao sangramento varicoso, nossa estratégia foi prevenir a ruptura varicosa com a realização de ligadura elástica de varizes esofagianas a cada 4 semanas até a sua erradicação, conforme recomendado pelo Consenso de Baveno V. ${ }^{53}$ No período de seguimento, dois pacientes do grupo placebo apresentaram hemorragia digestiva sem 
identificação da origem do sangramento. Ambos os pacientes tinham varizes esofágicas erradicadas e, na endoscopia após o sangramento, não foram evidenciados sinais de sangramento nas veias varicosas. Um dos pacientes necessitou de transfusão de hemácias e recebeu alta. $O$ outro evoluiu para 0 óbito na mesma internação.

Tabela 10. Comparação entre os grupos metoprolol e placebo em relação aos efeitos adversos do tratamento - desfecho de segurança $(n=78$ pacientes)

\begin{tabular}{lcc}
\hline Sintomas & $\begin{array}{c}\text { Metoprolol } \\
\mathbf{n = 4 1}\end{array}$ & $\begin{array}{c}\text { Placebo } \\
\mathbf{n = 3 7}\end{array}$ \\
\hline Tonturas & 3 & 1 \\
Náuseas & 0 & 2 \\
Dispneia & 0 & 1 \\
Cefaleia & 1 & 0 \\
Disfunção erétil & 0 & 1 \\
Palpitações & 0 & 1 \\
\hline
\end{tabular}

\subsection{Comparação dos pacientes com resposta inotrópica anormal} versus aqueles com resposta inotrópica normal

Esses grupos foram divididos conforme a resposta do débito cardíaco ao estresse. Assim, aqueles pacientes com aumento do débito cardíaco $>30 \%$ no pico do estresse foram chamados de grupo com resposta inotrópica normal. Ao contrário, aqueles com aumento do débito cardíaco $\leq 30 \%$ no pico do estresse foram chamados de resposta inotrópica anormal. Para essa comparação, consideraremos os grupos metoprolol e placebo como um só. A análise com correção do "fator metoprolol" também será descrita. 


\section{Comparação entre os grupos em relação às características gerais}

Exceto quanto ao número de pacientes do gênero feminino (maior no grupo resposta inotrópica anormal) não encontramos diferenças estatisticamente significantes quanto aos demais parâmetros. (tabela 11)

Tabela 11. Características gerais dos pacientes com resposta inotrópica normal e anormal - $\mathrm{n}=125$ pacientes

\begin{tabular}{|c|c|c|c|}
\hline Parâmetros & $\begin{array}{c}\text { Resposta } \\
\begin{array}{c}\text { Inotrópica anormal } \\
\mathrm{n}=78\end{array} \\
\end{array}$ & $\begin{array}{c}\text { Resposta } \\
\text { Inotrópica } \\
\text { normal } \\
n=47\end{array}$ & $\mathbf{p}$ \\
\hline Idade (anos) & $52(45-57)$ & $51(42,5-55)$ & 0,73 \\
\hline Gênero feminino n(\%) & $46(59)$ & $17(36,1)$ & 0,01 \\
\hline Cor branca $\mathrm{n}(\%)$ & $32(42,1)$ & $20(43,4)$ & 0,91 \\
\hline $\mathrm{IMC}\left(\mathrm{Kg} / \mathrm{m}^{2}\right)$ & $24,9(23,5-28)$ & $26,3(23,6-30,4)$ & 0,38 \\
\hline Frequência cardíaca (b/min) & $72(68-80)$ & $72(64-80)$ & 0,70 \\
\hline \multicolumn{4}{|l|}{ Pressão arterial - mmHg } \\
\hline Sistólica & $120(100-130)$ & $120(110-130)$ & 0,37 \\
\hline Diastólica & $80(70-80)$ & $78(70-80)$ & 0,58 \\
\hline \multicolumn{4}{|l|}{ Classe Funcional (NYHA) n(\%) } \\
\hline I e II & $46(61)$ & $35(76)$ & \multirow[t]{2}{*}{0,11} \\
\hline III e IV & $30(39)$ & $11(24)$ & \\
\hline \multicolumn{4}{|l|}{ Etiologia da cirrose $\mathrm{n}(\%)$} \\
\hline Hepatite C & $43(55)$ & $24(52)$ & \multirow{2}{*}{0,85} \\
\hline Outras causas & $35(45)$ & $22(48)$ & \\
\hline \multicolumn{4}{|l|}{ Classe Child-Pugh n(\%) } \\
\hline$A / B$ & $66(86)$ & $40(87)$ & \multirow{2}{*}{0,46} \\
\hline $\mathrm{C}$ & $11(14)$ & $6(13)$ & \\
\hline Escore MELD & $13(11-16)$ & $12(10-16)$ & 0,66 \\
\hline $\begin{array}{l}\text { Tempo de doença - cirrose } \\
\text { (anos) }\end{array}$ & $6(2-10)$ & $5(3-8,7)$ & 0,88 \\
\hline \multicolumn{4}{|l|}{ Comorbidades n(\%) } \\
\hline Diabetes mellitus & $16(20)$ & $13(28)$ & 0,21 \\
\hline HAS & $14(18)$ & $9(19)$ & 1,00 \\
\hline Dislipidemia & $2(2,6)$ & $1(2,1)$ & 1,00 \\
\hline
\end{tabular}


História de tabagismo

Sedentarismo

Medicamentos $\mathrm{n}(\%)$

Propranolol

Espironolactona

Furosemida

Inibidores da ECA
27 (35)

$51(72)$

$41(53,2)$

$28(36,4)$

$24(31,2)$

$6(7,9)$
18 (39)

$31(77)$

0,70

0,65

$2(47,8)$

0,58

$16(34,8)$

1,00

$11(23,9)$

0,41

$2(4,3)$

0,71

As variáveis contínuas estão expressas em medianas e intervalos interquartis.

NA: não se aplica; MELD: model for end-stage liver disease; HAS: hipertensão arterial sistêmica;

IMC: índice de massa corpórea; NYHA: New York Heart Association; ECA: enzima conversora de angiotensina.

\section{Comparação em relação aos parâmetros ecocardiográficos}

A análise dos parâmetros ecocardiográficos mostra que o grupo resposta inotrópica anormal apresentou volume de átrio esquerdo maior, espessura do septo interventricular menor, resposta inotrópica basal maior e PSAP maior, nas comparações com o grupo resposta inotrópica normal.

Tabela 12. Características ecocardiográficas dos pacientes - n=125 pacientes

\begin{tabular}{|c|c|c|c|}
\hline Parâmetros & $\begin{array}{c}\text { Resposta } \\
\text { inotrópica anormal } \\
(\mathrm{n}=78)\end{array}$ & $\begin{array}{c}\text { Resposta } \\
\text { inotrópica normal } \\
(\mathrm{n}=47)\end{array}$ & $\mathbf{p}$ \\
\hline Volume do $\mathrm{AE}\left(\mathrm{ml} / \mathrm{mm}^{3}\right)$ & $28(25,2-34,5)$ & $24(21-30)$ & 0,03 \\
\hline $\begin{array}{l}\text { Diâmetro diastólico do VE - } \\
\mathrm{mm}\end{array}$ & $48(44-51)$ & $48(44-50)$ & 0,51 \\
\hline $\begin{array}{l}\text { Diâmetro sistólico do VE - } \\
\text { mm }\end{array}$ & $30(28-33)$ & $29(27-32)$ & 0,52 \\
\hline Volume diastólico do VE - ml & $84(66,5-104)$ & $74(56-99)$ & 0,17 \\
\hline Volume sistólico do VE - ml & $27,5(21,2-36,7)$ & $26(19,2-38)$ & 0,55 \\
\hline $\begin{array}{l}\text { Espessura da parede VE - } \\
\mathrm{mm}\end{array}$ & $9(8-10)$ & $10(9-11)$ & 0,05 \\
\hline
\end{tabular}


Septo interventricular $-\mathrm{mm}$

Índice de massa do VE - $\mathrm{g} / \mathrm{m}^{2}$

Fração de ejeção do VE - \%

Diâmetro do VD - mm

Onda S do VD - cm/s

Disfunção diastólica n(\%)

VTI basal $-\mathrm{cm}$

VTI estresse $-\mathrm{cm}$

PSAP - mmHg
$8(8-9)$

$85,5(72-96,2)$

$65(60-70)$

$37(32,7-40)$

$15(12-15)$

$12(15,3)$

$26(23-29,6)$

$24(21,6-26)$

$28(25-31)$
$9(8-10)$

0,01

$84,5(68,2-92,7) \quad 0,63$

66 (63-70)

0,79

$37(31-40)$

0,59

$13(12-17)$

0,34

$11(23,4)$

0,34

$23(20-26) \quad 0,008$

$37(47,9) \quad<0,001$

25 (20-30)

0,04

Resultados apresentados em mediana e intervalo interquartil.

VE: ventrículo esquerdo; VD: ventrículo direito; VTI: integral velocidade-tempo. 


\section{Comparação em relação aos parâmetros laboratoriais}

A análise laboratorial para avaliação de biomarcadores cardiovasculares e, em especial, avaliação dos marcadores de ativação neuro-humoral, contemplou a dosagem do peptídeo natriurético tipo $B$ (BNP), noradrenalina, atividade da renina plasmática, troponina e também exames gerais para avaliação de gravidade da doença hepática.

Observa-se que o grupo resposta inotrópica anormal apresentou níveis maiores de BNP, com significância estatística, em relação ao grupo resposta inotrópica normal. (tabela 13) Vê-se ainda que no grupo resposta inotrópica anormal, os níveis séricos de creatinina e hemoglobina foram menores, porém dentro da faixa de valores normais.

Não houve diferença entre os grupos em relação aos demais exames laboratoriais avaliados. (tabela 13)

Tabela 13. Comparação entre os grupos resposta inotrópica anormal e normal quanto aos parâmetros laboratoriais ( $n=125$ pacientes)

\begin{tabular}{|c|c|c|c|}
\hline Parâmetros & $\begin{array}{l}\text { Resposta inotrópica } \\
\text { anormal }(n=78)\end{array}$ & $\begin{array}{l}\text { Resposta inotrópica } \\
\text { normal }(n=47)\end{array}$ & $\mathbf{p}$ \\
\hline BNP (pg/mL) & $62(49-101)$ & $24(11,2-61,7)$ & $<0,001$ \\
\hline $\begin{array}{l}\text { Noradrenalina } \\
(\mathrm{pg} / \mathrm{mL})\end{array}$ & $360,5(245-494,5)$ & $355(260-568)$ & 0,74 \\
\hline $\begin{array}{l}\text { Atividade da renina } \\
\text { plasmática }(\mathrm{ng} / \mathrm{mL} / \mathrm{h})\end{array}$ & $1,3(0,4-5)$ & $1,2(0,7-2,9)$ & 0,65 \\
\hline Troponina I (ng/mL) & $0,01(0,01-0,01)$ & $0,01(0,01-0,01)$ & 0,54 \\
\hline $\begin{array}{l}\text { Hemoglobina } \\
(\mathrm{mg} / \mathrm{dL})\end{array}$ & $12,6(11,5-13,3)$ & $13,2(12,4-14,9)$ & 0,03 \\
\hline Plaquetas $\left(/ \mathrm{mm}^{3}\right)$ & $70000(47000-99000)$ & $71000(52000-98000)$ & 0,58 \\
\hline Creatinina (mg/dL) & $0,7(0,61-0,83)$ & $0,75(0,68-0,9)$ & $<0,001$ \\
\hline Sódio sérico (mg/dL) & $141(138-142)$ & $141(138-143)$ & 0,62 \\
\hline $\begin{array}{l}\text { Bilirrubina total } \\
\text { (mg/dL) }\end{array}$ & $2,04(1,57-2,85)$ & $1,69(1,38-4,01)$ & 0,49 \\
\hline
\end{tabular}


INR

Resultados apresentados em mediana e intervalo interquartil.

BNP:peptídeo natriurético tipo B; INR: razão normatizada internacional

\section{Comparação quanto aos parâmetros eletrofisiológicos}

O intervalo QT não foi diferente entre os grupos avaliados. Não houve diferença entre os grupos em relação aos parâmetros que estimaram a variabilidade da frequência cardíaca (SDNN 24 horas, SDANN, rMSSD, pNN50 e análise expectral). (tabela 14)

Tabela 14. Características eletrofisiológicas dos pacientes $-\mathrm{n}=125$ pacientes

\begin{tabular}{|c|c|c|c|}
\hline Parâmetro & $\begin{array}{l}\text { Resposta inotrópica } \\
\text { anormal }(n=78)\end{array}$ & $\begin{array}{c}\text { Resposta inotrópica } \\
\text { normal (47) }\end{array}$ & $\mathbf{p}$ \\
\hline Intervalo $\mathrm{QT}^{\star}-\mathrm{ms}$ & $\begin{array}{c}434 \\
(425-455)\end{array}$ & $\begin{array}{c}439,5 \\
(419,7-452)\end{array}$ & 0,29 \\
\hline SDNN 24h - ms & $\begin{array}{c}82 \\
(71-97)\end{array}$ & $\begin{array}{c}83,5 \\
(65,7-99,7)\end{array}$ & 0,18 \\
\hline SDANN - ms & $\begin{array}{c}71 \\
(58-83)\end{array}$ & $\begin{array}{c}71,5 \\
(56,7-90,5)\end{array}$ & 0,21 \\
\hline rMSSD - ms & $\begin{array}{c}29 \\
(22-39)\end{array}$ & $\begin{array}{c}26 \\
(17-32,5)\end{array}$ & 0,43 \\
\hline pNN50 - \% & $\begin{array}{c}8 \\
(3-15)\end{array}$ & $\begin{array}{c}5,5 \\
(1-10,2)\end{array}$ & 0,56 \\
\hline $\begin{array}{l}\text { Análise espectral } 24 \mathrm{~h} \\
-\mathrm{ms}^{2}\end{array}$ & $\begin{array}{c}1375,4 \\
(1036,9-1613,5)\end{array}$ & $\begin{array}{c}1230 \\
(774,2-1881,8)\end{array}$ & 0,43 \\
\hline
\end{tabular}

*Intervalo QT corrigido pela fórmula de Fridericia

Resultados apresentados em mediana e intervalo interquartil.

SDNN: desvio-padrão de todos os intervalos RR

SDANN: desvio-padrão da média dos intervalos RR

RMSSD:raiz quadrada da média das diferenças sucessivas ao quadrado, entre NN adjacentes

pNN50: percentagem das diferenças sucessivas entre os intervalos $N N>50$ ms.

\section{Desfechos clínicos em seis meses na comparação entre os grupos conforme a resposta inotrópica ao estresse (sem considerar a intervenção)}

Foram considerados para a análise os desfechos: ascite, síndrome hepatorrenal, internações, encefalopatia, infecções bacterianas, hemorragia 
varicosa, morte e desfechos combinados. Na análise de cada desfecho isoladamente, as internações foram mais frequentes no grupo resposta inotrópica anormal. Não houve diferença na ocorrência dos demais desfechos isolados em 6 meses de seguimento. (tabela 15) Na análise dos desfechos combinados, houve maior taxa entre os pacientes com resposta inotrópica anormal: $26(33,3 \%)$ versus $8(17 \%), p=0,03$. A curva de sobrevida livre de eventos está representada abaixo. (figura 14)

Fez-se ainda a correção do fator "tratamento com metoprolol", retirando-se a hipotética interferência do metoprolol mediante a regressão múltipla de Cox. Quando se comparou somente o grupo placebo (sem exposição ao metoprolol) com o grupo resposta inotrópica normal, observouse que não houve diferença entre os grupos em nenhum dos desfechos avaliados, apenas uma tendência nos desfechos combinados (razão de risco $=2,2$; intervalo de confiança $=0,91-5,46 ; p=0,079)$. Em relação à correção com a regressão múltipla de Cox, não houve diferença entre os grupos, nem mesmo em relação aos desfechos combinados (razão de risco $=1,88$; intervalo de confiança $=0,74-4,77 ; p=0,18$ ).

Tabela 15. comparação entre os grupos resposta inotrópica anormal e resposta normal em relação aos desfechos clínicos - $n=125$ pacientes

\begin{tabular}{lcccc}
\hline Desfecho - n (\%) & $\begin{array}{c}\text { Resposta } \\
\text { anormal }\end{array}$ & $\begin{array}{c}\text { Resposta } \\
\text { normal }\end{array}$ & Razão de risco (IC) & p \\
\hline Ascite & $7(8,9)$ & $1(2,1)$ & $4,54(0,56-36,92)$ & 0,15 \\
Síndrome hepatorrenal & $1(1,2)$ & 0 & NA & 0,99 \\
Crises de encefalopatia & $11(14,1)$ & $5(10,6)$ & $1,45(0,51-4,19)$ & 0,48 \\
Infecções & $4(5,1)$ & 0 & NA & 0,99 \\
Hemorragia varicosa & 0 & 0 & NA & NA \\
Internações & $14(17,9)$ & $2(4,2)$ & $4,76(1,08-20,95)$ & 0,03 \\
Morte & $7(8,9)$ & $2(4,2)$ & $2,27(0,47-10,93)$ & 0,30 \\
Desfechos combinados* & $26(33,3)$ & $8(17,0)$ & $2,3(1,04-5,09)$ & 0,03 \\
\hline
\end{tabular}


*Desfechos combinados (ascite, síndrome hepatorrenal, hemorragia varicosa, internações, crises de encefalopatia, infecções e morte)

NA: não se aplica

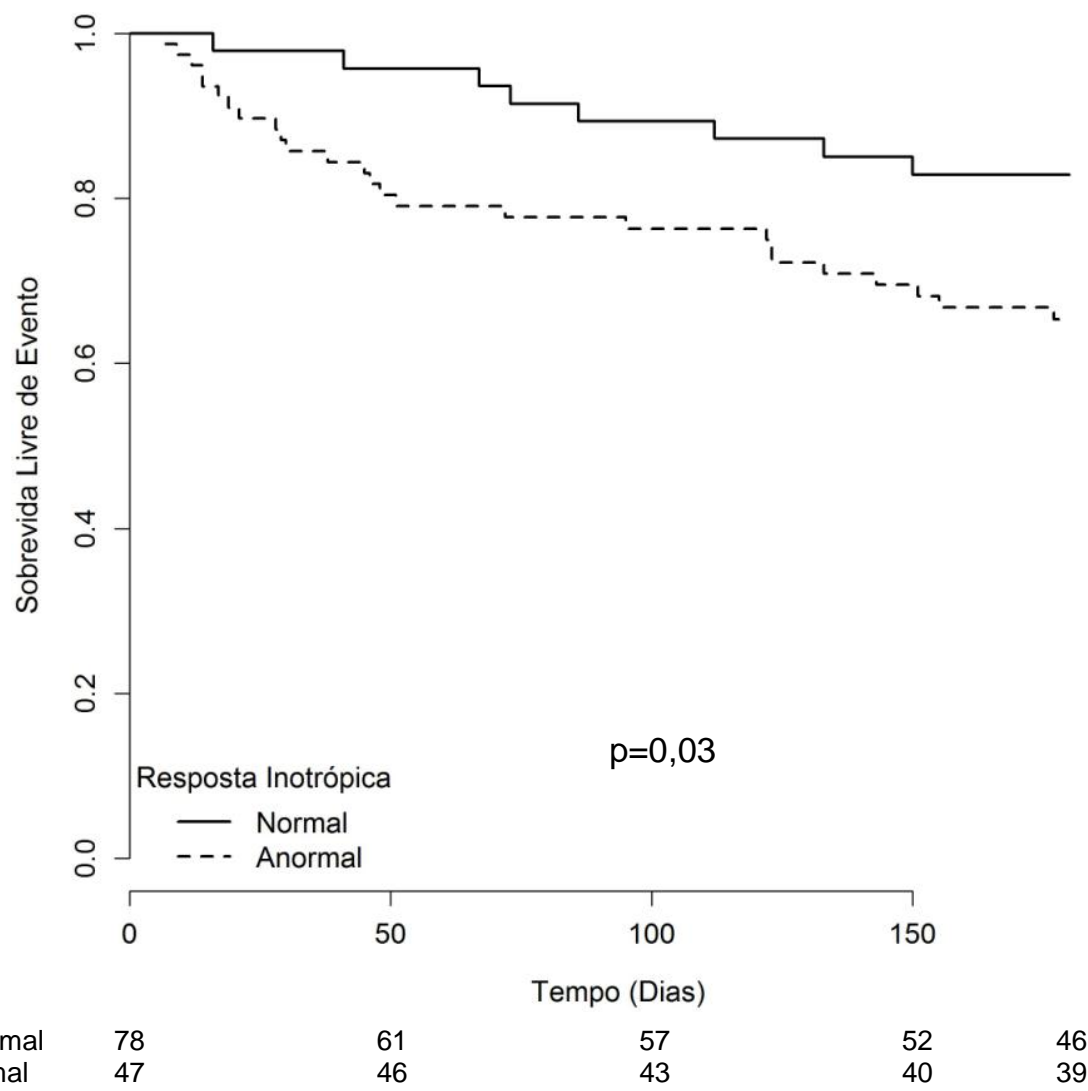

$\begin{array}{ll}\text { Resposta anormal } & 78 \\ \text { Resposta normal } & 47\end{array}$

$46-43$

39

Figura 14. Curva de sobrevida livre de eventos comparando os grupos resposta inotrópica anormal e normal (desfechos combinados: ascite, encefalopatia, síndrome hepatorrenal, infecções, hemorragia varicosa, internações e morte)

Comparação entre os grupos com alteração dos "parâmetros combinados" (disfunção sistólica, disfunção diastólica e prolongamento do intervalo QT)

Os chamados "parâmetros combinados" resultam das alterações frequentemente sugeridas pela literatura como definidoras da "cardiomiopatia cirrótica".

Oito $(6,4 \%)$ dos 125 pacientes preencheram os critérios dos "parâmetros combinados". 
Ao se comparar o grupo com "parâmetros combinados" versus o grupo sem os "parâmetros combinados", em relação aos dados clínicos, ecocardiográficos, eletrocardiográficos e laboratoriais, notou-se diferença apenas em relação ao parâmetro ecocardiográfico espessura da parede posterior, que foi $10 \mathrm{~mm}(9-10 \mathrm{~mm})$ no grupo com os "parâmetros combinados" e $9 \mathrm{~cm}(8-9 \mathrm{~mm})$ no grupo sem os parâmetros combinados, $p=0,008$.

Ao se fazer a comparação entre os grupos para a análise dos eventos clínicos, não houve associação entre os "parâmetros combinados" e os eventos clínicos, nem mesmo na combinação dos desfechos (razão de risco=2,6; intervalo de confiança $=0,91-7,44 ; p=0,073$. (figura15)

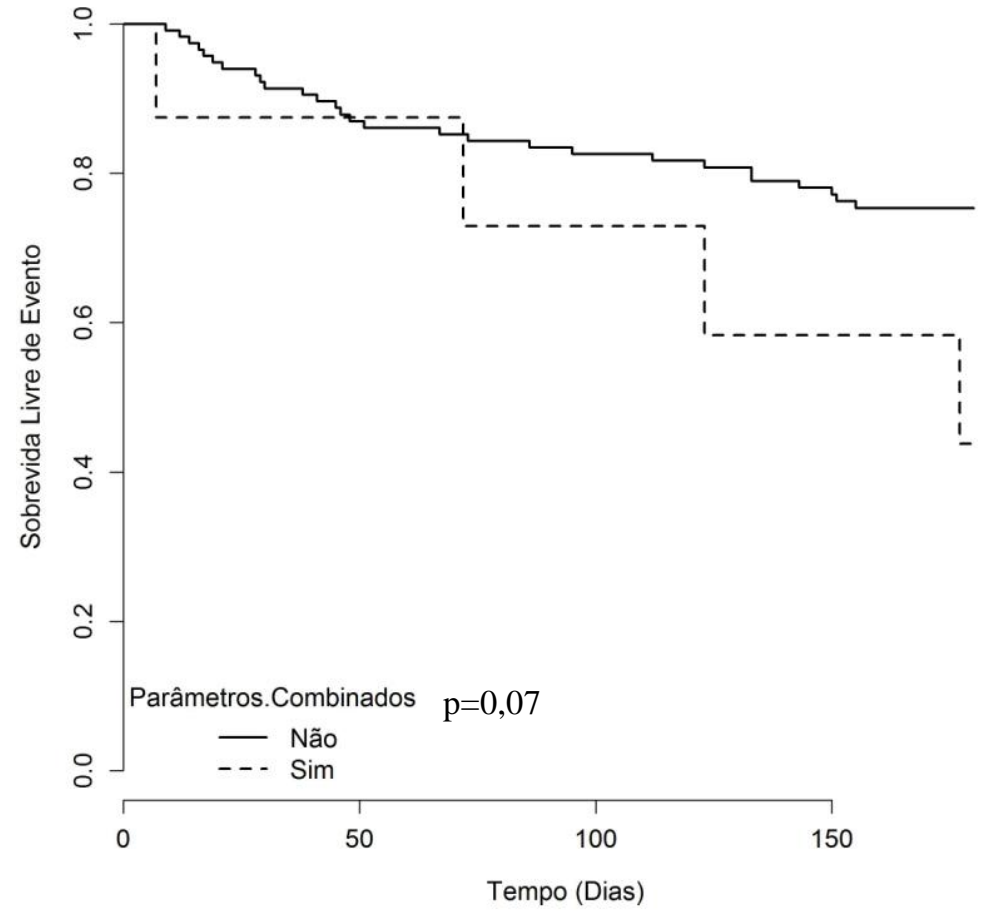

Figura 15. Curva de sobrevida livre de eventos comparando os grupos com os "parâmetros combinados" (alteração de sístole, diástole e QT prolongado) para os desfechos combinados (ascite, encefalopatia, síndrome hepatorrenal, infecções, hemorragia varicosa, internações e morte) 
Discussão 


\section{DISCUSSÃO}

\subsection{Efeito do succinato de metoprolol na disfunção cardíaca relacionada à cirrose}

As alterações cardíacas relacionadas à cirrose são secundárias ao padrão circulatório hiperdinâmico e à exposição à ativação neuro-humoral, em especial pelas catecolaminas e sistema renina-angiotensinaaldosterona. ${ }^{57}$ Assim como na insuficiência cardíaca, o sistema nervoso simpático tem um papel de destaque na modulação da circulação hiperdinâmica da cirrose. Ao longo do tempo, notam-se alterações cardíacas tanto estruturais quanto funcionais, inicialmente adaptativas e, posteriormente, patológicas, decorrentes da exposição ao padrão circulatório com hiperfluxo e também do efeito direto de mediadores químicos como noradrenalina, aldosterona e óxido nítrico. ${ }^{58}$ Essas alterações traduzem-se, principalmente, por dilatação das cavidades esquerdas e hipertrofia ventricular $^{59 ; 60 ; 61}$ - em relação à morfologia - e resposta anormal ao estresse e disfunção diastólica - quanto à função. Tomadas em conjunto, essas alterações têm sido consideradas uma forma de cardiomiopatia própria da cirrose - a cardiomiopatia cirrótica.

O succinato de metoprolol, assim como o bisoprolol e o carvedilol, modifica a história natural das cardiomiopatias de diferentes causas. ${ }^{62}$ Através da redução da ação simpática no miocárdio, promove a reversão do remodelamento cardíaco e, nos pacientes com disfunção sistólica, aumenta a sobrevida. ${ }^{63 ; 64}$

Os betabloqueadores são largamente utilizados em Hepatologia como agente redutor da pressão no sistema portal, com aplicação na profilaxia primária e na prevenção do ressangramento por varizes esôfago-gástricas e por gastropatia hipertensiva. ${ }^{53}$ Apesar dos dados robustos em relação ao tratamento da hipertensão portal, até o momento não há estudos desenhados para avaliar se os betabloqueadores poderiam reverter 0 remodelamento cardíaco e a disfunção cardíaca que se observam na 
cirrose. Embora haja sérios problemas metodológicos, alguns estudos recentes lançam dúvidas sobre a segurança dos betabloqueadores em pacientes com cirrose avançada, pois a redução do débito cardíaco e a hipotensão, associados ao tratamento farmacológico, traduzem-se clinicamente em aumento da mortalidade, pelo menos no subgrupo de pacientes classificados como Child C. ${ }^{65}$

Diante dessas considerações, no presente estudo, foram incluídos 125 pacientes com cirrose de etiologia não alcoólica. Algumas restrições na inclusão foram aplicadas para evitar influência de outros fatores que causam alterações miocárdicas e, desta forma, introduzir vieses que poderiam confundir a análise. Excluímos pacientes com história de ingestão alcoólica. Estudos prévios que analisaram a existência de uma cardiomiopatia específica dos cirróticos incluíram, em suas casuísticas, um percentual alto de pacientes com cirrose alcoólica, ${ }^{66}$ aspecto que compromete a avaliação dos dados, já que o álcool é conhecido agente cardiotóxico, com efeito direto no remodelamento cardíaco e capaz de provocar disfunção miocárdica específica ${ }^{67} \mathrm{~A}$ limitação da idade em 60 anos também foi exigida devido à possibilidade de alterações relacionadas ao envelhecimento do sistema cardiovascular, como a disfunção diastólica do idoso, o aumento da massa do ventrículo esquerdo e a resposta inadequada ao estresse. ${ }^{68}$ Adicionalmente, ao estudarmos uma amostra com pacientes mais jovens, ao redor dos 50 anos de idade, torna-se menos provável a existência de casos latentes de cardiomiopatia isquêmica como fator causal das alterações cardíacas nessa população. Em que pese tratar-se de casuística relativamente jovem, investigamos doença coronariana assintomática, realizando ecocardiograma de estresse farmacológico em todos os pacientes do estudo, com resultados negativos.

Tivemos o cuidado de definir uma faixa de escore MELD entre 10 e 20 para a participação do estudo, com o intuito de evitar o predomínio de casos de insuficiência hepática leve, já que isso implicaria em menores efeitos da cirrose no coração, por haver menor reajuste neuro-humoral, poucas alterações hemodinâmicas, além de menor tempo de exposição à doença. 
Por outro lado, ao evitar incluir pacientes com escore MELD mais elevado, portanto, pacientes mais graves, tivemos a preocupação em prever um tempo de seguimento sem transplante ou com sobrevida adequados ao estudo. Assim, essa amostra com gravidade intermediária da doença permitiu a análise dos desfechos sem comprometimento do poder do estudo, com apenas $6 \%$ de perdas, sendo a metade delas por transplante durante 0 seguimento.

No nosso estudo, o vírus da hepatite $C$ foi a principal causa de cirrose. Embora seja assunto em debate na literatura, não há dados convincentes que suportem a hipótese que o vírus da hepatite $\mathrm{C}$ possa causar miocardiopatia ou miocardite e que esse fator pode ter interferido nos resultados. $^{69 ;} 70$ Essa possibilidade torna-se ainda mais remota se considerarmos que houve distribuição semelhante dos casos com vírus da hepatite $\mathrm{C}$ entre os grupos em comparação e que as avaliações clínicas e por exames complementares mostrou que o coração desses pacientes foi morfologicamente semelhante ao dos pacientes com cirrose por outras causas.

Outros possíveis fatores causadores de IC específica em pacientes com doença do fígado são a sobrecarga de ferro e a deficiência de tiamina. Em relação à sobrecarga de ferro, tanto na hemocromatose primária quanto na secundária há efeito tóxico sobre o miocárdio. ${ }^{71} \mathrm{Em}$ nosso estudo, a hemocromatose foi posta entre os critérios de exclusão.

A deficiência de tiamina é uma conhecida causa de IC de alto débito em pacientes etilistas. ${ }^{72}$ Apesar de não termos dosado sistematicamente os níveis de tiamina em nosso pacientes, tivemos o cuidado de excluir os pacientes com etilismo, de forma que é pouco provável que houvesse deficiência de tiamina em número significativo de pacientes, a ponto de influenciar os resultados.

A anemia tem efeito sobre o sistema cardiovascular e sobre o miocárdio. Em diferentes causas de anemia, como nas betatalassemias e nos estados de deficiência de ferro, há remodelamento cardíaco, com aumento da massa e também dos volumes do ventrículo esquerdo. ${ }^{73}$ Os 
níveis baixos de hemoglobina estão associados a menor viscosidade plasmática, queda da resistência vascular sistêmica, com ativação do sistema neuro-humoral e aumento do fluxo sanguíneo (aumento do débito cardíaco), caracterizando um estado de alto débito. ${ }^{74} \mathrm{Em}$ nossa casuística encontramos níveis de hemoglobina que denotam anemia muito leve, acima de $12 \mathrm{~g} / \mathrm{dL}$ em ambos os grupos, valor insuficiente para explicar a circulação hiperdinâmica observada em nossos pacientes. Além da deficiência de tiamina e da anemia grave, tivemos a preocupação em investigar a possibilidade de outras causas de insuficiência cardíaca de alto débito em nosssa casuística, de forma que é pouco provável que o estado de alto débito observado nos pacientes pudesse ter outra etiologia diferente da cirrose. Aspecto importante a ser levado em consideração na análise dos resultados desse estudo é o fato do diabetes mellitus e da hipertensão arterial sistêmica causarem cardiomiopatia, mesmo na ausência de doença coronariana. Na população estudada, notou-se prevalência de $18,4 \%$ de HAS leve, controlada com uma única droga anti-hipertensiva. $O$ diabetes mellitus está associado à disfunção miocárdica específica chamada cardiomiopatia diabética. ${ }^{75} \mathrm{~A}$ prevalência de $23 \%$ na população do estudo em discussão é alta, refletindo a prevalência da esteatohepatite não alcoólica como causa da cirrose. Vale lembrar que, na comparação entre grupos, após a randomização, tanto diabetes quanto HAS leve tiveram prevalência semelhante nos dois grupos, de modo que consideramos improvável que essas condições tenham influenciado nos resultados.

Os pacientes foram submetidos ao ecocardiograma para avaliação da resposta inotrópica ao estresse. Através da medida da VTI, demonstramos que $62 \%$ deles tiveram reposta inotrópica inadequada ao estresse, conforme definida pelo aumento $\leq 30 \%$ da VTI no estresse, em comparação com o basal.

O succinato de metoprolol foi comparado com o placebo para reversão da disfunção cardíaca relacionada à cirrose, representada pela resposta inotrópica anormal ao estresse. O uso do medicamento por, no mínimo, seis meses, numa dose média de $121 \mathrm{mg}$ por paciente, mostrou-se 
eficaz ao reduzir a frequência cardíaca e seguro por não ter causado hipotensão importante. Essa dose de metoprolol alcançada é comparável às doses atingidas em estudos que demonstraram a eficácia do medicamento em outras populações. ${ }^{39 ; 63}$

Diferentemente do que foi demonstrado em estudo com insuficiência cardíaca com fração de ejeção reduzida, ${ }^{39 ; 43 ;} 76$ o metoprolol não mostrou nenhum efeito sobre os parâmetros ecocardiográficos em seis meses de tratamento. Ao ser comparado com placebo, não houve diferença na melhora da resposta inotrópica ao estresse, nem nos desfechos clássicos de remodelamento cardíaco, como os volumes sistólico e diastólico do ventrículo esquerdo.

Tendo em vista que as alterações de forma e função do coração têm correlação forte com prognóstico e sua correção tem grande impacto sobre morbidade e mortalidade, a ineficácia do metoprolol na reversão do remodelamento cardíaco antecipa a ausência de efeitos clínicos benéficos nesse cenário. ${ }^{77 ;} 78 \mathrm{O}$ resultado negativo do metoprolol no presente estudo pode ser explicado, parcialmente, pela manutenção da agressão ao coração, haja vista a permanência da exposição aos efeitos da circulação hiperdinâmica. Apesar do bloqueio dos receptores das catecolaminas no coração, os pacientes continuaram com elevado fluxo sanguíneo motivado por outros fatores como a intensa vasodilatação sistêmica pela liberação de mediadores endoteliais como o óxido nítrico. Esse estado de alto débito, com necessidade de bombeamento de grande volume de sangue em cada batimento, por si só, é fator promotor de remodelamento adaptativo que, ao longo do tempo, mostra-se deletério. ${ }^{14}$ Esse argumento é reforçado pela demonstração na literatura de reversão das alterações cardíacas da cirrose no período pós-operatório tardio do transplante de fígado, ${ }^{61}$ sinalizando que, talvez essa seja a única forma de reverter o remodelamento cardíaco associado à cirrose.

O uso dos betabloqueadores na insuficiência cardíaca de alto débito já se mostrou benéfico em outros cenários. ${ }^{79}$ Por interferir no círculo vicioso da hiperativação simpática, essas drogas quando administradas de forma 
gradativa com adequada monitorização dos seus efeitos hemodinâmicos beneficiam os pacientes com insuficiência cardíaca de alto débito. No estado de alto débito da cirrose, não há elevação importante das pressões de enchimento das câmaras cardíacas e nem manifestações de insuficiência cardíaca, portanto, os betabloqueadores não seriam contraindicados nesses pacientes.

Pode-se especular que os betabloqueadores poderiam causar um desajuste hemodinâmico inicial e o efeito benéfico ser mais tardio. Essas drogas causam redução da frequência cardíaca e, consequentemente, do débito cardíaco, com piora dos sintomas no início do tratamento dos pacientes com insuficiência cardíaca. ${ }^{80}$ Mas, em nosso estudo, não percebemos piora dos sintomas e não houve maior incidência de efeitos adversos com o medicamento. Estudos com metoprolol em insuficiência cardíaca com fração de ejeção $<40 \%$ mostraram que a reversão do remodelamento cardíaco é vista a partir de três meses de tratamento, ${ }^{39 ; 43 ; 76}$ período de tempo menor do que o definido no presente estudo. $\mathrm{Na}$ população em análise, apesar das alterações morfológicas cardíacas serem as mais comuns, também avaliamos desfechos funcionais relacionados ao estresse, o que teoricamente aumentaria a probabilidade de detecção de eventual efeito benéfico do tratamento. Dessa forma, pensamos que o tempo de seis meses para reavaliação no nosso estudo foi adequado, especialmente em relação ao desfecho primário (normalização da resposta inotrópica). Outros fatores agressores podem ser corresponsabilizados na gênese das alterações cardíacas nos cirróticos e não inibidos pelos betabloqueadores. $\mathrm{O}$ eixo renina-angiotensina-aldosterona está ativado na cirrose $^{7 ; 8}$ e pode ter papel importante nas alterações cardíacas nessa população. Além disso, mediadores como óxido nítrico, ${ }^{81}$ e endocanabinóides ${ }^{9}$ têm efeito direto nos cardiomiócitos e podem contribuir para a perpetuação das alterações cardíacas.

Estudos mostram que níveis elevados da noradrenalina no sangue estão associados ao aumento da mortalidade por todas as causas e à ocorrência de eventos clínicos da insuficiência cardíaca. ${ }^{12} \mathrm{Em}$ pacientes com 
disfunção ventricular assintomática, a noradrenalina está elevada e exerce efeito tóxico sobre o cardiomiócito, prejudicando a atividade e/ou viabilidade dessas células. ${ }^{82}$ Os betabloqueadores reduzem os efeitos deletérios das catecolaminas sobre o cardiomiócito, sendo que os benefícios estendem-se para a redução da mortalidade. ${ }^{63}$

O nível da noradrenalina nos pacientes com cirrose é caracteristicamente elevado, fato confirmado em nosso estudo. Após o tratamento, observamos uma tendência de redução maior no grupo com metoprolol, embora não estatisticamente significante. Não houve diferença entre os níveis de catecolamina ao término do tratamento, entre os dois grupos. Vale lembrar que, geralmente, o tratamento com betabloqueador não reduz necessariamente os níveis de catecolaminas séricas, ${ }^{83}$ mas aumenta a densidade dos receptores beta 1 no miocárdio e promove o rearranjo da via de sinalização no interior do miócito, melhorando a resposta inotrópica. ${ }^{84}$

O BNP pode ser empregado na avaliação da resposta terapêutica na insuficiência cardíaca, ${ }^{85}$ embora o nível sérico tenha resposta variável após a introdução dos betabloqueadores, podendo permanecer na mesma faixa ${ }^{86}$ ou reduzir-se. ${ }^{83}$ No presente estudo, a dosagem desse biomarcador mostrou-se, na mediana, dentro da normalidade em ambos os grupos, levando-se em consideração o ponto de corte diagnóstico de insuficiência cardíaca $(<100 \mathrm{pg} / \mathrm{dL}$ ). Nenhum paciente de ambos os grupos apresentou nível de BNP acima de $400 \mathrm{pg} / \mathrm{dL}$. Embora tenha havido diferença entre as medianas dos grupos na avaliação inicial, não houve diferença entre os grupos quando comparados em relação aos valores acima de $100 \mathrm{pg} / \mathrm{dL}$. Valores pouco aumentados de BNP, na faixa não diagnóstica de IC, têm sido descritos em pacientes com cirrose, sem haver, necessariamente IC associada. ${ }^{30 ;} 31$ Portanto, consideramos que não houve efeito do tratamento com metoprolol nesse biomarcador.

Outra forma de avaliar as repercussões do tratamento com betabloqueador é através da análise do efeito sobre a variabilidade da frequência cardíaca. Devido à grande atividade autonômica simpática na 
cirrose, sabe-se que essa população tem redução na variabilidade da frequência cardíaca, e essa associação é tão mais marcada quanto mais grave for a doença hepática. ${ }^{87}$ Essa associação foi demonstrada com os parâmetros SDNN, SDANN, pNN50 e a análise espectral, que são variantes estatísticas medidas no domínio do tempo, que demonstram a variação da frequência cardíaca entre um ciclo e outro. ${ }^{87 ; 88}$ No nosso estudo, através do Holter de 24 horas, analisamos a variabilidade da frequência cardíaca com os índices: SDNN, SDANN, pNN50, RMSSD e análise espectral. Na comparação basal entre os grupos, SDNN e índice SDANN foram menores no grupo placebo, mas os demais parâmetros não foram diferentes na comparação dos dois grupos randomizados. O tratamento com metoprolol não modificou a variabilidade da frequência cardíaca após seis meses, independentemente do parâmetro de aferição. Esse resultado está de acordo com estudos prévios em pacientes pós-infarto do miocárdio em que os betabloqueadores não normalizaram os parâmetros da variabilidade da frequência cardíaca, embora tenham aumentado a sobrevida dos pacientes. ${ }^{49}$ Além disso, esse dado do nosso estudo está em é consonância com a ausência de efeito do betabloqueador sobre os parâmetros ecocardiográficos e com o BNP.

Estudo prévios mostraram que o QT prolongado ( $>440 \mathrm{~ms}$ ) ocorre em $52 \%$ dos cirróticos, observação confirmada no presente estudo, onde encontramos QT>440 ms em $52 \%$ dos cirróticos, quando corrigimos o intervalo QT pela fórmula de Fridericia. ${ }^{29}$ Entretanto, diferente de estudos anteriores ${ }^{89}$ o uso do betabloqueador não modificou o intervalo QT nessa população.

A avaliação de eficácia, nesse ensaio clínico, mostrou que o metoprolol foi igual ao placebo em relação aos desfechos clínicos. Não houve aumento de incidência de eventos clínicos relacionados nem à doença hepática nem à cardíaca. Mesmo quando combinamos os desfechos clínicos (surgimento de ascite, crise de encefalopatia, infecções, síndrome hepatorrenal, hemorragia varicosa, internações e mortalidade), observamos ausência de diferença entre os grupos droga ativa e placebo.Os desfechos 
de segurança mereceram especial atenção no presente estudo. Não houve maior incidência de efeitos adversos entre os pacientes em terapia com metoprolol. Apenas uma paciente em uso de metoprolol desenvolveu síndrome hepatorrenal, o que é diferente do que foi recentemente demonstrado num estudo retrospectivo onde o propranolol esteve associado à hipotensão e maior taxa de disfunção renal nos pacientes que se apresentaram com peritonite bacteriana espontânea. ${ }^{90}$

Em relação à hemorragia varicosa, dois $(1,6 \%)$ pacientes apresentaram sangramento digestivo durante o seguimento, sendo que ambos pertenciam ao grupo placebo. Em ambos os casos, as endoscopias prévias mostravam varizes erradicadas por tratamento endoscópico e não foram identificados sítios de sangramento a partir das varizes esofágicas, não sendo preenchidos os critérios para o desfecho de sangramento varicoso.

$\mathrm{Na}$ historia evolutiva da cirrose, o sangramento varicoso ocorre em $15 \%$ dos pacientes ao ano, naqueles que nunca sangraram e em até $60 \%$ ao ano, naqueles que já sangraram. ${ }^{91} \mathrm{~A}$ profilaxia primária do sangramento com propranolol reduz em $46 \%{ }^{92}$ (NNT=11) o risco de sangramento e a ligadura elástica $64 \%(\mathrm{NNT}=4,1) .{ }^{93}$ No caso da profilaxia secundaria, o esquema combinado reduz as taxas de ressangramento para até $10 \%{ }^{91}$

Embora 0 desenho do presente estudo não objetivasse uma comparação direta entre metoprolol e propranolol, não observamos taxas de sangramento superiores àquelas que costumam ocorrer com o tratamento padrão. Esses resultados podem ser explicados porque o metoprolol tem algum efeito na pressão portal. Em um estudo, o metoprolol foi comparado ao propranolol em relação à redução da pressão portal e do fluxo hepático. $\mathrm{A}$ pressão portal foi reduzida em média em $3,8 \mathrm{mmHg}$ no grupo metoprolol e em $6,8 \mathrm{mmHg}$ no grupo propranolol, diferença não significante. Todavia, o propranolol reduziu o fluxo hepático total em $20,4 \%$, fenômeno não observado com a terapia com metoprolol, o que poderia, segundo os autores, ser uma vantagem para pacientes com função hepática muito deteriorada. ${ }^{41} \mathrm{Em}$ outro estudo controlado, o metoprolol foi asociado a 
redução da pressão portal em $60 \%$ dos pacientes tratados após 1 a 2 meses de tratamento. ${ }^{94}$

Portanto, embora seguro, o metoprolol não foi eficaz na reversão da disfunção cardíaca em pacientes com cirrose não alcoólica. Não houve benefício na terapia com metoprolol em relação aos desfechos ecocardiográficos, laboratoriais, eletrofisiológicos e clínicos, incluindo mortalidade.

\subsection{Comparação entre os pacientes com resposta inotrópica anormal e resposta inotrópica normal}

A dificuldade de incremento do débito cardíaco ao estresse é a principal alteração cardíaca nos pacientes com cirrose. ${ }^{58}$ Os estudos iniciais em ratos demonstraram que o coração exposto à cirrose tem menor capacidade de reagir às provocações com estimuladores dos receptores beta-adrenérgicos. ${ }^{24}$ Essa alteração foi demonstrada também em humanos. Nota-se que, tanto ao estresse farmacológico quanto ao estresse físico, o incremento do débito cardíaco é menor em cirróticos do que em controles normais. $^{25}$

Estruturalmente, os corações dos pacientes com cirrose apresentam aumento do volume das cavidades esquerdas e aumento do índice de massa ventricular. ${ }^{23 ;} 95$ Essas alterações tornam-se mais acentuadas conforme há aumento da gravidade da doença. ${ }^{14}$

A denominação cardiomiopatia cirrótica foi proposta em 1989 para designar essas alterações adaptativas do coração do paciente com cirrose à circulação hiperdinâmica que caracteriza a doença. Desde então, o seu diagnóstico tem sido sugerido pela combinação de três alterações cardíacas: disfunção sistólica ao estresse, disfunção diastólica e prolongamento do intervalo QT. ${ }^{58}$ Porém, até o momento, não há critérios de consenso ou pontos de corte validados - que definam cada um desses parâmetros, haja vista a inexistência de estudos apropriados em humanos que combinem esses itens ou que façam sua associação com o prognóstico da cirrose. 
A diretriz da Sociedade Européia de Cardiologia define cardiomiopatia como uma desordem miocárdica na qual o músculo cardíaco é estruturalmente e funcionalmente anormal, na ausência de doença coronária, hipertensiva, valvar ou congênita que explique as alterações encontradas. ${ }^{96}$ Sob a denominação de cardiomiopatia estão várias doenças com etiologias muito diferentes e também alterações cardíacas muito distintas. Classificam-se as cardiomiopatias em familiar e não familial, sendo cada grupo subdividido - conforme a alteração morfológica (fenotípica) - em dilatadas, hipertróficas ou restritivas. ${ }^{96} \mathrm{~A}$ cardiomiopatia cirrótica ainda é pouco conhecida no meio cardiológico e tida como uma entidade a ser definida, não sendo contemplada como cardiomiopatia específica nessa classificação.

O único estudo publicado até o momento com avaliação da disfunção inotrópica em cirróticos através do ecocardiograma sob estresse examinou transversalmente 71 pacientes. A resposta inotrópica anormal foi definida pelo aumento menor que $10 \%$ da fração de ejeção do ventrículo esquerdo ao estresse, diminuição menor que $20 \%$ no volume diastólico final do ventrículo esquerdo ao estresse e diminuição menor que 10\% no volume sistólico final do ventrículo esquerdo ao estresse, em relação ao basal. A disfunção inotrópica foi encontrada em $25,4 \%$ dos pacientes avaliados. ${ }^{66}$ Porém, vale ressaltar que $74 \%$ dessa casuística foi constituída por cirrose de etiologia alcoólica, fator que contamina a análise dos dados pela existência do efeito do álcool no miocárdio como possível causador de remodelamento e disfunção. ${ }^{67}$

No presente estudo, fizemos a avaliação de 125 pacientes com cirrose não alcoólica com ecocardiograma sob estresse com dobutamina. $\mathrm{Na}$ estimativa do débito cardíaco pela VTI, demonstramos que $62 \%$ dos pacientes apresentaram reposta inotrópica anormal, conforme definida pelo aumento $<30 \%$ da $\mathrm{VTI}$ ao estresse. Optamos por não considerar tal alteração isoladamente como sinônimo de cardiomiopatia cirrótica, já que a maioria dos autores sugere que essa entidade seja caracterizada a partir da combinação de critérios de sístole, diástole e alteração eletrofisiológica. 
A população estudada apresentava mediana de idade de 51 anos, com doença hepática de gravidade intermediária (mediada do escore MELD 13; Child-Pugh A/B 86\%), composta em sua maioria por pacientes com o diagnóstico de infeção pelo vírus da hepatite $C(53 \%)$. Na comparação das características basais entre os grupos com resposta inotrópica normal e anormal, nota-se que não houve diferença com significância estatística.

Tivemos a preocupação em excluir outros possíveis fatores causadores de IC específica ou de estado de alto débito em pacientes com doença do fígado como o uso de álcool, deficiência de tiamina, anemia grave, tireotoxicose e a sobrecarga de ferro, conforme discutido anteriormente. Condições como diabetes mellitus e hipertensão arterial sistêmica, que podem causar cardiomiopatia, mesmo na ausência de comprometimento coronariano, apresentaram distribuição semelhante entre os grupos, de forma que é pouco provável que os resultados possam ter sido influenciado pela presença dessas condições.

A resposta inotrópica anormal ao estresse se associou aos marcadores de cardiomiopatia, o que reforça a disfunção inotrópica ao estresse como um fator discriminante de cardimiopatia nessa população. Dentre os parâmetros ecocardiográficos, foi evidenciado maior volume do átrio esquerdo nos pacientes com resposta inotrópica inadequada. É válido lembrar que nessa casuística não foram incluídos doentes com valvopatias ou outras cardiomiopatias primárias que justificassem essa alteração anatômica. Acrescente-se que, ainda em relação aos parâmetros ecocardiográficos, os níveis de pressão sistólica da artéria pulmonar foram maiores nesses pacientes, embora todos os pacientes tenham apresentado níveis abaixo de $40 \mathrm{mmHg}$.

Notou-se também que os níveis de BNP sérico foram mais elevados entre os pacientes com resposta inotrópica anormal. É possível que os níveis do BNP se elevem pela disfunção do ventrículo esquerdo, mesmo com fração de ejeção normal. A disfunção diastólica não justifica essa alteração do BNP, haja vista que não houve correlação entre a resposta inotrópica ao estresse e a disfunção diastólica, conforme discutiremos a 
seguir. Consideramos pouco provável que o aumento dos níveis de BNP pudesse decorrer do comprometimento do ventrículo direito pela hipertensão pulmonar, uma vez que não se documentou hipertensão pulmonar importante pelo ecocardiograma, e a avaliação da função do ventrículo direito não demonstrou alteração em nenhum dos pacientes, ao parâmetro da onda S.

O coração exposto à cirrose é fisiologicamente e histologicamente diferente dos controles saudáveis. As modificações no sarcolema do cardiomiócito caracterizam-se por redução da densidade dos receptores beta, ${ }^{97}$ além de um conteúdo maior de colesterol e menor de lipídeos, com alterações nas proteínas carreadoras de íons. As mudanças na permeabilidade e no transporte de íons levam às alterações eletrofisiológicas como o prolongamento do intervalo QT. Dentro das células musculares, a via de sinalização simpática também é anormal. ${ }^{24}$ Isso explica a ausência de resposta adequada ao estímulo com dobutamina descrita na literatura e confirmada em $62 \%$ dos pacientes do nosso estudo. É provável que os cardiomiócitos dos pacientes com resposta inotrópica anormal estejam sujeitos a maiores repercussões da cirrose e que estejam menos adaptados às situações em que há exigência de aumento da performance cardíaca, como durante os episódios de infecções bacterianas, nos estados de hipervolemia e no transplante hepático.

O papel da disfunção diastólica nos paciente com cirrose é assunto controverso, especialmente por haver dificuldade na caracterização das alterações de relaxamento, independentemente da população em estudo. ${ }^{51}$ No miocárdio de animais com cirrose, foi demonstrada redução da função de importantes proteínas envolvidas no relaxamento do cardiomiócito, além de haver substituição do colágeno III por colágeno I, culminando em redução da capacidade de relaxamento. ${ }^{98}$ Muitos estudos com ecocardiograma mostram que a alteração do relaxamento cardíaco é frequente e torna-se mais evidente nos pacientes com ascite, em especial ascite volumosa, alcançando a cifra de $63.5 \%$ dos pacientes ${ }^{26}$ Porém, esses estudos usaram a relação do fluxo E/A isoladamente ou associada ao tempo de 
dasaceleração ${ }^{99}$ como parâmetros definidores da disfunção, prática atualmente em desuso. No presente estudo, foram usados parâmetros definidores mais recentemente propostos pela da Sociedade Americana de Ecocardiografia $^{51}$ para caracterizar a função diastólica. Nessa avaliação, leva-se em consideração um combinado de parâmetros com inclusão do Doppler tecidual e alterações morfológicas atriais. Encontramos uma prevalência de 18,4\% de disfunção diastólica (16,8\% grau I e 1,6\% grau II) De fato, nos estudos mais recentes em populações não cirróticas, com metodologia de aferição da função diastólica semelhante à que utilizamos, a prevalência de disfunção tem sido na magnitude de $25 \%$ dos casos, ${ }^{100}$ indicando que, talvez, a prevalência de disfunção diastólica não seja maior na população de pacientes com cirrose.

Ao combinar a disfunção sistólica $(<30 \%$ de aumento do débito cardíaco ao estresse) com a disfunção diastólica (combinação de parâmetros ecocardiográficos validados) e o prolongamento do intervalo QT>440 ms, encontramos uma prevalência de $6,4 \%$ (oito pacientes) de alteração combinada. Porém, os pacientes desse grupo não se mostraram diferentes dos demais em relação aos outros parâmetros ecocardiográficos, laboratoriais e eletrofisiológicos. Na avaliação dos desfechos clínicos, notouse que não houve diferença na incidência de eventos clínicos ou mortalidade entre os grupos. Portanto, a combinação desses parâmetros não parece ser a melhor forma de definir cardiomiopatia nessa população. Ressalte-se que os pontos de corte para a definição de cada critério foram definidos a partir de dados de outras populações, levando-se em consideração que não existem estudos prévios com metodologia semelhante nesse mesmo grupo de pacientes.

No presente estudo, demonstramos que a disfunção cardíaca definida pela incapacidade de incremento inotrópico ao estresse, como parâmetro isolado, foi relacionada à maior taxa de eventos clínicos combinados relacionados à cirrose em seis meses. Portanto, foi o único marcador de pior evolução clínica, mostrando-se melhor preditor que a definição com a combinação dos três parâmetros. 
Do mesmo modo, quando são usados os parâmetros combinados (resposta inotrópica anormal + disfunção diastólica + QT>440ms) não se consegue correlação com nenhum desfecho clínico, mostrando que essa forma de caracterizar a disfunção cardíaca do cirrótico, apesar de mais ampla é menos acurada.

Há alguma evidência na literatura que a disfunção miocárdica na cirrose possa estar associada à síndrome hepatorrenal. Nos pacientes que desenvolvem peritonite bacteriana espontânea, a síndrome hepatorrenal está associada ao débito cardíaco reduzido e pressão arterial média mais baixa. ${ }^{34}$ Possivelmente, a cadiomiopatia cirrótica determina incapacidade de incremento no débito cardíaco com menor perfusão renal e consequente disfunção renal e aumento da mortalidade. No nosso estudo, houve apenas um caso de síndrome hepatorrenal no grupo com resposta inotrópica anormal.

Outros autores demonstraram que pacientes com alteração da diástole - definida pela relação $E / A \leq 1$ apresentaram maior mortalidade em um ano após o implante do TIPS. ${ }^{99}$ Esse estudo tem críticas especialmente pela definição da alteração diastólica, que é pouco acurada. Embora com reservas, há lógica nessa associação. Isso porque, logo após a colocação do TIPS, há aumento súbito e importante da pré-carga, com possibilidade de desenvolvimento de insuficiência cardíaca ou outros eventos cardiovasculares naqueles pacientes que não tem funções sistólica ou diastólica adequadas para se ajustar à nova condição hemodinâmica. No nosso estudo, nenhum paciente foi submetido ao TIPS, portanto não temos esse dado.

Nos pacientes submetidos ao transplante hepático, a descompensação cardíaca é, em alguns centros, descrita como a principal causa de óbito no período pós-transplante imediato. ${ }^{101}$ Mas esse fato estaria ligado à existência de doenças cardíacas primárias, como doença coronária e outras cardiomiopatias. A disfunção cardíaca pode-se manifestar no intraoperatório do transplante de fígado. Após a reperfusão do enxerto, alguns pacientes apresentam bradicardia, queda do débito cardíaco e elevação das 
pressões de enchimento. ${ }^{102} \mathrm{~A}$ disfunção cardíaca nesse momento crucial do transplante é chamada síndrome pós-reperfusão. Especula-se que a cardiomiopatia cirrótica seja fator predisponente à síndrome pós-reperfusão. Mas, a rigor, essa possibilidade ainda não foi adequadamente estudada na literatura. Um estudo retrospectivo que incluiu pacientes com e sem cardiopatias de diferentes causas, demonstrou, na análise multivariada, que o septo interventricular espessado é associado ao aumento da mortalidade. ${ }^{103}$ No nosso estudo, não encontramos correlação entre alterações estruturais e evolução clínica.

Devemos considerar a dificuldade em interpretar os diferentes estudos que avaliaram a relação entre alterações cardíacas relacionadas à cirrose e prognóstico pelo alto grau de heterogeneidade no desenho do estudo, casuística e definição de eventos. No nosso estudo, não incluímos a etiologia alcoólica e excluímos os pacientes com outras cardiomiopatias. É o primeiro estudo com coleta prospectiva dos dados que avalia a repercussão clínica da disfunção cardíaca relacionada à cirrose. Demonstramos que a disfunção sistólica relacionada ao estresse mostrou ser marcador de pior evolução em seis meses, caracterizada por diferença significante na sobrevida livre de eventos clínicos e por menores taxas de hospitalização nos pacientes com resposta inotrópica normal.

\section{Limitações do estudo}

O presente estudo tem algumas limitações que devem ser discutidas. Poder-se-ia especular que o tempo de tratamento de seis meses seria insuficiente para se observar a reversão do remodelamento em um coração submetido à exposição continuada a um estado de alto débito. Todavia, a literatura demonstra que, já em quatro meses de tratamento com metoprolol, há efeito anti-remodelamento do betabloqueador, não podendo, isoladamente, esse fato explicar os resultados negativos do estudo. ${ }^{43}$ Não há, até o momento, definição de consenso do que seria a disfunção cardíaca do cirrótico. Por não termos uma forma de diagnóstico padrão-ouro, não conseguimos achar um ponto-de-corte ideal para a análise da VTI na 
resposta inotrópica ao estresse. Dessa forma, extrapolamos, a partir de outros estudos, que a resposta do débito cardíaco ao estresse com incremento menor do que $30 \%$ seria adequada para a caracterização de uma resposta inotrópica anormal.

A casuística foi formada fundamentalmente por pacientes com cirrose de gravidade moderada e, seriam justamente os pacientes com doença mais avançada os candidatos naturais a maior benefício com o betabloqueio. Porém, um estudo incluindo tais pacientes seria impraticável nos dias de hoje pelos seguintes motivos: a) A sobrevida em pacientes com cirrose descompensada é reduzida, da magnitude de $28 \%$ a $50,8 \%$ em cinco anos; ${ }^{104 ;} 105$ b) Quanto mais grave a doença hepática, maior a probabilidade do paciente ser transplantado. Portanto, não haveria tempo para um seguimento adequado para verificar o efeito do betabloqueador em longo prazo. c) Os betabloqueadores estão atualmente sob suspeita de aumentar a mortalidade em pacientes com cirrose avançada. ${ }^{65}$ Esse efeito deletério pode estar relacionado ao bloqueio dos mecanismos compensadores nos pacientes mais graves, com consequente redução do débito cardíaco e da pressão arterial, determinando piora da condição clínica.

\section{Perspectivas}

O tratamento da cardiomiopatia cirrótica não está definido. Poucos estudos avaliaram a terapêutica da disfunção cardíaca da cirrose. Novos estudos podem focar na modulação de outros mecanismos fisiopatológicos envolvidos direta ou indiretamente na gênese da disfunção cardíaca. Além do bloqueio do sistema nervoso simpático, testado nesse estudo, o bloqueio do sistema renina-angiotensina-aldosterona pode ser uma alternativa atraente a ser testada, assim como a modulação da disfunção endotelial característica da cirrose. As estatinas diminuem a resistência intra-hepática pelo aumento da liberação de óxido nítrico, que é o principal mediador envolvido na iniciação e manutenção da circulação hiperdinâmica da cirrose. Estudos clínicos mostram que as estatinas são relevantes para o tratamento 
da hipertensão portal. Resta saber se essa classe de drogas ao melhorar a função endotelial teria algum efeito na reversão do remodelamento. Do mesmo modo, há claramente espaço para o teste de drogas que reduzem a resistência intra-hepática e a circulação hiperdinâmica, em particular as substâncias com efeito modulador nos receptores endocanabinóides.

A disfunção cardíaca na cirrose constitui uma linha de investigação ainda pouco explorada. á espaço para estudos em relação aos marcadores diagnósticos e prognósticos da cardiomiopatia cirrótica. Embora a estimativa da reserva contrátil pelo ecocardiograma seja um método útil para a avaliação das disfunções miocárdicas nos cirróticos. Estudos recentes mostram que a ressonância cardíaca é um método promissor no estudo das cardiomiopatias. Este método tem boa capacidade de avaliação tanto morfológica quanto funcional das disfunções miocárdicas, mesmo quando essas são incipientes. O papel da ressonância poderá ser explorado no diagnóstico da cardiomiopatia cirrótica. Em relação ao prognóstico, embora haja correlação da disfunção cardíaca com pior evolução na cirrose, ainda não estão definidos quais marcadores cardiovasculares predizem complicações clínicas ou eventos cardiovasculares no perioperatório do transplante hepático. 


\section{CONCLUSÕES}

$>$ Nesse estudo, o succinato de metoprolol foi igual ao placebo na recuperação da resposta inotrópica em pacientes com cirrose não alcoólica.

$>$ Não houve benefício na terapia com succinato de metoprolol em relação aos desfechos ecocardiográficos, laboratoriais, eletrofisiológicos e clínicos.

$>$ O succinato de metoprolol mostrou-se seguro para o uso em pacientes com cirrose de gravidade intermediária.

> Os pacientes com resposta inotrópica anormal apresentaram pior evolução em relação àqueles com resposta inotrópica normal. 
ANEXO A - Ficha de avaliação

HOSPITAL DAS CLÍNICAS DA FMUSP

HEPATOLOGIA/ TRANSPLANTE HEPÁTICO/

ECOCARDIOGRAFIA/INCOR

FICHA DE AVALIAÇÃO DA FUNÇÃO CARDÍACA EM CIRRÓTICOS PRÉ

E PÓS TX HEPÁTICO

Etiqueta do paciente

Data:

$/ 2013$

Critérios de exclusão:

DPOC ( ) asma ( ) IC descompensada ( )

valvopatia moderada/grave ( ) IRC dialítica ( ) $\quad \mathrm{CHC}$ avançado ( )

Antecedente de intolerância a betabloqueador ( )

Consumo importante de álcool ( ) tireoideopatias descompensada ( ) Hemocromatose ( ) Bradicardia ( ) hipotensão importante PA<90/60 ( )

Médico:

Preenche critério de inclusão: $\operatorname{sim}($ ) não ( )

Mora no Estado de São Paulo: $\operatorname{sim}($ ) não ( )

Telefones contato: 
HOSPITAL DAS CLÍNICAS DA FMUSP.

HEPATOLOGIA/ TRANSPLANTE HEPÁTICO/

ECOCARDIOGRAFIA/INCOR

FICHA DE AVALIAÇÃO DA FUNÇÃO CARDÍACA EM CIRRÓTICOS PRÉ E PÓS TX HEPÁTICO

Nome

RG data nasc idade sexo data inclusão

Raça: branco ( ) negro ( ) oriental ( ) índio ( ) mestiço ( ) Endereço

\section{Telefones}

\section{Caracterização clínica}

Listado para transplante $\operatorname{sim}($ ) não ( ) posição na lista

Etiologia da hepatopatia

Tempo de evolução da hepatopatia em anos

Diagnóstico de cirrose: biópsia ( ) critérios clínicos/endoscópicos/imagem ( )

Child-Pugh Meld calculado

Consumo de álcool: sim ( ) não ( ) quantidade tempo abstinência

CHC: $\operatorname{sim}($ ) não ( )

CHC: critério de Milão sim ( ) não ( )

quimioembolização prévia sim( ) não( )

Hipertensão portal: varizes sim( ) não( )

gastropatia sim ( ) não ( )

HDA prévia: $\operatorname{sim}($ ) não ( ) № episódios último episódio Ascite: ausente ( ) discreta ( ) moderada( ) volumosa( ) Encefalopatia: ausente ( ) grau 1 ou 2( ) grau 3 ou 4( ) PBE prévia: $\operatorname{sim}($ ) não ( ) 
Icterícia: $\quad \operatorname{sim}(\mathrm{)})$ não( )

Dispnéia aos esforços: $\operatorname{sim}($ ) não ( )

Classe funcional ( )I ( )II ( )III ( )IV

Platipnéia: sim ( ) não ( ) [dispnéia que ocorre na posição ereta e melhora no decúbito dorsal]

Estase de jugulares: sim ( ) não ( )

Ausculta cardíaca:

sopro:

Edema de membros: ausente( ) $1+($ ) $2+($ ) $3+($ ) $4+($ )

Baqueteamento digital: sim( ) não( ) Cianose: $\operatorname{sim}($ ) não( )

PA

FC

Peso

Altura

IMC

\section{Fatores de risco para doença coronariana e antecedentes}

a) hipertensão arterial sistêmica sim ( ) não ( )

b) tabagismo atual sim ( ) não ( )

c) tabagismo pregresso sim ( ) não ( )

d) dislipidemia sim ( ) não ( )

e) diabetes mellitus sim ( ) não ( )

f) sedentarismo sim ( ) não ( )

g) angina sim ( ) não ( )

h) arritmias cardíacas sim ( ) não ( )

i) insuficiência cardíaca sim ( ) não ( )

j) doença arterial periférica sim ( ) não ( )

I) insuficiência renal sim ( ) não ( )

m) antecedente de infarto agudo do miocárdio/ revascularização:

$\operatorname{sim}($ ) não ( )

n) antecedente de AVC ou ataque isquêmico transitório sim ( ) não ( )

o) antecedente de tromboembolismo pulmonar sim ( ) não ( )

p) antecedente de aneurisma aórtico sim ( ) não ( )

r) antec. familiar coronariopatia precoce sim ( ) não ( )

[homem $<55$ anos ou mulher $<65$ anos] 
Medicações em uso:

furosemida ( espironolactona ( )

propranolol ( ) dose Inibidor da ECA ( ) antibiótico ( ) bloqueador canal de $\mathrm{Ca}($ ) outros

\section{Laboratório:}

hemoglobina hematócrito ureia creatinina

TSH_ T4L___licemia___sódio____ potássio___proteina C
reativa_ácido úrico albumina colesterol total HDL LDL VLDL triglicérides

TGO _ _ TGP__ FA_ GGT__ BT

TP INR Insulina basal HOMA outros

\section{Dosagens específicas:}

BNP

ARP

Noradrenalina

Adrenalina Troponina

Colheu soroteca? ( ) sim ( ) não

\section{Radiografia de tórax:}

Normal: sim ( ) não ( ) índice cardio-torácico

Achados

anormais

\section{Eletrocardiograma:}

Normal: sim ( ) não ( ) QT corrigido

Achados

anormais 
ECOCARDIOGRAMA TRANSTORÁCICO 2D( ) 3D( )

DdVE VdVE:

VD:

AO :

DsVE: VsVE:

Septo:

$\mathrm{Pp}$ :

D\%: FEVE(Simpson):

FEVE (Teich): DC:

Massa VE: I Massa VE:

AE: Vol

AE:

E:

A:

E/A:

E': $A^{\prime}$ :

S:

$E / E^{\prime}:$

TD: TRIV:

PSAP: Bolhas: Sim ( ) Não ( ) Ciclo

Forame Oval Patente: Sim ( ) Não ( )

SOB ESTRESSE FARMACOLÓGICO

FC MÁX:

FC SUB:

FC ATING:

VTI DE SAÍDA: VTI PICO DE SAÍDA:

VTI AO REPOUSO: VTI AO PICO: DC PICO:

\begin{tabular}{|l|l|l|l|l|l|l|l|}
\hline & REP & $\begin{array}{l}5 \\
\text { ucg } / \mathrm{kg} / \mathrm{min}\end{array}$ & $\begin{array}{l}10 \\
\text { ucg } / \mathrm{kg} / \mathrm{min}\end{array}$ & $\begin{array}{l}20 \\
\text { ucg } / \mathrm{kg} / \mathrm{min}\end{array}$ & $\begin{array}{l}30 \\
\text { ucg } / \mathrm{kg} / \mathrm{min}\end{array}$ & $\begin{array}{l}40 \\
\mathrm{ucg} / \mathrm{kg} / \mathrm{min}\end{array}$ & RECUP \\
\hline PA & & & & & & & \\
\hline FC & & & & & & & \\
\hline SINTOM & & & & & & & \\
\hline
\end{tabular}

ALT. SEGMENTAR: SIM ( ) NÃO( ) ECG: ARRITMIA: SIM

( ) NÃO ( )

DOBUTAMINA DOSE: ATROPINA : SIM（） NÃO（） DOSE:

METOPROLOL: SIM（） NÃO（） DOSE: 


\section{SEGUIMENTO}

Data

Tempo de tratamento Medicamento comp/dia adesão $\operatorname{sim}($ ) não ( ) PA $\mathrm{X}$ $\mathrm{mmHg} \quad \mathrm{FC}$ tontura ( ) hipotensão ( ) dispnéia ( ) Outro efeito adverso Intercorrênciasclínicas

Ajuste da dose ( ) sim ( ) não Dose___ cp/dia Continua no estudo ( ) $\operatorname{sim}$ ( ) não

$\mathrm{Cr}$

BT INR $\mathrm{Na}$ Albumina MELD:

Child-Pugh

Data

Tempo de tratamento Medicamento comp/dia adesão $\operatorname{sim}($ ) não ( ) PA $\mathrm{mmHg}$ FC tontura ( ) hipotensão ( ) dispnéia ( ) Outro efeito adverso Intercorrênciasclínicas

Ajuste da dose ( )sim ( ) não Dose $\mathrm{cp} / \mathrm{dia}$

Continua no estudo ( ) $\operatorname{sim}$ ( ) não

$\mathrm{Cr}$ BT INR $\mathrm{Na}$ Albumina MELD:

Child-Pugh

Data

Tempo de tratamento Medicamento comp/dia adesão $\operatorname{sim}()$ não ( ) PA $x$ $\mathrm{mmHg} F \mathrm{FC}$ tontura ( ) hipotensão ( ) dispnéia ( ) Outro efeito adverso 
Intercorrênciasclínicas

Ajuste da dose ( ) sim ( ) não Dose__ cp/dia

Continua no estudo ( ) sim ( ) não

$\mathrm{Cr} \_\mathrm{BT} \_\mathrm{INR} \_\mathrm{Na} \_$___ Albumina__ MELD:

Child-Pugh

Data

Tempo de tratamento Medicamento comp/dia adesão $\operatorname{sim}($ ) não( ) PA $\mathrm{x}$ $\mathrm{mmHg} F \mathrm{FC}$

tontura ( ) hipotensão ( ) dispnéia ( ) Outro efeito

adverso

Intercorrênciasclínicas

Ajuste da dose ( )sim ( ) não Dose__ cp/dia

Continua no estudo ( ) sim ( ) não

Cr__ BT INR $\mathrm{Na}$ Albumina MELD:

Child-Pugh

Data

Tempo de tratamento Medicamento comp/dia adesão sim( ) não ( ) PA $\mathrm{x}$ $\mathrm{mmHg} \mathrm{FC}$ tontura ( ) hipotensão ( ) dispnéia ( ) Outro efeito adverso Intercorrênciasclínicas

Ajuste da dose ( )sim ( ) não Dose__ cp/dia Continua no estudo ( ) sim ( ) não $\mathrm{Cr}$ BT INR $\mathrm{Na}$ Albumina MELD:

Child-Pugh 
Data

Tempo de tratamento Medicamento comp/dia adesão $\operatorname{sim}()$ não ( ) PA $\mathrm{X}$ $\mathrm{mmHg} \quad \mathrm{FC}$

tontura ( ) hipotensão ( ) dispnéia ( ) Outro efeito

adverso

Intercorrênciasclínicas

Ajuste da dose ( ) sim ( ) não Dose___ cp/dia

Continua no estudo ( ) sim ( ) não

$\mathrm{Cr}$ INR $\mathrm{Na}$ Albumina MELD:

Child-Pugh

Data

Tempo de tratamento Medicamento comp/dia

adesão $\operatorname{sim}()$ não ( )

PA $\mathrm{X}$ $\mathrm{mmHg} \quad \mathrm{FC}$

tontura ( ) hipotensão ( ) dispnéia ( ) Outro efeito adverso

Intercorrênciasclínicas

Ajuste da dose ( ) sim ( ) não Dose___cp/dia

Continua no estudo ( ) sim ( ) não

$\mathrm{Cr}$

BT INR

$\mathrm{Na}$

Albumina

MELD:

Child-Pugh

Data

Tempo de tratamento Medicamento comp/dia

adesão $\operatorname{sim}($ ) não ( )

PA $\mathrm{X}$ $\mathrm{mmHg} \quad \mathrm{FC}$

tontura ( ) hipotensão ( ) dispnéia ( ) Outro efeito adverso Intercorrênciasclínicas cp/dia 
Continua no estudo ( ) sim ( ) não
$\mathrm{Cr}$
BT
INR
$\mathrm{Na}$
Albumina
MELD:

Child-Pugh

\section{EVOLUÇÃO CLÍNICA PÓS-TX}

Disfunção renal no seguimento sim ( ) não ( )

data

Creatinina mais elevada

Critérios para síndrome hepato-renal sim ( ) não ( )

Transplantado sim ( ) não ( ) data

ÓBITO sim ( ) não ( ) data

Fígado ( ) rim ( ) retransplante hepático ( )

\section{Intra-operatório}

Volume de cristalóides recebidos

Volume de hemoderivados

Índice cardíaco

Capilar pulmonar

PVC

Scv02

PAP RVS RVP

Drogas vasoativas

\section{Pos-operatório imediato}

Volume de cristalóides recebidos

Volume de hemoderivados

Índice cardíaco

Capilar pulmonar

PVC

Scv02 


$\mathrm{PAP} \_\mathrm{RVS} \_\mathrm{RVP} \_$
Drogas vasoativas

Hemodiálise $\operatorname{sim}(\quad)$ não ( ) motivo

Comentários 


\section{ANEXO B - Termo de Consentimento Livre e Esclarecido}

\section{HOSPITAL DAS CLÍNICAS}

da Faculdade de Medicina da Universidade de São PaUlo

CaIXa Postal, 8091 - São PaUlo - Brasil

TERMO DE CONSENTIMENTO LIVRE E ESCLARECIDO

(Instruções para preenchimento no verso)

\section{I - DADOS DE IDENTIFICAÇÃO DO SUJEITO DA PESQUISA OU RESPONSÁVEL LEGAL}

1. NOME DO PACIENTE

DOCUMENTO DE IDENTIDADE № :

SEXO : M

DATA NASCIMENTO:

ENDEREÇO №

APTO:

BAIRRO:

CEP:.

TELEFONE: DDD

CIDADE

2.RESPONSÁVEL LEGAL

NATUREZA (grau de parentesco, tutor, curador etc.)

DOCUMENTO DE IDENTIDADE :

SEXO: M Z F Z̆

DATA NASCIMENTO.:

ENDEREÇO:

BAIRRO:

№

APTO:

CEP:

TELEFONE: DDD (

CIDADE:

...).

\section{II - DADOS SOBRE A PESQUISA CIENTÍFICA}

1. TÍTULO DO PROTOCOLO DE PESQUISA: Efeito do metoprolol na reversão da disfunção cardíaca nos cirróticos não-alcoólicos. Estudo Randomizado.

PESQUISADOR: Fernando Bacal

CARGO/FUNÇÃO: Médico Assistente INSCRIÇÃO CONSELHO REGIONAL № 66061

UNIDADE DO HCFMUSP: Instituto do Coração

3. AVALIAÇÃO DO RISCO DA PESQUISA:

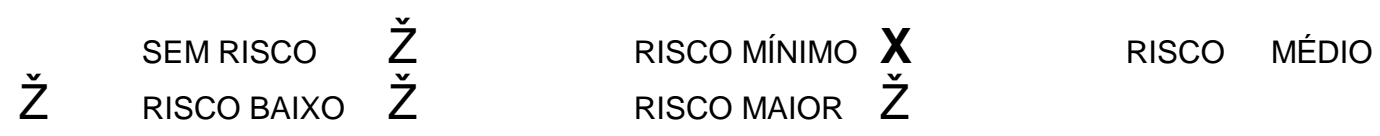

(probabilidade de que o indivíduo sofra algum dano como consequência imediata ou tardia do estudo) 4.DURAÇÃO DA PESQUISA : 02 anos. 


\section{III - REGISTRO DAS EXPLICAÇÕES DO PESQUISADOR AO PACIENTE OU SEU REPRESENTANTE LEGAL SOBRE A PESQUISA CONSIGNANDO:}

1. justificativa e os objetivos da pesquisa; 2. procedimentos que serão utilizados e propósitos, incluindo a identificação dos procedimentos que são experimentais; 3 . desconfortos e riscos esperados; 4. benefícios que poderão ser obtidos; 5. procedimentos alternativos que possam ser vantajosos para o indivíduo.

1. $O(A)$ senhor (a) é portador (a) de uma doença do fígado que chamamos cirrose hepática. Essa doença é caracterizada por diminuição do tamanho do fígado e comprometimento de sua função em fases avaçadas de sua doença. Alguns pacientes, como conseqüência da doença do fígado, a cirrose, desenvolvem uma doença do coração que chamamos de cardiomiopatia cirrótica. Tal doença caracteriza-se por aumento do tamanho do coração e comprometimento de sua função, tanto na hora de bombear o sangue (ou seja, na sístole), quanto na hora de encher-se de sangue (ou seja, na diástole), o que traz repercussões importantes no seu quadro clínico e na sua qualidade de vida, aumentando seu cansaço e diminuindo sua capacidade de exercício. O objetivo desse estudo é observar se um remédio, o metoprolol, é eficaz em reverter o processo de dilatação do coração em pacientes com problemas de saúde como o seu. O metoprolol é um remédio já conhecido, amplamente utilizado pelos médicos, principalmente cardiologistas. Uma parte dos pacientes receberá um comprimido que chamamos placebo, que não possue a substância metoprolol. Isso é necessário para controlarmos a resposta dos senhores pacientes ao uso do medicamento, para compararmos se há diferença entre os pacientes que tomam e os que não tomam o remédio propriamente dito.

2. O (A) senhor (a) fará um ecodopplercardiograma (que é um ultra-som do coração) sob estresse com dobutamina para avaliarmos a função e o comprometimento desse órgão. Colherá, ainda, amostras de sangue para dosagem de substâncias que estão relacionadas ao seu problema do coração. Esses exames serão colhidos na primeira consulta com o cardiologista e no seguimento em três e seis meses. Se o (a) senhor (a) estiver na fila do transpalnte do fígado, quando transplantar, continuará sendo seguido pelo cardiologista desse estudo no período de 3 e 6 meses após o transplante.

3. Os efeitos colaterais mais comuns descritos com uso do metoprolol incluem : tonturas, cefaléia (dor de cabeça), fadiga (cansaço), bradicardia (diminuição do ritmo do coração), hipotensão postural (queda da pressão), broncoespasmo (chieira no peito) em pacientes predispostos, náuseas, dor abdominal, diarréia, o que deverá ser relatado ao médico.

4. Caso haja confirmação de que o metoprolol é capaz de ajudar a melhorar a função do coração em pacientes com cirrose hepática e conseqüente comprometimento da função do coração, tal medicamento poderá ser usado de forma precoce e segura em pacientes cirróticos, tanto para corrigir o problema cardíaco quanto para pervení-lo.

5. No caso deste estudo, ainda não há procedimentos alternativos estabelecidos em relação à proteção do coração do paciente com cirrose. Entretanto, pacientes que apresentam varizes de esôfago precisam receber algum tratamento preventivo para evitar a sua ruptura e sangramento. Quando o paciente nunca apresentou sangramento, ele poderá, em conjunto 
com o seu médico, optar entre receber medicamento (propranolol) ou tratamento endoscópico com ligadura elástica das varizes. Internacionalmente, a ligadura elástica é o método preferido pelos pacientes porque, apesar do risco de sangramento por úlceras, não há os outros efeitos adversos associados ao medicamento propranolol como falta de ar, impotência, tontura, hipotensão etc., que contra-indicam seu uso em $15 \%$ dos pacientes ou provocam a suspensão do tratamento em outros $15 \%$, de forma que pelo menos um terço dos pacientes que optam pelo medicamento propranolol não estão protegidos.

\title{
IV - ESCLARECIMENTOS DADOS PELO PESQUISADOR SOBRE GARANTIAS DO SUJEITO DA PESQUISA CONSIGNANDO:
}

1. acesso, a qualquer tempo, às informações sobre procedimentos, riscos e benefícios relacionados à pesquisa, inclusive para dirimir eventuais dúvidas.

2. liberdade de retirar seu consentimento a qualquer momento e de deixar de participar do estudo, sem que isto traga prejuízo à continuidade da assistência.

3. salvaguarda da confidencialidade, sigilo e privacidade.

4. disponibilidade de assistência no HCFMUSP, por eventuais danos à saúde, decorrentes da pesquisa.

5. viabilidade de indenização por eventuais danos à saúde decorrentes da pesquisa.

\section{INFORMAÇÕES DE NOMES, ENDEREÇOS E TELEFONES DOS RESPONSÁVEIS PELO ACOMPANHAMENTO DA PESQUISA, PARA CONTATO EM CASO DE INTERCORRÊNCIAS CLÍNICAS E REAÇÕES ADVERSAS.}

\author{
1- Fernando Bacal - Av Dr Enéas de Carvalho Aguiar, 44 - CEP: 05403900 - São Paulo- \\ SP Brasil - Tel: 1130695419
}

\section{OBSERVAÇÕES COMPLEMENTARES:}

Não há observações complementares a serem feitas.

\section{VII - CONSENTIMENTO PÓS-ESCLARECIDO}

Declaro que, após convenientemente esclarecido pelo pesquisador e ter entendido o que me foi explicado, consinto em participar do presente Protocolo de Pesquisa
São Paulo,
de
de 20 . 


\section{ANEXO C - Randomização}

\section{Projeto de Pesquisa $\mathbf{n}^{\circ}$ 0010/11}

Título : "Efeito do succinato de metoprolol na disfunção cardiaca em cirróticos não alcoólicos. Estudo randomizado".

Pesquisador: Dr. Odilson Marcos Silvestre

Randomização: http://www. graphpad.com/quickcalcs/index.cfm

\begin{tabular}{|c|c|c|c|c|}
\hline \multicolumn{5}{|c|}{ Placebo } \\
\hline 3 & 4 & 6 & 8 & 9 \\
\hline 11 & 13 & 15 & 16 & 17 \\
\hline 20 & 22 & 25 & 26 & 28 \\
\hline 29 & 32 & 33 & 35 & 39 \\
\hline 41 & 43 & 45 & 48 & 51 \\
\hline 52 & 53 & 55 & 57 & 58 \\
\hline 63 & 64 & 65 & 69 & 73 \\
\hline 75 & 76 & 77 & 80 & 81 \\
\hline 82 & 83 & 85 & 88 & 91 \\
\hline 94 & 95 & 96 & 99 & 100 \\
\hline
\end{tabular}

\begin{tabular}{|c|c|c|c|c|}
\hline \multicolumn{5}{|c|}{ Metoprolol } \\
\hline 1 & 2 & 5 & 7 & 10 \\
\hline 12 & 14 & 18 & 19 & 21 \\
\hline 23 & 24 & 27 & 30 & 31 \\
\hline 34 & 36 & 37 & 38 & 40 \\
\hline 42 & 44 & 46 & 47 & 49 \\
\hline 50 & 54 & 56 & 59 & 60 \\
\hline 61 & 62 & 66 & 67 & 68 \\
\hline 70 & 71 & 72 & 74 & 78 \\
\hline 79 & 84 & 86 & 87 & 89 \\
\hline 90 & 92 & 93 & 97 & 98 \\
\hline
\end{tabular}




\section{REFERÊNCIAS}

1 TSOCHATZIS, E. A.; BOSCH, J.; BURROUGHS, A. K. Liver cirrhosis. Lancet, Jan 2014. ISSN 1474-547X. Disponível em: < http://www.ncbi.nlm.nih.gov/pubmed/24480518 >.

2 MØLLER, S. et al. Determinants of the hyperdynamic circulation and central hypovolaemia in cirrhosis. Gut, v. 60, n. 9, p. 1254-9, Sep 2011. ISSN 1468-3288. Disponível em: < http://www.ncbi.nlm.nih.gov/pubmed/21504996 >.

3 IWAKIRI, Y. The molecules: mechanisms of arterial vasodilatation observed in the splanchnic and systemic circulation in portal hypertension. J Clin Gastroenterol, v. 41 Suppl 3, p. S288-94, 2007 Nov-Dec 2007. ISSN 0192-0790. Disponível em: < http://www.ncbi.nlm.nih.gov/pubmed/17975478 >.

KISZKA-KANOWITZ, M. et al. Blood volume distribution in patients with cirrhosis: aspects of the dual-head gamma-camera technique. $\mathbf{J}$ Hepatol, v. 35, n. 5, p. 605-12, Nov 2001. ISSN 0168-8278. Disponível em: < http://www.ncbi.nlm.nih.gov/pubmed/11690706 >.

HENRIKSEN, J. H. et al. The sympathetic nervous system in liver disease. J Hepatol, v. 29, n. 2, p. 328-41, Aug 1998. ISSN 01688278. Disponível em: < http://www.ncbi.nlm.nih.gov/pubmed/9722218 $>$.

KOWALSKI, H. J.; ABELMANN, W. H. The cardiac output at rest in Laennec's cirrhosis. J Clin Invest, v. 32, n. 10, p. 1025-33, Oct 1953. ISSN 0021-9738.

Disponível em: http://www.ncbi.nlm.nih.gov/pubmed/13096569 >. 
ARROYO, V.; GINÈS, P. J Hepatol, v. 17 Suppl 2, p. S24-8, 1993. ISSN 0168-8278.

Disponível em: http://www.ncbi.nlm.nih.gov/pubmed/8491967 >.

BANSAL, S.; LINDENFELD, J.; SCHRIER, R. W. Sodium retention in heart failure and cirrhosis: potential role of natriuretic doses of mineralocorticoid antagonist? Circ Heart Fail, v. 2, n. 4, p. 370-6, Jul 2009. ISSN 1941-3297. Disponível em: < http://www.ncbi.nlm.nih.gov/pubmed/19808361 >.

MENDIZÁBAL, V. E.; ADLER-GRASCHINSKY, E. Cannabinoid system as a potential target for drug development in the treatment of cardiovascular disease. Curr Vasc Pharmacol, v. 1, n. 3, p. 301-13, Oct 2003. ISSN 1570-1611. Disponível em: < http://www.ncbi.nlm.nih.gov/pubmed/15320476 >.

ALQAHTANI, S. A.; FOUAD, T. R.; LEE, S. S. Cirrhotic cardiomyopathy. Semin Liver Dis, v. 28, n. 1, p. 59-69, Feb 2008. ISSN 0272-8087.

Disponível em: http://www.ncbi.nlm.nih.gov/pubmed/18293277 >.

LEE, R. F.; GLENN, T. K.; LEE, S. S. Cardiac dysfunction in cirrhosis. Best Pract Res Clin Gastroenterol, v. 21, n. 1, p. 125-40, 2007. ISSN 1521-6918. Disponível em: http://www.ncbi.nlm.nih.gov/pubmed/17223501 >.

BENEDICT, C. R. et al. Prognostic significance of plasma norepinephrine in patients with asymptomatic left ventricular dysfunction. SOLVD Investigators. Circulation, v. 94, n. 4, p. 690-7, Aug 1996. ISSN 0009-7322. Disponível em: < http://www.ncbi.nlm.nih.gov/pubmed/8772689 >. 
COHN, J. N.; FERRARI, R.; SHARPE, N. Cardiac remodeling-concepts and clinical implications: a consensus paper from an international forum on cardiac remodeling. Behalf of an International Forum on Cardiac Remodeling. J Am Coll Cardiol, v. 35, n. 3, p. 56982, Mar 2000. ISSN 0735-1097. Disponível em: < http://www.ncbi.nlm.nih.gov/pubmed/10716457 >.

SILVESTRE, O. M. et al. Impact of the severity of end-stage liver disease in cardiac structure and function. Ann Hepatol, v. 12, n. 1, p. 85-91, 2013 Jan-Feb 2013. ISSN 1665-2681. Disponível em: < http://www.ncbi.nlm.nih.gov/pubmed/23293198 >.

NING, X. H. et al. Signaling and expression for mitochondrial membrane proteins during left ventricular remodeling and contractile failure after myocardial infarction. J Am Coll Cardiol, v. 36, n. 1, p. 282-7, Jul 2000. ISSN 0735-1097. Disponível em: < http://www.ncbi.nlm.nih.gov/pubmed/10898447 >. in rats. Circ Res, v. 44, n. 4, p. 503-12, Apr 1979. ISSN 0009-7330. Disponível em: < http://www.ncbi.nlm.nih.gov/pubmed/428047 >. HILL, J. A.; OLSON, E. N. Cardiac plasticity. N Engl J Med, v. 358, n. 13, p. 1370-80, Mar 2008. ISSN 1533-4406. Disponível em: < http://www.ncbi.nlm.nih.gov/pubmed/18367740 >.

GOULD, L. et al. Cardiac hemodynamics in alcoholic heart disease. Ann Intern Med, v. 71 , n. 3, p. 543-54, Sep 1969. ISSN 0003-4819. Disponível em: < http://www.ncbi.nlm.nih.gov/pubmed/5809681 >. 
LIMAS, C. J. et al. Impaired left ventricular function in alcoholic cirrhosis with ascites. Ineffectiveness of ouabain. Circulation, v. 49, n. 4, p. 754-60, Apr 1974. ISSN 0009-7322. Disponível em: < http://www.ncbi.nlm.nih.gov/pubmed/4361711 >.

CARAMELO, C. et al. Effect of volume expansion on hemodynamics, capillary permeability and renal function in conscious, cirrhotic rats. Hepatology, v. 6, n. 1, p. 129-34, 1986 Jan-Feb 1986. ISSN 02709139. Disponível em: < http://www.ncbi.nlm.nih.gov/pubmed/3943778 $>$.

LEE, S. S. Cardiac abnormalities in liver cirrhosis. West $\mathbf{J}$ Med, v. 151, n. 5, p. 530-5, Nov 1989. ISSN 0093-0415. Disponível em: < http://www.ncbi.nlm.nih.gov/pubmed/2690463 >.

MILANI, A. et al. Cirrhotic cardiomyopathy. Dig Liver Dis, v. 39, n. 6, p. 507-15, Jun 2007. ISSN 1590-8658. Disponível em: < http://www.ncbi.nlm.nih.gov/pubmed/17383244 >.

LOSSNITZER, D. et al. Myocardial late gadolinium enhancement cardiovascular magnetic resonance in patients with cirrhosis. $\mathbf{J}$ Cardiovasc Magn Reson, v. 12, p. 47, 2010. ISSN 1532-429X. Disponível em: < http://www.ncbi.nlm.nih.gov/pubmed/20704762 >.

MA, Z.; MIYAMOTO, A.; LEE, S. S. Role of altered beta-adrenoceptor signal transduction in the pathogenesis of cirrhotic cardiomyopathy in rats. Gastroenterology, v. 110, n. 4, p. 1191-8, Apr 1996. ISSN 00165085. Disponível em: < http://www.ncbi.nlm.nih.gov/pubmed/8613009 $>$. 
WONG, F. et al. The cardiac response to exercise in cirrhosis. Gut, v. 49, n. 2, p. 268-75, Aug 2001. ISSN 0017-5749. Disponível em: < http://www.ncbi.nlm.nih.gov/pubmed/11454805 >.

NAZAR, A. et al. LEFT ventricular function assessed by echocardiography in cirrhosis: relationship to systemic hemodynamics and renal dysfunction. J Hepatol, v. 58, n. 1, p. 51-7, Jan 2013. ISSN 1600-0641. Disponível em:

http://www.ncbi.nlm.nih.gov/pubmed/22989573 >.

RUÍZ-DEL-ÁRBOL, L. et al. Diastolic dysfunction is a predictor of poor outcomes in patients with cirrhosis, portal hypertension and a normal creatinine. Hepatology, May 2013. ISSN 1527-3350. Disponível em: < http://www.ncbi.nlm.nih.gov/pubmed/23703953 >.

FINUCCI, G. et al. Q-T interval prolongation in liver cirrhosis. Reversibility after orthotopic liver transplantation. Jpn Heart J, v. 39, n. 3, p. 321-9, May 1998. ISSN 0021-4868. Disponível em: < http://www.ncbi.nlm.nih.gov/pubmed/9711183 >.

ZAMBRUNI, A. et al. QT interval correction in patients with cirrhosis. J Cardiovasc Electrophysiol, v. 18, n. 1, p. 77-82, Jan 2007. ISSN 1540-8167. Disponível em: http://www.ncbi.nlm.nih.gov/pubmed/17229304 >.

FARIAS, A. Q. et al. Serum B-type natriuretic peptide in the initial workup of patients with new onset ascites: a diagnostic accuracy study. Hepatology, v. 59, n. 3, p. 1043-51, Mar 2014. ISSN 15273350. Disponível em: $<$ http://www.ncbi.nlm.nih.gov/pubmed/23907731 >. 
HENRIKSEN, J. H. et al. Increased circulating pro-brain natriuretic peptide (proBNP) and brain natriuretic peptide (BNP) in patients with cirrhosis: relation to cardiovascular dysfunction and severity of disease. Gut, v. 52, n. 10, p. 1511-7, Oct 2003. ISSN 0017-5749. Disponível em: < http://www.ncbi.nlm.nih.gov/pubmed/12970147 >.

PATERON, D. et al. Elevated circulating cardiac troponin I in patients with cirrhosis. Hepatology, v. 29, n. 3, p. 640-3, Mar 1999. ISSN 0270-9139. em:

http://www.ncbi.nlm.nih.gov/pubmed/10051461 >.

RUIZ-DEL-ARBOL, L. et al. Systemic, renal, and hepatic hemodynamic derangement in cirrhotic patients with spontaneous bacterial peritonitis. Hepatology, v. 38, n. 5, p. 1210-8, Nov 2003. ISSN 0270-9139. Disponível em: http://www.ncbi.nlm.nih.gov/pubmed/14578859 >.

RUIZ-DEL-ARBOL, L. et al. Circulatory function and hepatorenal syndrome in cirrhosis. Hepatology, v. 42, n. 2, p. 439-47, Aug 2005. ISSN 0270-9139. Disponível em: http://www.ncbi.nlm.nih.gov/pubmed/15977202 >.

KRAG, A. et al. The cardiorenal link in advanced cirrhosis. Med Hypotheses, v. 79, n. 1, p. 53-5, Jul 2012. ISSN 1532-2777. Disponível em: < http://www.ncbi.nlm.nih.gov/pubmed/22537409 >.

KRAG, A. et al. Low cardiac output predicts development of hepatorenal syndrome and survival in patients with cirrhosis and ascites. Gut, v. 59, n. 1, p. 105-10, Jan 2010. ISSN 1468-3288. Disponível em: < http://www.ncbi.nlm.nih.gov/pubmed/19837678 >. 
GINÈS, P. et al. Transjugular intrahepatic portosystemic shunting versus paracentesis plus albumin for refractory ascites in cirrhosis. Gastroenterology, v. 123, n. 6, p. 1839-47, Dec 2002. ISSN 00165085. Disponível em: http://www.ncbi.nlm.nih.gov/pubmed/12454841 >.

HALL, S. A. et al. Time course of improvement in left ventricular function, mass and geometry in patients with congestive heart failure treated with beta-adrenergic blockade. J Am Coll Cardiol, v. 25, n. 5, p. 1154-61, Apr 1995. ISSN 0735-1097. Disponível em: < http://www.ncbi.nlm.nih.gov/pubmed/7897129 >.

COLUCCI, W. S. et al. Metoprolol reverses left ventricular remodeling in patients with asymptomatic systolic dysfunction: the REversal of VEntricular Remodeling with Toprol-XL (REVERT) trial. Circulation, v. 116, n. 1, p. 49-56, Jul 2007. ISSN 1524-4539. Disponível em: < http://www.ncbi.nlm.nih.gov/pubmed/17576868 >.

HEMSTREET, B. A. Evaluation of carvedilol for the treatment of portal hypertension. Pharmacotherapy, v. 24, n. 1, p. 94-104, Jan 2004. ISSN 0277-0008. Disponível em: http://www.ncbi.nlm.nih.gov/pubmed/14740791 >.

WESTABY, D. et al. Selective and non-selective beta receptor blockade in the reduction of portal pressure in patients with cirrhosis and portal hypertension. Gut, v. 25, n. 2, p. 121-4, Feb 1984. ISSN 0017-5749. Disponível em: http://www.ncbi.nlm.nih.gov/pubmed/6693039 >. $\mathrm{CR} / \mathrm{XL}$ in patients with heart failure: results of the MERIT-HF Trial. 
Clin Cardiol, v. 22 Suppl 5, p. V30-5, Oct 1999. ISSN 0160-9289. Disponível em: < http://www.ncbi.nlm.nih.gov/pubmed/10526701 >.

GROENNING, B. A. et al. Antiremodeling effects on the left ventricle during beta-blockade with metoprolol in the treatment of chronic heart failure. J Am Coll Cardiol, v. 36, n. 7, p. 2072-80, Dec 2000. ISSN 0735-1097. Disponível em: $<$ http://www.ncbi.nlm.nih.gov/pubmed/11127443 >.

MAZZAFERRO, V. et al. Liver transplantation for the treatment of small hepatocellular carcinomas in patients with cirrhosis. $\mathbf{N}$ Engl $\mathbf{J}$ Med, v. 334, n. 11, p. 693-9, Mar 1996. ISSN 0028-4793. Disponível em: < http://www.ncbi.nlm.nih.gov/pubmed/8594428 >.

PARTHENAKIS, F. I. et al. Value of Doppler index combining systolic and diastolic myocardial performance in predicting cardiopulmonary exercise capacity in patients with congestive heart failure: effects of dobutamine. Chest, v. 121, n. 6, p. 1935-41, Jun 2002. ISSN 00123692.

Disponível em:

http://www.ncbi.nlm.nih.gov/pubmed/12065360 >.

PELLIKKA, P. A. et al. Normal stroke volume and cardiac output response during dobutamine stress echocardiography in subjects without left ventricular wall motion abnormalities. Am J Cardiol, v. 76, n. 12, p. 881-6, Nov 1995. ISSN 0002-9149. Disponível em: < http://www.ncbi.nlm.nih.gov/pubmed/7484825 >.

MONIN, J. L. et al. Aortic stenosis with severe left ventricular dysfunction and low transvalvular pressure gradients: risk stratification by low-dose dobutamine echocardiography. J Am Coll Cardiol, v. 37, n. 8, p. 2101-7, Jun 2001. ISSN 0735-1097. Disponível em: < http://www.ncbi.nlm.nih.gov/pubmed/11419894 >. 
SALERNO, F. et al. Diagnosis, prevention and treatment of hepatorenal syndrome in cirrhosis. Gut, v. 56, n. 9, p. 1310-8, Sep 2007. ISSN 0017-5749. Disponível em: < http://www.ncbi.nlm.nih.gov/pubmed/17389705 >.

Heart rate variability: standards of measurement, physiological interpretation and clinical use. Task Force of the European Society of Cardiology and the North American Society of Pacing and Electrophysiology. Circulation, v. 93, n. 5, p. 1043-65, Mar 1996. ISSN 0009-7322. Disponível em: http://www.ncbi.nlm.nih.gov/pubmed/8598068 >.

RUDSKI, L. G. et al. Guidelines for the echocardiographic assessment of the right heart in adults: a report from the American Society of Echocardiography endorsed by the European Association of Echocardiography, a registered branch of the European Society of Cardiology, and the Canadian Society of Echocardiography. J Am Soc Echocardiogr, v. 23, n. 7, p. 685-713; quiz 786-8, Jul 2010. ISSN 1097-6795.

Disponível em: http://www.ncbi.nlm.nih.gov/pubmed/20620859 >.

NAGUEH, S. F. et al. Recommendations for the evaluation of left ventricular diastolic function by echocardiography. $\mathbf{J}$ Am Soc Echocardiogr, v. 22, n. 2, p. 107-33, Feb 2009. ISSN 1097-6795. Disponível em: < http://www.ncbi.nlm.nih.gov/pubmed/19187853 >.

SCHULZ, K. F. et al. CONSORT 2010 Statement: updated guidelines for reporting parallel group randomised trials. BMC Med, v. 8, p. 18, 2010. ISSN 1741-7015. Disponível em: < http://www.ncbi.nlm.nih.gov/pubmed/20334633 >. 
DE FRANCHIS, R.; FACULTY, B. V. Revising consensus in portal hypertension: report of the Baveno $\mathrm{V}$ consensus workshop on methodology of diagnosis and therapy in portal hypertension. $\mathbf{J}$ Hepatol, v. 53, n. 4, p. 762-8, Oct 2010. ISSN 1600-0641. Disponível em: < http://www.ncbi.nlm.nih.gov/pubmed/20638742 >.

SCHULZ, K. F. et al. CONSORT 2010 statement: updated guidelines for reporting parallel group randomized trials. Ann Intern Med, v. 152, n. 11, p. 726-32, Jun 2010. ISSN 1539-3704. Disponível em: < http://www.ncbi.nlm.nih.gov/pubmed/20335313 >.

O'BRIEN, P. C.; FLEMING, T. R. A multiple testing procedure for clinical trials. Biometrics, v. 35 , n. 3 , p. 549-56, Sep 1979. ISSN 0006-341X. Disponível em:

http://www.ncbi.nlm.nih.gov/pubmed/497341 >.

MCCULLOUGH, P. A. et al. B-type natriuretic peptide and clinical judgment in emergency diagnosis of heart failure: analysis from Breathing Not Properly (BNP) Multinational Study. Circulation, v. 106, n. 4, p. 416-22, Jul 2002. ISSN 1524-4539. Disponível em: < http://www.ncbi.nlm.nih.gov/pubmed/12135939 >.

MØLLER, S.; HENRIKSEN, J. H. Circulatory abnormalities in cirrhosis with focus on neurohumoral aspects. Semin Nephrol, v. 17, n. 6, p. 505-19, Nov 1997. ISSN 0270-9295. Disponível em: < http://www.ncbi.nlm.nih.gov/pubmed/9353862 >.

ZARDI, E. M. et al. Cirrhotic cardiomyopathy. J Am Coll Cardiol, v. 56, n. 7, p. 539-49, Aug 2010. ISSN 1558-3597. Disponível em: < http://www.ncbi.nlm.nih.gov/pubmed/20688208 >. 
FINUCCI, G. et al. Left ventricular diastolic function in liver cirrhosis. Scand J Gastroenterol, v. 31, n. 3, p. 279-84, Mar 1996. ISSN 00365521. Disponível em: < http://www.ncbi.nlm.nih.gov/pubmed/8833359 $>$.

ABD-EL-AZIZ, T. A. et al. Evaluation of cardiac function in patients with liver cirrhosis. Intern Med, v. 49, n. 23, p. 2547-52, 2010. ISSN 1349-7235. Disponível em:

http://www.ncbi.nlm.nih.gov/pubmed/21139291 >.

TORREGROSA, M. et al. Cardiac alterations in cirrhosis: reversibility after liver transplantation. J Hepatol, v. 42, n. 1, p. 68-74, Jan 2005. ISSN 0168-8278. Disponível em: http://www.ncbi.nlm.nih.gov/pubmed/15629509 >.

BROPHY, J. M.; JOSEPH, L.; ROULEAU, J. L. Beta-blockers in congestive heart failure. A Bayesian meta-analysis. Ann Intern Med, v. 134, n. 7, p. 550-60, Apr 2001. ISSN 0003-4819. Disponível em: < http://www.ncbi.nlm.nih.gov/pubmed/11281737 >.

HJALMARSON, A. et al. Effects of controlled-release metoprolol on total mortality, hospitalizations, and well-being in patients with heart failure: the Metoprolol $\mathrm{CR} / \mathrm{XL}$ Randomized Intervention Trial in congestive heart failure (MERIT-HF). MERIT-HF Study Group. JAMA, v. 283 , n. 10, p. 1295-302, Mar 2000. ISSN 0098-7484. Disponível em: < http://www.ncbi.nlm.nih.gov/pubmed/10714728 >.

WAAGSTEIN, F. et al. Increased exercise ejection fraction and reversed remodeling after long-term treatment with metoprolol in congestive heart failure: a randomized, stratified, double-blind, placebo-controlled trial in mild to moderate heart failure due to ischemic or idiopathic dilated cardiomyopathy. Eur J Heart Fail, v. 5, 
n. 5, p. 679-91, Oct 2003. ISSN 1388-9842. Disponível em: < http://www.ncbi.nlm.nih.gov/pubmed/14607208 >.

SERSTÉ, T. et al. Deleterious effects of beta-blockers on survival in patients with cirrhosis and refractory ascites. Hepatology, v. 52, n. 3, p. 1017-22, Sep 2010. ISSN 1527-3350. Disponível em: < http://www.ncbi.nlm.nih.gov/pubmed/20583214 >.

KIM, M. Y. et al. Dobutamine stress echocardiography for evaluating cirrhotic cardiomyopathy in liver cirrhosis. Korean J Hepatol, v. 16, n. 4, p. 376-82, Dec 2010. ISSN 1738-222X. Disponível em: < http://www.ncbi.nlm.nih.gov/pubmed/21415581 >.

GEORGE, A.; FIGUEREDO, V. M. Alcoholic cardiomyopathy: a review. J Card Fail, v. 17, n. 10, p. 844-9, Oct 2011. ISSN 1532-8414. Disponível em: < http://www.ncbi.nlm.nih.gov/pubmed/21962423 >.

LAKATTA, E. G. et al. Human aging: changes in structure and function. J Am Coll Cardiol, v. 10, n. 2 Suppl A, p. 42A-47A, Aug 1987. ISSN 0735-1097. Disponível em: < http://www.ncbi.nlm.nih.gov/pubmed/3298368 >.

REIS, F. J. et al. Prevalence of hepatitis C and B virus infection in patients with idiopathic dilated cardiomyopathy in Brazil: a pilot study. Braz J Infect Dis, v. 11, n. 3, p. 318-21, Jun 2007. ISSN 1413-8670. Disponível em: < http://www.ncbi.nlm.nih.gov/pubmed/17684632 >.

DALEKOS, G. N. et al. Idiopathic dilated cardiomyopathy: lack of association with hepatitis $C$ virus infection. Heart, v. 80, n. 3, p. 270-5, Sep 1998. ISSN 1355-6037. Disponível em: < http://www.ncbi.nlm.nih.gov/pubmed/9875087 >. 
KREMASTINOS, D. T.; FARMAKIS, D. Iron overload cardiomyopathy in clinical practice. Circulation, v. 124, n. 20, p. 2253-63, Nov 2011. ISSN 1524-4539. Disponível em: < http://www.ncbi.nlm.nih.gov/pubmed/22083147 >.

MEHTA, P. A.; DUBREY, S. W. High output heart failure. QJM, v. 102, n. 4, p. 235-41, Apr 2009. ISSN 1460-2393. Disponível em: < http://www.ncbi.nlm.nih.gov/pubmed/18990720 >.

VACCARI, M. et al. Left ventricular remodeling, systolic function, and diastolic function in young adults with beta-thalassemia intermedia: a Doppler echocardiography study. Chest, v. 121, n. 2, p. 506-12, Feb 2002. ISSN 0012-3692. Disponível em: < http://www.ncbi.nlm.nih.gov/pubmed/11834665 >.

NAITO, Y. et al. Adaptive response of the heart to long-term anemia induced by iron deficiency. Am J Physiol Heart Circ Physiol, v. 296, n. 3, p. H585-93, Mar 2009. ISSN 0363-6135. Disponível em: < http://www.ncbi.nlm.nih.gov/pubmed/19136608 >.

BOUDINA, S.; ABEL, E. D. Diabetic cardiomyopathy revisited. Circulation, v. 115, n. 25, p. 3213-23, Jun 2007. ISSN 1524-4539. Disponível em: < http://www.ncbi.nlm.nih.gov/pubmed/17592090 >.

HOLE, T. et al. Metoprolol CR/XL improves systolic and diastolic left ventricular function in patients with chronic heart failure. Echocardiography, v. 21, n. 3, p. 215-23, Apr 2004. ISSN 07422822. Disponível em: http://www.ncbi.nlm.nih.gov/pubmed/15053783 >. fundamental to the progression (and regression) of heart failure. J Am 
Coll Cardiol, v. 57, n. 13, p. 1477-9, Mar 2011. ISSN 1558-3597. Disponível em: < http://www.ncbi.nlm.nih.gov/pubmed/21435517 >.

UDELSON, J. E.; KONSTAM, M. Relation between left ventricular remodeling and clinical outcomes in heart failure patients with left ventricular systolic dysfunction. J Card Fail, v. 8, n. 6 Suppl, p. S46571, Dec 2002. ISSN 1071-9164. Disponível em: < http://www.ncbi.nlm.nih.gov/pubmed/12555159 >.

ISLEY, W. L.; DAHL, S.; GIBBS, H. Use of esmolol in managing a thyrotoxic patient needing emergency surgery. Am J Med, v. 89, n. 1, p. 122-3, Jul 1990. ISSN 0002-9343. Disponível em: < http://www.ncbi.nlm.nih.gov/pubmed/1973332 >.

KO, D. T. et al. Adverse effects of beta-blocker therapy for patients with heart failure: a quantitative overview of randomized trials. Arch Intern Med, v. 164, n. 13, p. 1389-94, Jul 2004. ISSN 0003-9926. Disponível em: < http://www.ncbi.nlm.nih.gov/pubmed/15249347 >.

LIU, H.; MA, Z.; LEE, S. S. Contribution of nitric oxide to the pathogenesis of cirrhotic cardiomyopathy in bile duct-ligated rats. Gastroenterology, v. 118, n. 5, p. 937-44, May 2000. ISSN 00165085. Disponível em: http://www.ncbi.nlm.nih.gov/pubmed/10784593 >. MANN, D. L. et al. Adrenergic effects on the biology of the adult mammalian cardiocyte. Circulation, v. 85, n. 2, p. 790-804, Feb 1992. ISSN 0009-7322. Disponível em: http://www.ncbi.nlm.nih.gov/pubmed/1370925 >. therapeutic indicator in idiopathic dilated cardiomyopathy during beta- 
blocker therapy: a potential of hormone-guided treatment. Am Heart J, v. 141, n. 6, p. 925-32, Jun 2001. ISSN 0002-8703. Disponível em: < http://www.ncbi.nlm.nih.gov/pubmed/11376305 >.

SIGMUND, M. et al. Effects of metoprolol on myocardial betaadrenoceptors and $\mathrm{Gi}$ alpha-proteins in patients with congestive heart failure. Eur J Clin Pharmacol, v. 51, n. 2, p. 127-32, 1996. ISSN 0031-6970. Disponível em:

http://www.ncbi.nlm.nih.gov/pubmed/8911876 >.

YANCY, C. W. et al. 2013 ACCF/AHA guideline for the management of heart failure: a report of the American College of Cardiology Foundation/American Heart Association Task Force on Practice Guidelines. J Am Coll Cardiol, v. 62, n. 16, p. e147-239, Oct 2013. ISSN 1558-3597. Disponível em: http://www.ncbi.nlm.nih.gov/pubmed/23747642 >.

YOSHIZAWA, A. et al. Brain natriuretic peptide response is heterogeneous during beta-blocker therapy for congestive heart failure. J Card Fail, v. 10, n. 4, p. 310-5, Aug 2004. ISSN 1071-9164. Disponível em: < http://www.ncbi.nlm.nih.gov/pubmed/15309697 >.

COELHO, L. et al. Autonomic function in chronic liver disease assessed by Heart Rate Variability Study. Rev Port Cardiol, v. 20, n. 1, p. 25-36, Jan 2001. ISSN 0870-2551. Disponível em: < http://www.ncbi.nlm.nih.gov/pubmed/11291332 >.

FLEISHER, L. A. et al. Heart rate variability as a predictor of autonomic dysfunction in patients awaiting liver transplantation. Dig Dis Sci, v. 45, n. 2, p. 340-4, Feb 2000. ISSN 0163-2116. Disponível em: < http://www.ncbi.nlm.nih.gov/pubmed/10711448 >. 
HENRIKSEN, J. $\mathrm{H}$. et al. Acute non-selective beta-adrenergic blockade reduces prolonged frequency-adjusted Q-T interval (QTc) in patients with cirrhosis. J Hepatol, v. 40, n. 2, p. 239-46, Feb 2004. ISSN 0168-8278. Disponível em: < http://www.ncbi.nlm.nih.gov/pubmed/14739094 >.

MANDORFER, $M$. et al. Nonselective $\beta$ Blockers Increase Risk for Hepatorenal Syndrome and Death in Patients With Cirrhosis and Spontaneous Bacterial Peritonitis. Gastroenterology, v. 146, n. 7, p. 1680-1690.e1, Jun 2014. ISSN 1528-0012. Disponível em: < http://www.ncbi.nlm.nih.gov/pubmed/24631577 >.

GARCIA-TSAO, G. et al. Prevention and management of gastroesophageal varices and variceal hemorrhage in cirrhosis. Hepatology, v. 46, n. 3, p. 922-38, Sep 2007. ISSN 0270-9139. Disponível em: < http://www.ncbi.nlm.nih.gov/pubmed/17879356 >.

D'AMICO, G.; PAGLIARO, L.; BOSCH, J. Pharmacological treatment of portal hypertension: an evidence-based approach. Semin Liver Dis, v. 19, n. 4, p. 475-505, 1999. ISSN 0272-8087. Disponível em: < http://www.ncbi.nlm.nih.gov/pubmed/10643630 >.

IMPERIALE, T. F.; CHALASANI, N. A meta-analysis of endoscopic variceal ligation for primary prophylaxis of esophageal variceal bleeding. Hepatology, v. 33, n. 4, p. 802-7, Apr 2001. ISSN 02709139.

Disponível em:

http://www.ncbi.nlm.nih.gov/pubmed/11283842 > .

BÜTZOW, G. H.; REMMECKE, J.; BRÄUER, A. Metoprolol in portal hypertension. A controlled study. Klin Wochenschr, v. 60, n. 20, p. 1311-4, Oct 1982. ISSN 0023-2173. Disponível em: < http://www.ncbi.nlm.nih.gov/pubmed/7144066 >. 
MERLI, M. et al. Cardiac dysfunction in cirrhosis is not associated with the severity of liver disease. Eur J Intern Med, v. 24, n. 2, p. 1726, Mar 2013. ISSN 1879-0828. Disponível em: < http://www.ncbi.nlm.nih.gov/pubmed/22958907 >.

ELLIOTT, P. et al. Classification of the cardiomyopathies: a position statement from the European Society Of Cardiology Working Group on Myocardial and Pericardial Diseases. Eur Heart J, v. 29, n. 2, p. 270-6, Jan 2008. ISSN 0195-668X. Disponível em: < http://www.ncbi.nlm.nih.gov/pubmed/17916581 >.

LEE, S. S. et al. Desensitization of myocardial beta-adrenergic receptors in cirrhotic rats. Hepatology, v. 12, n. 3 Pt 1, p. 481-5, Sep 1990. ISSN 0270-9139. Disponível em: < http://www.ncbi.nlm.nih.gov/pubmed/2169452 >.

GLENN, T. K. et al. Role of cardiac myofilament proteins titin and collagen in the pathogenesis of diastolic dysfunction in cirrhotic rats. $\mathbf{J}$ Hepatol, v. 55, n. 6, p. 1249-55, Dec 2011. ISSN 0168-8278. Disponível em: < http://www.ncbi.nlm.nih.gov/pubmed/21703204 >.

CAZZANIGA, M. et al. Diastolic dysfunction is associated with poor survival in patients with cirrhosis with transjugular intrahepatic portosystemic shunt. Gut, v. 56, n. 6, p. 869-75, Jun 2007. ISSN 0017-5749. Disponível em: http://www.ncbi.nlm.nih.gov/pubmed/17135305 >.

KUZNETSOVA, T. et al. Prognostic value of left ventricular diastolic dysfunction in a general population. J Am Heart Assoc, v. 3, n. 3, p. e000789, 2014. ISSN 2047-9980. Disponível em: < http://www.ncbi.nlm.nih.gov/pubmed/24780207 >. 
VANWAGNER, L. B. et al. High early cardiovascular mortality following liver transplantation. Liver Transpl, Jul 2014. ISSN 15276473.

Disponível

em:

http://www.ncbi.nlm.nih.gov/pubmed/25044256 >.

RIPOLL, C. et al. Cardiac dysfunction during liver transplantation: incidence and preoperative predictors. Transplantation, v. 85, n. 12, p. 1766-72, Jun 2008. ISSN 0041-1337. Disponível em: < http://www.ncbi.nlm.nih.gov/pubmed/18580469 >.

SAFADI, A. et al. Perioperative risk predictors of cardiac outcomes in patients undergoing liver transplantation surgery. Circulation, v. 120, n. 13, p. 1189-94, Sep 2009. ISSN 1524-4539. Disponível em: < http://www.ncbi.nlm.nih.gov/pubmed/19752326 >.

PROPST, A. et al. Prognosis and life expectancy in chronic liver disease. Dig Dis Sci, v. 40, n. 8, p. 1805-15, Aug 1995. ISSN 01632116. Disponível em: < http://www.ncbi.nlm.nih.gov/pubmed/7648984 $>$.

PLANAS, R. et al. Natural history of decompensated hepatitis $C$ virusrelated cirrhosis. A study of 200 patients. J Hepatol, v. 40, n. 5, p. 823-30, May 2004. ISSN 0168-8278. Disponível em: < http://www.ncbi.nlm.nih.gov/pubmed/15094231 >. 